\title{
A NATIONAL POLICY MODEL FOR THE HUNGARIAN FOOD AND AGRICULTURE SECTOR
}

Csaba Csáki

International Institute for Applied Systems Analysis, A ustria, and Karl Marx University of Economic Sciences, Budapest, Hungary.

RR-81-23

October 1981

INTERNATIONAL INSTITUTE FOR APPLIED SYSTEMS ANALYSIS

Laxenburg, Austria 
International Standard Book Number 3-7045-0018-6

Research Reports, which record research conducted at IIASA, are independently reviewed before publication. However, the views and opinions they express are not necessarily those of the Institute or the National Member Organizations that support it.

\section{Copyright 1981 \\ International Institute for Applied Systems Analysis}

All rights reserved. No part of this publication may be reproduced or transmitted in any form or by any means, electronic or mechanical, including photocopy, recording, or any information storage or retrieval system, without permission in writing from the publisher. 


\section{FOREWORD}

Understanding the nature and dimension of the food problem and the policies available to alleviate it has been the focal point of the Food and Agriculture Program at the International Institute for Applied Systems Analysis (IIASA) since the program began in 1977.

The national food systems are highly interdependent, and yet the major policy options exist at the national level. To explore these policy options, therefore, it is necessary both to develop policy models for national economies and to link them together by trade and by capital transfers. For greater realism the models in this scheme of analysis are being kept descriptive rather than normative. Ultimately it is proposed to link models of twenty countries, which together account for nearly $80 \%$ of such important agricultural at tributes as area, production, population, exports and imports.

As a first step towards the development of agricultural policy models of centrally planned agricultural systems, the Hungarian Agricultural Model(HAM) has been developed as a prototype model for Council for Mutual Economic Assistance (CMEA) countries. First the general structure of the model and its mathematical description were completed. As a second stage of the HAM project, the first relatively aggregated version of the model (HAM-1) was elaborated and implemented in both IIASA and Hungarian computers. After two years' work, the second and final, more disaggregated version of the model (HAM-2) was constructed.

In this paper Professor Csaba Csáki summarizes the results of the whole HAM project and presents the general features and mathematical description of the model in detail. The two actual model variants and their use and the validation procedures used are also discussed. The computation and data base of the model are not discussed in detail here.

KIRIT S. PARIKH Acting Program Leader Food and Agriculture Program 



\section{PREFACE}

At the International Institute for Applied Systems Analysis (IIASA) the development of the Hungarian Agricultural Model (HAM), as a prototy pe for models of centrally planned economies, was completed at the end of 1979. In 1977 the general structure of the model and its detailed mathematical structure were completed. The second step in the HAM project was the first, relatively aggregated version of the model (HAM-1). After almost two years of work using the experience gained with this more aggregated model, a more sophisticated version, HAM-2, has been constructed.

The development of the Hungarian Agricultural Model is a joint undertaking of the Food and Agriculture Program (FAP) at IIASA and three institutes in Hungary - the Research Institute for National Planning of the National Planning Bureau (OT TGI), the Research Institute for Agricultural Economics of the Ministry of Food and Agriculture (MEM AKI), and the Department of Agricultural Economics at the Karl Marx University of Economic Sciences (MKKE).

Groups working on HAM in Hungary were led by A. Jónás, K. Kelemen, S. Mészáros, M. Sebestyén, and L. Zeőld. The entire work was coordinated by C. Csáki. C. Forgács, L. Kleininger, I. Monori, G. Módos, F. Stréhn, and K. Varga also participated in the work.

The working group of HAM is grateful to Professor Ferenc Rabár, Michiel Keyzer, Günther Fischer and András Pór of IIASA for their continuous support and their comments on the entire work. In the elaboration of HAM the conclusions of several discussions with Soviet, Bulgarian, Czechoslovakian and Polish scientists on the entire modeling framework were also utilized. 



\section{CONTENTS}

Summary 1

PART ONE. OBJECTIVES AND GENERAL MODEL OUTLINE 3

1 The Basic Characteristics of Food and Agriculture Systems in the Centrally Planned Economies and IIASA's Approach to their Modeling 4

2 State of the Art in Modeling Centrally Planned Agricultural Systems 5

3 Some Features of Hungarian Agriculture 7

4 Main Features of the Hungarian Agricultural Model 9

5 General Structure and Operation of HAM 12

6 Mathematical Description of HAM Model Structure 23

PART TWO. TOWARD THE DEVELOPMENT OF A DETAILED NATIONAL POLICY MODEL - - FIRST VERSION OF THE HUNGARIAN AGRICULTURAL MODEL (HAM-1)

1 Objectives in Developing HAM-1 60

2 Description of HAM-1 $\quad 61$

3 Computation of HAM-1 $\quad 75$

4 Experiments with HAM-1 76

5 Conclusions of the HAM-1 Experiment 85

PART THREE. FINAL VERSION OF THE HUNGARIAN AGRICULTURAL $\begin{array}{ll}\text { MODEL (HAM-2) } & 87\end{array}$

1 Objectives, Commodity Coverage, and Data Base of HAM-2 88

2 Description of HAM-2 $\quad 89$

3 Verification and Validation of HAM-2 105

4 Experiments in the Use of HAM-2 111

5 Some Perspectives of Hungarian Agriculture as Projected by HAM-2 114

$\begin{array}{ll}\text { Bibliography } & 116\end{array}$

$\begin{array}{ll}\text { Appendix } & 117\end{array}$ 



\title{
A NATIONAL POLICY MODEL FOR THE HUNGARIAN FOOD AND AGRICULTURE SECTOR
}

\author{
Csaba Csáki
}

International Institute for Applied Systems Analysis, Austria, and Karl Marx University of Econonic Sciences, Budapest, Hungary.

\section{SUMMARY}

The development at IIASA of the Hungarian Agricultural Model (HAM), as a prototype of models of centrally planned food and agriculture systems was completed at the end of 1979. The model is a joint undertaking of the Food and Agriculture Program at IIASA and three institutes in Hungary. The results of the entire three-year HAM project are summarized in this paper. HAM is a descriptive, recursive simulation model describing the Hungarian food and agriculture system as a disaggregated part of an economic system closed at the national and the international levels. The model, which will ultimately become one of a system of interconnected models, is structured according to the major elements of the centrally planned food and agriculture systems. Two spheres are differentiated within the model. The government economic management and planning submodel describes the decision making and control activities of the government. The production submodel deals with the fulfillment of central plan targets, covering the whole national economy. The general structure of the model and its mathematical description are discussed first. Two versions of HAM have in fact been produced. HAM-1 is a relatively aggregated model (10 food and agricultural commodities are considered); HAM-2 is more disaggregated (45 commodities are considered) and further refined. The two models are described in separate parts of the report, together with the results of the validation procedure and the conclusions of the actual calculations. 



\section{PART ONE}

Objectives and General Model Outline 


\section{THE BASIC CHARACTERISTICS OF FOOD AND AGRICULTURE SYSTEMS IN THE CENTRALLY PLANNED ECONOMIES AND IIASA'S APPROACH TO THEIR MODELING}

In the Council for Mutual Economic Assistance (CMEA) member countries agricultural policy and policy goals are determined by the fact that they are integral parts of the central plan for the whole national economy. The basic figures for production and consumption are fixed in the national plan and are realized by a coordinated system of sectoral (industry, agriculture etc.), regional, local (country, city etc.) and enterprise plans.

In the planning of a country's economic development the ever-increasing fulfillment of constantly growing personal demands by the harmonious growth of production is considered a basic economic requirement. The major goals of agricultural policy are therefore to satisfy consumer and industrial requirements for agricultural products, as established in the national plan. Thus the government's agricultural aims in a given period of time can be listed as one or more of the following:

the attainment of a satisfactory increase in food production and increased efficiency and productivity in agriculture (1) by the concentration and specialization of agricultural production through the organization of large-scale state and cooperative farms and agro-industrial combines and (2) by the modernization of the whole food production system or certain branches thereof by introducing industrialized production methods and techniques;

- the attainment of a certain degree of self-sufficiency of the country in agricultural products;

- the optimization of foreign exchange earnings from agriculture;

- the improvement of the living and working conditions of the population;

- the emphasized development of food processing industries to increase the share of processed foodstuffs being produced for consumption and export.

It should be stressed that in any given period of time only a few of the above policy goals can be emphasized in any one given country. In the centrally planned countries, socalled direct and indirect policy instruments are used to realize the targets given in the national plan. In the CMEA countries, the system of policy instruments applied is generally more complicated in agriculture than in any other field of the economy.

The following list shows the complexity of the policy instruments used. The direct economic regulators of the government are for example:

- the determination of the type, size, location and schedule of the most important agricultural investments;

- the setting of targets for farm production;

-- the central distribution of technical and financial resources of production;

- the determination of labor flow within agriculture and between agriculture and other branches of the economy;

- the establishment of new production organizations in agriculture. 
The indirect economic regulators of government are for example:

- state pricing and price policy;

- state budget and tax policy;

- the regulation of the depreciation system;

- the control of wages and the system of personal incentives in agriculture;

- centralized credit and interest policy;

- state subsidies;

-. export tariffs and import restrictions;

-- exchange rates.

In the CMEA member countries the methods of handling agricultural production are not uniform. The main policy goals are similar, but methods for their realization often differ. Both direct and indirect means are applied in each country, but their roles are different. The governments in countries with centralized economic management systems operate basically by means of direct economic regulators. The state control in those with decentralized economic management systems is essentially through indirect economic means.

With respect to the modeling of agriculture, on the basis of this review of agricultural policy goals and instruments we can draw the following two basic conclusions.

Firstly, in the centrally planned economies the whole agricultural system is controlled by the national plan and the market has only a partial role determined directly and indirectly by targets for production and consumption. We therefore need a model structure different from those developed for the conditions in the market economies.

Secondly, although the major agricultural policy goals are similar, there is no unified agricultural policy in the CMEA countries as there is in the European Community (EC) countries. A country-by-country approach therefore offers greater possibilities for the modeling of this area.

\section{STATE OF THE ART IN MODELING CENTRALLY PLANNED AGRICULTURAL SYSTEMS}

In the centrally planned countries of Europe several models have been developed to describe the agricultural economy. These modeling efforts were strongly influenced by the existing planning system of the economy and the actual needs of the national planning bureaus and other planning authorities. Since the first attempts in the late 1950s development has taken place in three stages.

Most of the last decade can be considered the period of pioneer work. In the majority of the countries the first macromodels of agriculture were constructed then. The solution of basic methodological problems was emphasized and the work had mainly experimental and scientific characteristics. The contribution of these models to policy decisions was thus very small.

In the early 1970s more sophisticated and detailed models were built and mathematical methods became an accepted element of the techniques used for the preparation of important agricultural decisions. On the whole, however, the mathematical models of agriculture systems played only a partial role in the actual planning procedure. 
Recently the elaboration and implementation of computer-based planning and information system* has begun in the majority of the centrally planned countries. The modeling of agriculture systems is coordinated with this task and the agricultural sector of the national economy is treated as one of the most important elements of this system, serving as a framework for a set of more detailed agricultural models (e.g. sectoral, regional, or by enterprise).

In most cases the modeling of agriculture has been connected with the elaboration of the national five-year and long-range ( 15 20-year) plans. The main objective of these models is to aid decision-making on:

- resource allocation and the production structure of agriculture; regional allocation of production and policy instruments (targets, prices, tax system, subsidies etc.).

The models generally cover the agricultural production sector, but models that include the food processing sphere can also be found. The remaining part of the national economy is derived exogenously. In a few cases the agricultural model was connected with an aggregated model of the whole national economy (two-level planning).

The methodology used is mostly linear programming. A deterministic and normative approach is common. Random factors (weather, world market etc.) are introduced by running the model with different assumptions. Recently multiperiod models have also been developed for long-range planning purposes. The objectives of planning efforts could be basically fulfilled by these methods. Econometric models and simulation techniques have been used only in a few special cases, but until HAM no detailed macromodels of the entire agricultural system had been completed based on the latter methods.

The most important features of the mathematical programming models developed now follow.

Agricultural production is modeled in a very detailed way. The production variables are generally differentiated according to:

production sectors (state farms, cooperative farms, private and household plots); production regions,

soil categories;

-- technologies (e.g. irrigated or dry, partly or fully mechanized);

- most important crop and animal varieties.

The resource requirements are calculated under the assumption of fixed coefficients. These and all other coefficients of the models are adjusted figures that are projected based on the trend of technological development and the evaluation of the current situation. The inputs represent fertilizer, labor (annual or peak requirements), machinery, buildings, feed (according to main type) and water. The resources available for agriculture or its sectors, regions and products are mostly given in physical units. In certain cases the lower bounds of their usage are also restricted (for example, a minimum level of employment must be guaranteed for the members of the cooperative farms).

\footnotetext{
*These systems are called automated management systems (ASUs) in the (MIA member countries.
} 
In the agricultural models consumer and industrial demand are handled exogenously. Fixed production requirements are given based on the targets for the standard of living and industrial requirements. Substitution is often permitted among agricultural products, especially foods required according to the structure of the models. Foreign trade is represented by export and import variables given separately for Western, Socialist and Third World markets. The foreign trade variables are also restricted by upper and lower bounds. The changes in stocks are modeled as well.

The models use a set of different prices (producer prices, export prices etc.). All the prices are fixed and exogenous. Most of the models contain a set of financial balances for the modeling of financial flows connected with agricultural production. The financing of investments is described in this module, and these equations have a very important role in the planning of economic regulators. The allocation of investments is restricted by a set of constraints (lower or upper bounds are given according to product(s), region(s) etc.).

In the objective function the main agricultural policy goals are expressed as:

the maximization of the gross domestic product from agriculture;

- the maximization of the national income from agriculture;

- the maximization of the foreign balance of payments;

-- the maximization of foreign exchange earnings from agriculture;

- the minimization of production expenses with a required level of production and positive balance of payments.

The experience of the previous modeling work was borne in mind in developing our modeling framework.

\section{SOME FEATURES OF HUNGARIAN AGRICULTURE}

Agriculture plays a traditionally important role within the Hungarian national economy. Although the share of agriculture in the production of national income has considerably decreased, agriculture still remains a very important national economic sector. An area of 6769.9 thousand hectares of land, over $70 \%$ of the total territory, was under cultivation in Hungary in 1974. Arable land represents $53.5 \%$ of national territory, one of the highest ratios in the world. In 1976 there were 2.0 million cat tle, 7.2 million pigs, 2.0 million sheep and 41 million poultry in Hungary.

In 1974 some $16.2 \%$ of the Hungarian national income was produced by, and $20.4 \%$ of the working population of 10.5 million was employed in, agriculture.

The per capita value of agricultural production is higher in Hungary than in the other centrally planned countries and in certain respects it exceeds the levels reached by countries of the European Conununity. In 1975 the per capita annual meat production in Hungary was $140 \mathrm{~kg}$, while the average for the EC countries was only $71 \mathrm{~kg}$, and for the USA 109 kg. In 1975 Hungary produced $25.9 \%$ of the total corn production of the CMEA countries. In addition to satisfying to a high degree the food demands of the population (in 1975, $3242 \mathrm{cal}$ and $100 \mathrm{~g}$ protein were consumed daily per capita), the Hungarian agricultural sector is also a considerable and regular supplier of products for export. 
Agricultural products and foodstuffs represent about 23\% of total Hungarian exports. For several years now, Hungary's foreign trade turnover figures for agricultural products has shown a significantly positive balance with both socialist and nonsocialist countries.

In the last few years Hungarian agriculture has developed relatively rapidly. The annual rate of development was $2.8 \%$ between 1966 and 1970 and $4.8 \%$ between 1971 and $1975 .^{*}$ In recent years progress has been made in increasing yields of cereals, mainly wheat and maize, and with poultry and pig breeding. The most important characteristics of Hungarian agriculture are described in Tables 1,2 , and 3.

TABLE 1 Major resources of Hungarian agriculture.

\begin{tabular}{|c|c|c|c|c|c|}
\hline Item & 1971 & 1972 & 1973 & 1974 & 1975 \\
\hline Cultivated area (1000 ha) & 6855 & 6846 & 6853 & 6783 & 6770 \\
\hline Irrigated area (1000 ha) & 465 & 485 & 482 & 482 & 487 \\
\hline Tractor capacity in 1000 horsepower & 3238 & 3257 & 3342 & 3399 & 3504 \\
\hline Fertilizer used $(\mathrm{kg} / \mathrm{ha})$ & 171 & 183 & 216 & 243 & 276 \\
\hline Labor force $(1000 \mathrm{~s})$ & 1167 & 1142 & 1110 & 1063 & 1039 \\
\hline
\end{tabular}

TABLE 2 Global production of major agricultural commodities in Hungary (1000 tonnes).

\begin{tabular}{lrrrrr}
\hline Item & 1971 & 1972 & 1973 & 1974 & 1975 \\
\hline Wheat & 3922 & 4095 & 4520 & 4971 & 4007 \\
Barley & 785 & 807 & 874 & 899 & 701 \\
Corn & 4732 & 5554 & 5963 & 6247 & 7172 \\
Sugarbeet & 2023 & 2909 & 2754 & 3708 & 4089 \\
Oilseeds & 263 & 215 & 244 & 192 & 244 \\
Tobacco & 16 & 17 & 20 & 17 & 17 \\
Potatoes & 1797 & 1349 & 1355 & 1720 & 1630 \\
Vegetables & 1682 & 1860 & 1845 & 1962 & 1632 \\
Fruits & 1231 & 1369 & 1466 & 1472 & 1355 \\
Grapes & 745 & 844 & 1016 & 692 & 813 \\
Meat ${ }^{a}$ & 1554 & 1626 & 1549 & 1689 & 1848 \\
Milk (million liters) & 1749 & 1756 & 1898 & 1959 & 1920 \\
Wool (kg) & 88 & 83 & 76 & 83 & 84 \\
Eggs (millions) & 3475 & 3217 & 3258 & 3628 & 4001 \\
\hline
\end{tabular}

all meat excluding fish.

Relatively large-scale farms are characteristic of Hungarian agriculture. The socialist sector of agriculture, i.e. the cooperative farms (including also the household plots** of their members) and state farms together are responsible for about $95 \%$ of the total agricultural production. The first cooperative farms were established in Hungary in the late 1940s, but the final organization of cooperative farms was completed only in 1961.1742 cooperative and 150 state farms were operating in the country in 1975; the average land areas per farm were 3078 and 6327 hectares respectively.

\footnotetext{
*In the Iast five years $12-13 \%$ of annual national investment funds was used in agriculture.

**Household farming still plays an important role, especially in animal husbandry. In $197528.8 \%$ of the total pig stock and $25.9 \%$ of the total cattle stock were kept on household plots.
} 
TABLE 3 The yields of the major agricultural commodities in Hungary (tonnes/ha).

\begin{tabular}{lrrrrrr}
\hline Item & 1971 & 1972 & 1973 & 1974 & 1975 & $\begin{array}{l}\text { CMEA average } \\
\text { in 1975 }\end{array}$ \\
\hline Wheat & 3.07 & 3.10 & 3.48 & 3.75 & 3.20 & 1.28 \\
Barley & 2.62 & 2.76 & 3.04 & 3.31 & 2.72 & 1.34 \\
Corn & 3.54 & 3.98 & 4.05 & 4.24 & 5.02 & 3.34 \\
Sugarbeet & 27.77 & 37.01 & 29.79 & 37.70 & 32.22 & 21.00 \\
Potatoes & 11.57 & 11.09 & 10.94 & 12.59 & 12.64 & 12.80 \\
Milk (1/cow) & 2354 & 2363 & 2458 & 2478 & 2446 & - \\
Eggs (no./hen) & 118 & 141 & 138 & 140 & 144 & - \\
Wool (kg/animal) & 4.5 & 4.7 & 4.4 & 4.7 & 4.4 & \\
\hline
\end{tabular}

State farms represent the most advanced agricultural enterprises in Hungary. Yields and average outputs surpass both the national average levels and those of the cooperative farms. Their equipment, of course, and also their assets are superior to the average in the country. Cooperative farms are organized on the basis of self-management and self-finance. Their management is secretly elected by the members. The most important decisions are taken by the members' assembly and the board of directors. The level of personal earnings depends directly on the gross income realized by the farm. As a result of this, although a certain minimum income level is guaranteed by the state, considerable differences may be found in the levels of personal earnings of cooperative farm members. The income distributions in cooperative farms as well as the increases in personal incomes are regulated by taxes.

The major agricultural policy goals are fixed in the five-year and long-range plans for agricultural development. Under the present (fifth) five-year plan (1976-80) the development of animal husbandry, in particular cattle and pig production, and the food processing industry, as well as the increase of foreign exchange earnings from the export of foodstuffs, are emphasized.* As has been mentioned, these targets are realized through the implementation of indirect economic means. The cooperative and state farms and other enterprises have a relatively wide economic independence; they are given no obligatory plan targets for their production activities.

\section{MAIN FEATURES OF THE HUNGARIAN AGRICULTURAL MODEL}

The major objective of the HAM project at IIASA was to develop a general modeling framework for the study of centrally planned food and agriculture systems, and to prove the appropriateness of our approach by developing a detailed prototype model. HAM is actually the first really detailed system simulation model describing the food and agriculture sector in a centrally planned country. The model is constructed according to the basic characteristics of IIASA's general model structure for centrally planned food and agriculture systems, representing a concrete example of the utilization of this framework.

The Hungarian Agricultural Model

is consistent and comparable with other parts of IIASA's food and agriculture model system;

\footnotetext{
*The planned annual growth rate for agriculnaral production is $3.4 \%$.
} 
incorporates the basic features of the CMEA member countries' economies;

- also describes the specific features of the Hungarian economy in food and agriculture;

-- is detailed enough to be used as an experimental tool for actual planning and forecasting purposes.

As with other elements of IIASA's food and agriculture model system, in the case of HAM our main goal is not straightforward optimization, but rather to make a tool that affords opportunities for a better understanding of the dynamic behavior of the Hungarian agricultural system and the interactions of its elements, so that the model can also be used for mid- and long-range projections. Unlike the normative agricultural models that have been developed, this model has a descriptive character. It reflects the present operation of the centrally planned food production systems and, therefore, the present decision-making practices and economic management of the government are described. At the same time various normative elements, such as government decisions and published plan targets influencing the projected operation of the system, are also considered.

In the model we try to endogenize a large part of the economic environment and the most important factors of food production. The food and agriculture is modeled as a disaggregated part of an economic system closed at the national as well as at the international level. HAM therefore has the following features:

- the food consumption sphere is incorporated;

- the nonfood production sectors of the economy are represented by assuming that they produce only one aggregated commodity;

- the economic, technical, biological and human aspects of food production are covered;

- both the production of agricultural raw materials and food processing are modeled;

- all products not individually represented are aggregated under "other" agricultural production and food processing;

financial equilibrium is maintained.

The overall methodology used in the model is a simulation technique. For the description of subsystems, suitable techniques such as linear programming, nonlinear optimization and economic methods are employed. The model is dynamic, with a one-year time increment. Subperiods within the year are not considered. The time horizon of the analysis is $15-20$ years. Random effects of weather and animal disease conditions can also be considered.

HAM is constructed according to the basic characteristics of the centrally planned economies in general, and the Hungarian food and agriculture system specifically. The model therefore has certain specific features not shown by other elements of the model system. The most important specific features are as follows.

1. Long-range government objectives, such as the growth of the whole economy, the growth rate of food production and consumption, a given relation of consumption to accumulation and a given positive balance of payments in food and agriculture, are considered exogenously as they are determined by the long-range development plan of the national economy. 
2. According to the real structure of agricultural production in these fields, various sectors (state, cooperative, household* and private farms) are considered. In addition to agriculture, food processing is handled separately and is not aggregated with the rest of the economy.

3. In central planning, the government has a crucial role in the system. The model therefore has to include a detailed description of the government's economic management activities.

4. The domestic market included in HAM is not directly related to the world market. The effects of the international market are filtered by the government's budget.

5. Four types of prices are distinguished in the model: the domestic consumer and producer, as well as international dollar and ruble prices. The domestic prices express government policy objectives instead of being related to a certain market equilibrium.

6. The inter-CMEA trade is considered as a separate segment of the international market.

7. In Hungary the overall targets for food and agriculture are primarily realized using indirect economic means (prices, taxes and subsidies); HAM-2 therefore represents a decentralized version of IIASA's model structure for CMEA countries, where producers' decisions play quite an important role.

The major characteristics of HAM are summarized in Table 4. HAM was obviously designed to be an element of the IIASA agricultural model system under development and

TABLE 4 General features of CMEA models at IIASA.

\begin{tabular}{ll}
\hline Common features & Specific features of HAM \\
\hline Descriptive & Government planning submodel \\
Dynamic & Various production sectors \\
Consumption is incorporated & Independent domestic market \\
Rest of the economy as one aggregated sector & Separated inter-CMEA trade \\
System model & Crucial role of government budget \\
Financial equilibrium & Special exchange module \\
Unified commodity coverage & \\
\hline
\end{tabular}

as such it will be linked with other national models and used for global investigations. Furthermore, HAM was constructed as an experimental tool for investigations connected with the development of Hungarian food and agriculture in the following ways.

On the basis of the model, the realization of major policy goals and plan targets and their main alternatives can be investigated. For example, the key factors and bottlenecks of realization, the considerations for a faster growth, the expected labor outflow from agriculture and the feasibility of the goals may be analyzed.

\footnotetext{
* A household farm is a private farming activity of cooperative farm members, mainly around their houses.
} 
- By linking it with other national models, HAM is suitable for studying the adjustments and reactions of the Hungarian food and agriculture system to a changing international market. For example, export and import structure, the desired level of specialization or self-sufficiency and the reaction of the domestic to the world market may be investigated.

- Finally, HAM is designed to be useful for the further development of the Hungarian economic management system, since the model can analyze the efficiency of policy instruments, the impacts of the new instruments and the areas of additional control requirements.

We hope that by developing the HAM structure and by offering possibilities for the investigation outlined above, we can contribute to the further development of the techniques of planning and economic management in Hungary. The HAM project can also be considered as an important part of the efforts for the introduction and more efficient use of computers in policy analysis and in macrolevel decision making.

\section{GENERAL STRUCTURE AND OPERATION OF HAM}

HAM was constructed in accordance with IIASA's general modeling principles for centrally planned food and agriculture systems. Figure 1 shows the structure of the final version of the model. HAM is in fact a system of interconnected models. Two spheres are differentiated within the system. The economic management and planning submodel describes the decision-making and control activities of the government. The production submodel covers every producing branch of the national economy, including the disaggregated food production sector. The major blocks of the latter submodel are related to production, consumption and trade in addition to the updating of available resource and model parameters.

Different mathematical formulations have been used for the descriptions of various subsystems. As far as the methodology of the model is concerned, first of all our attempts to describe the agricultural policy-making and planning activities of the government should be pointed out. In HAM the implementation of given policy objectives is fully endogenized. As has already been mentioned, long-range government objectives arc taken as determined by central planners. Government plan targets on food and agriculture are determined by a linear programming model. The investment decisions of the government and the adjustments of overall objectives and policy instruments are modeled by heuristic routines. This is one of the first attempts at a mathematical description of the pricing mechanism in a centrally planned economy.

The food and agriculture production is modeled according to producing sectors. The socialist agriculture (state and cooperative farms) is modeled by a linear programming model; the behavior of private and household farms is described by supply functions and a separated, nonoptimization heuristic type of model block is related to the food processing. A heuristic type of model is constructed to describe the investment decisions of producing firms. The output of the non-food-producing part of the economy is calculated using a Cobb-Douglas-type function. 


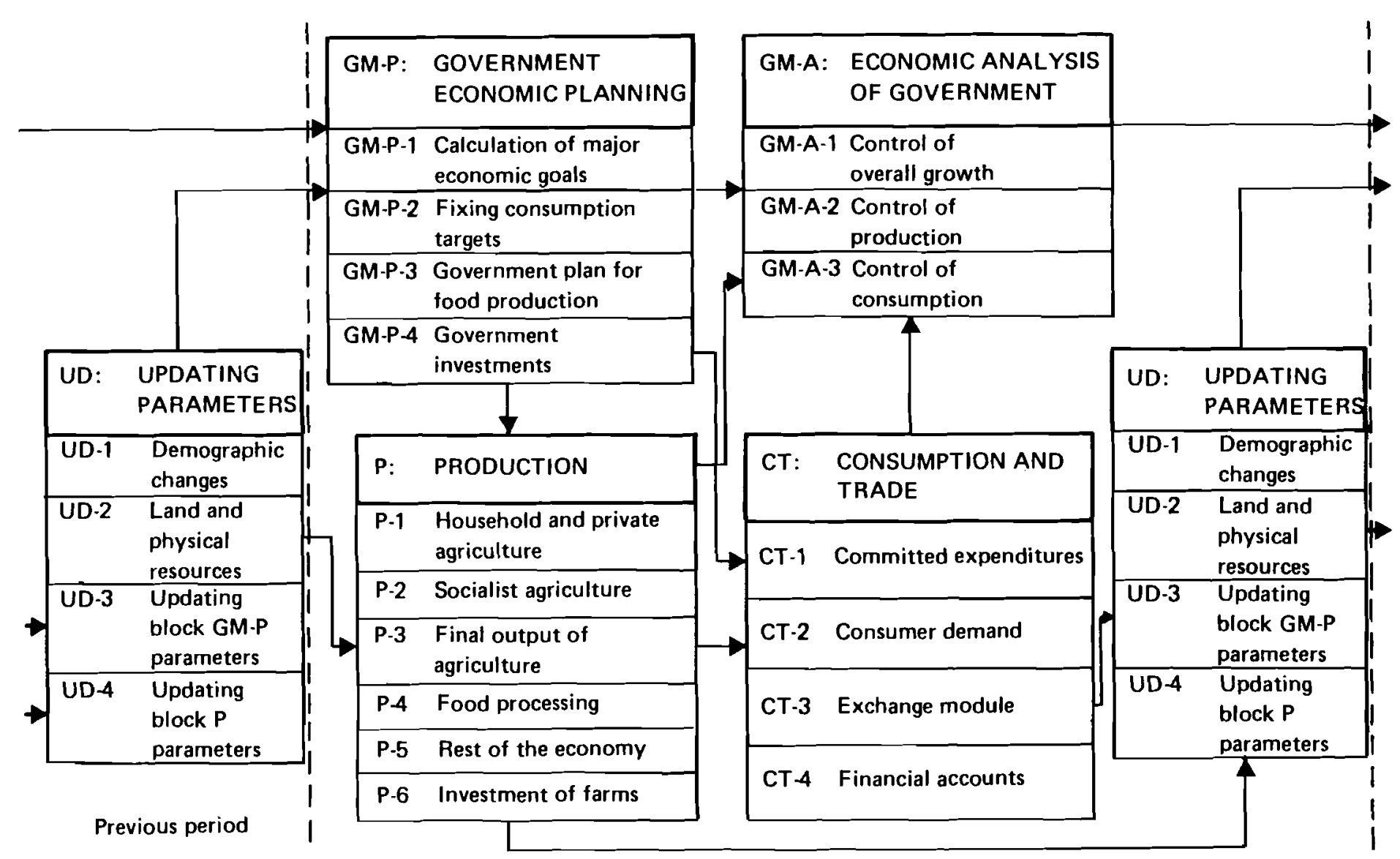


The Exchange module is a crucial part of the whole system. As has already been mentioned, an equilibrium type of model has been constructed to reach the balance-of-trade equilibrium and to adjust to changing international market conditions. A special version of the extended linear expenditure system has been estimated to describe consumer behavior.

The demographic changes and available resources are updated based on trend and depreciation functions. The production block parameters are actualized by using yield functions expressing the trends of biological development. Input coefficients are calculated based on production functions. The coefficients in the government economic planning module are updated based on the production block of the previous period.

The various blocks and modules of the model are interlinked through a relatively complicated system of relations and feedback loops. The major steps of HAM's solution are given in the following.

The overall objectives of the government: module GM-P-1

The first step is the setting of major economic goals of the government for a given period of simulation, i.e.:

-. the desired consumption fund;

- the desired growth of the whole economy;

- the desired gross productuon of food and agriculture;

- the related indicators of total investment funds in the rest of the economy and in food and agriculture;

-. the desired state of the balance of payments of the country.

These are determined based on the targets in the long range plan of the government for the desired growth of consumption, the whole economy and food and agriculture, as well as the share of food and agriculture in total investments. (The major interrelationships of the government economic planning block can be seen in Fig. 2)

\section{Plan targets for private consumption: module GM-P-2}

Based on the target value of total consumption and consumer prices updated at the end of the previous period, the planned structure of private consumption, as well as the planned total consumers' needs for individual commodities, is determined. Government objectives on the change in the consumption structure are considered and an extended linear expenditure system is used as the methodology of the calculation.

\section{Plan for food and agriculture: module GM-P-3}

The desired structure of food production (agriculture and food processing) and related exports and imports are calculated next. The desired gross output of food and agriculture (from GM-P-1) and certain minimum production requirements (based on the consumers' needs from GM-P-2) are considered as lower bounds in the linear programming model. The same applies to the required positive balance of payments from food and agriculture (also from GM-P-1). We assume that central planners want to obtain the most efficient structure of foreign trade in food and agricultural products, maximizing the net export returns on domestic production expenditures, and we use the international prices 

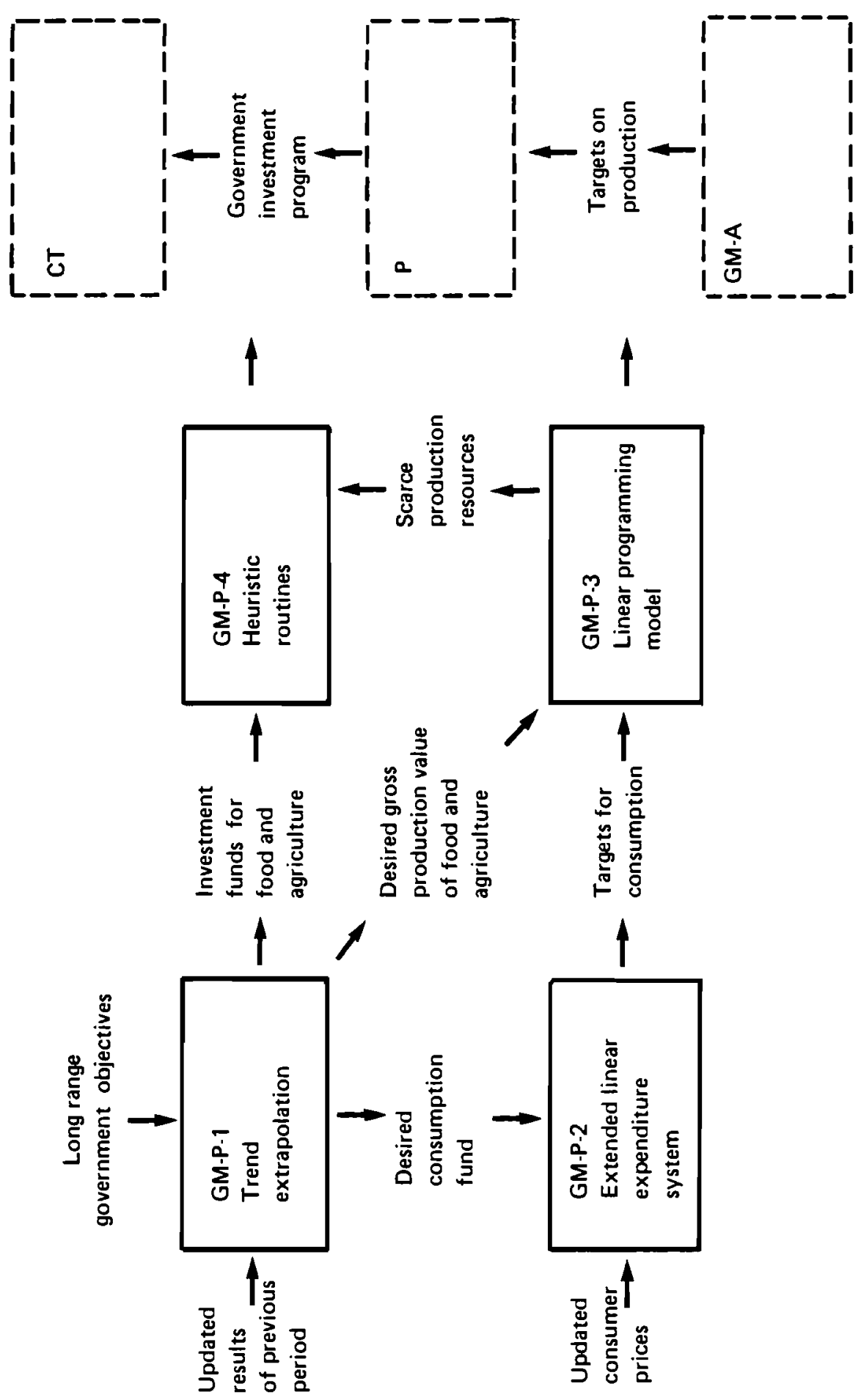
and production expenditures of the previous period. Obviously the maximization of the efficiency of foreign trade in agricultural products is only one possible goal of agricultural policy and it might conflict with other objectives. The model is capable of handling a wide range of possible objectives and has in fact been run with quite different assumptions. Upon the request of the Hungarian National Planning Bureau, foreign trade efficiency has been the focus of the first set of investigations. This model supplies the guidelines for the analysis at the end of the simulation of each year (module GM-A-1) and information on scarce resources where investment might be required.

\section{The government's plan on investments in food and agriculture: module GM-P-4}

The government's investment plan is elaborated by using heuristic routines. The investment program is settled based on the shadow prices of the module GM-P-3 solution and considering the scale requirements of various investments. In the case of food processing the decisions on new investments are partly centralized in Hungary and therefore they are modeled by GM-P-4. As far as agricultural investments and the rest of the investment in food processing are considered, only a desired program is calculated and this is used to distribute available government subsidies to firms' investments; however, the decisions on these kinds of investment are modeled within the production block.

\section{Production decisions of household and private agriculture: module P-1}

We assume that production decisions of the household and private sector are based on producer prices announced for the given period, expected yields, available land and labor force. Separate supply functions have been estimated for plant and animal production. Firstly the available land is distributed between various crops, with no constraint on labor. Secondly labor after deduction for plant production needs is used as the major limit on the volume of animal husbandry. The total amount of labor available for household and private agriculture is determined in the Updating module. The outputs of crop production calculated here might be subject to the random effects of the weather.

\section{Production decisions of socialist agriculture: module $P-2$}

A linear programming model is constructed to describe the decisions of socialist agricultural enterprises (cooperative and state farms) on production structure. For most of the commodities, two or three production technologies are considered and a relatively wide range of inputs to different products are taken as parameters determined in block UD. The linear prograniming model is structured according to resource utilization, commodity utilization and financial subsystems. The socialist sector maximizes its expected profit. The producer prices, wages and tax coefficients are given by block GM-A of the previous period. The producers' prices are not subject to changes during the simulated year, but crop yields might be influenced by the weather disturbance factor, as is household and private production. To avoid extreme solutions the change of production structure from one period to the next is constrained. These upper and lower bounds are determined based on the analysis of structural changes in the past. (The major interrelations of the Production block as well as the role of module P-2 can be seen in Fig. 3.)

\section{Outputs of agriculture: module $P-3$}

The final output of agricultural production is calculated in this module, based on modules P-1 and P-2. The random effects of weather on yields of annual and perennial 


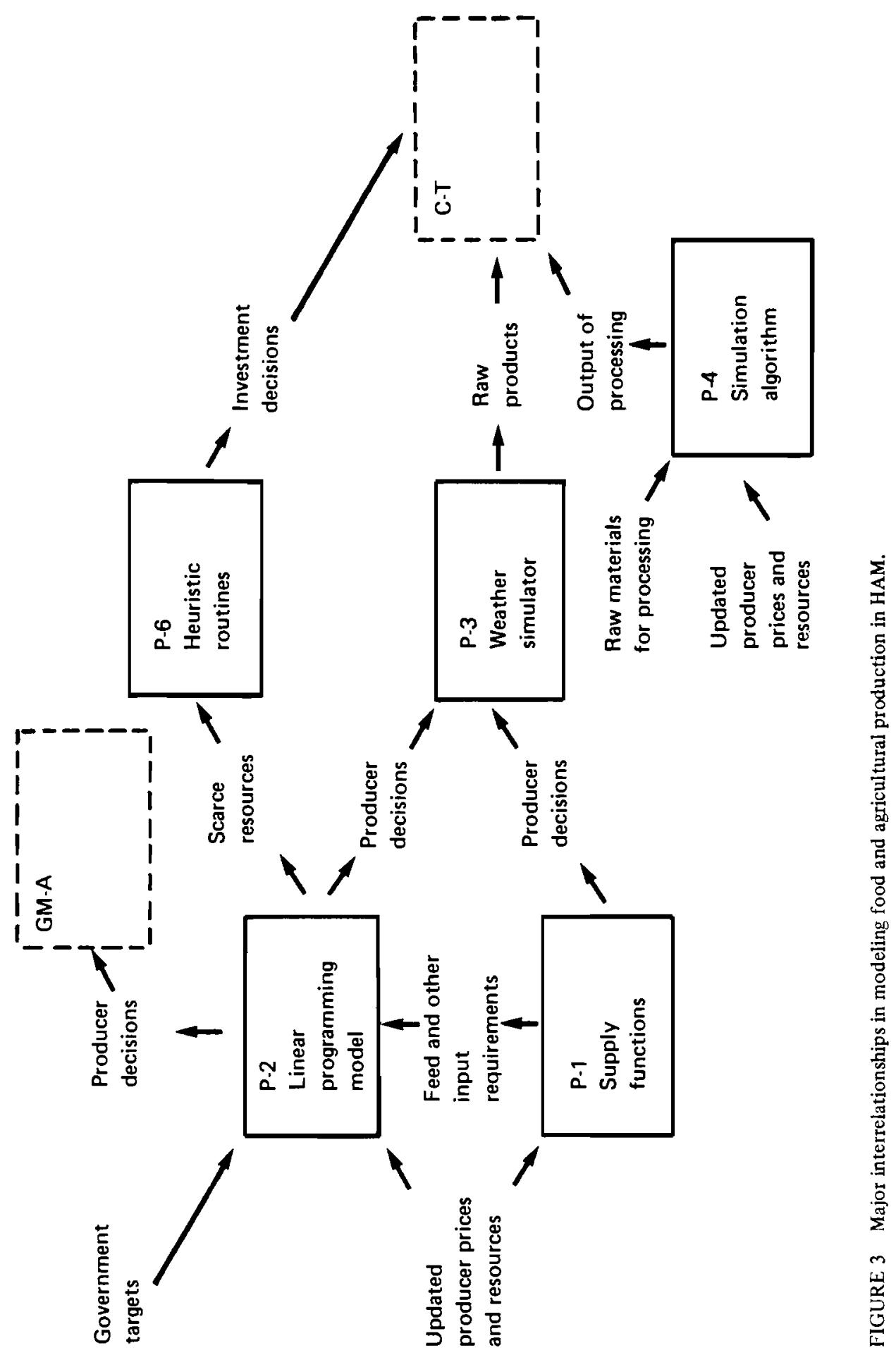


crops can be considered here. Obviously the output of animal husbandry is taken as calculated in module P-1 and P-2. If an agricultural commodity can be either processed or directly consumed, the available raw materials for processing are also determined in this module using exogenous rules and considering government preferences in the utilization of raw products (processing versus export or fresh consumption).

\section{Output of processed food commodities: module P-4}

As the outputs of agriculture are known, the output of the food processing industry can be determined. We assume that the food processing industry aims at the utilization of its resources based on a given supply of raw materials. We also assume that available fresh products need to be processed up to the level of existing capacities and also that raw materials for processing (except protein feeds) cannot be imported.

\section{Output of the nonagricultural sector: module P-5}

On the basis of the available production capacities and labor force, outputs are determined by a Cobb-Douglas type of production function. We assume that all the labor force other than that needed in food and agriculture is fully utilized in this sector. The rest of the economy is handled as one homogeneous commodity.

\section{Investment decisions of producing firms: module P-6}

The investment program of agricultural firms and food processing enterprises is determined using a methodology similar to that used in government investment decisions. The investment program is based on the shadow prices of the LP model in the P- 2 module and resource utilization in the P-4 module. Scaling of investments is also considered. Obviously investments are constrained by the funds available to the firms as well as by government subsidies.

\section{Calculations of committed expenditures: module CT-1}

First of all in module CT-1 the so-called committed expenditures, which cannot be further modified, are summarized. A simple calculation takes place based on former model elements to determine:

-. intermediate inputs actually used in production;

-- the income and income utilization of producing enterprises (socialist agriculture, food processing and the rest of the economy) including total committed demands (intermediate inputs plus certain investments);

- the endowments and committed expenditures of the population (private consumers);

- the government's income from producers and population and the government's committed expenditures.

\section{Modeling of consumers' demands: module CT-2}

Module CT-2 describes private consumption. The role of module CT-2 is to determine the per capita consumer demands, assuming that the endowment of consumers after the deduction of savings is fully spent in buying various commodities. The consumer demands for a specific commodity are therefore influenced by the consumer prices and the level of endowment. 
Calculation of noncommitted demands and exports-imports: moduls CT-3

Module CT-3 (Exchange module) is a crucial part of the entire model, where the final level of private and government consumption, as well as stocks satisfying balance of trade equilibrium conditions, are determined. It is important to note that the reaction mechanism of domestic demands to new world market conditions (prices) is described in this module.

\section{Accounting for a given period: module CT-4}

As the final results are obtained by Module CT-3 the detailed financial consequences of a given situation are calculated. This is the role of Module CT-4. (For connections in the CT Module, see Fig. 4.)

\section{Control of the overall growth: module GM-A-1}

As the next step in the simulation, the basic government policy instruments influencing the overall growth of the economy are revised based on the analysis of the performance of the whole system. From the actual growth rate of the economy the consumption fund for the next period is determined. The desired share of food and agriculture in total investment is adjusted on the basis of the growth rate for food and agriculture. Module GM-A-1 supplies the major parameters for module GM-P-1 for the forthcoming period.

Control of production structure and adjustment of producer prices: module GM-A-2

The producer's prices are changed by a comparison between the actual and the planned production. The basic principles of the procedure in revising producer prices of agricultural commodities are outlined in Fig. 5. The producer prices in food processing are revised in a somewhat simplified manner, as shown in Fig. 6. (Figure 7 outlines the basic connections of the GM-A block.)

\section{Control of consumption, revision of consumer prices: module GM-A-3}

The consumer price of a given commodity is modified (see Fig. 8) based on the comparison of the desired and the actual per capita consumption of the given commodity. During the revision, as Fig. 8 shows, relation of the consumer price to the producer price is also considered.

\section{Updating of parameters for the next period: block UD}

The final step in the simulation for one year is the updating of parameters for the next period. The available labor force and changes in population are calculated from existing demographic prognoses (module UD-1) in the same way as for basic land resources, for which the annual decrease in the amount of plowed land is taken as an exogenous parameter (module UD-2). The information for updating physical resources (module UD-2) on investments is supplied by previous model elements. The technical coefficients of production variables in the GM-P-3 module are calculated as a weighted average of the various production technologies that appear in production decisions for the actual period (module UD-3). The yield and output coefficients of the P-1 and P-2 modules are settled as a function of biological and technical development. The fertilizer usage is calculated from response functions. The other input coefficients are selected from the exogenously given set of parameters determined by experts for each technology considered and for each level of output (module UD-4). 


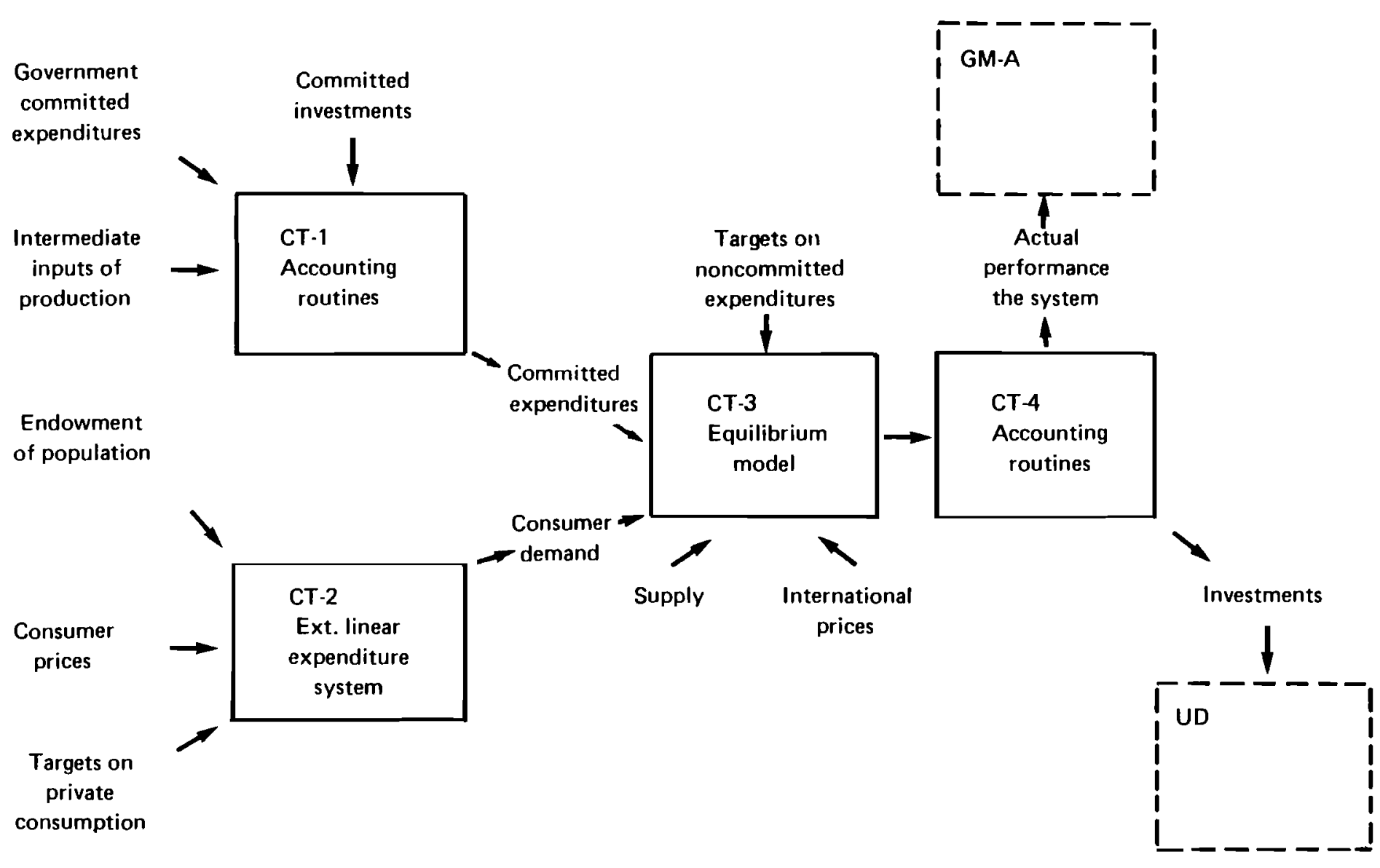

FIGURE 4 Major interrelationships in the consumption and trade block of HAM-2. 


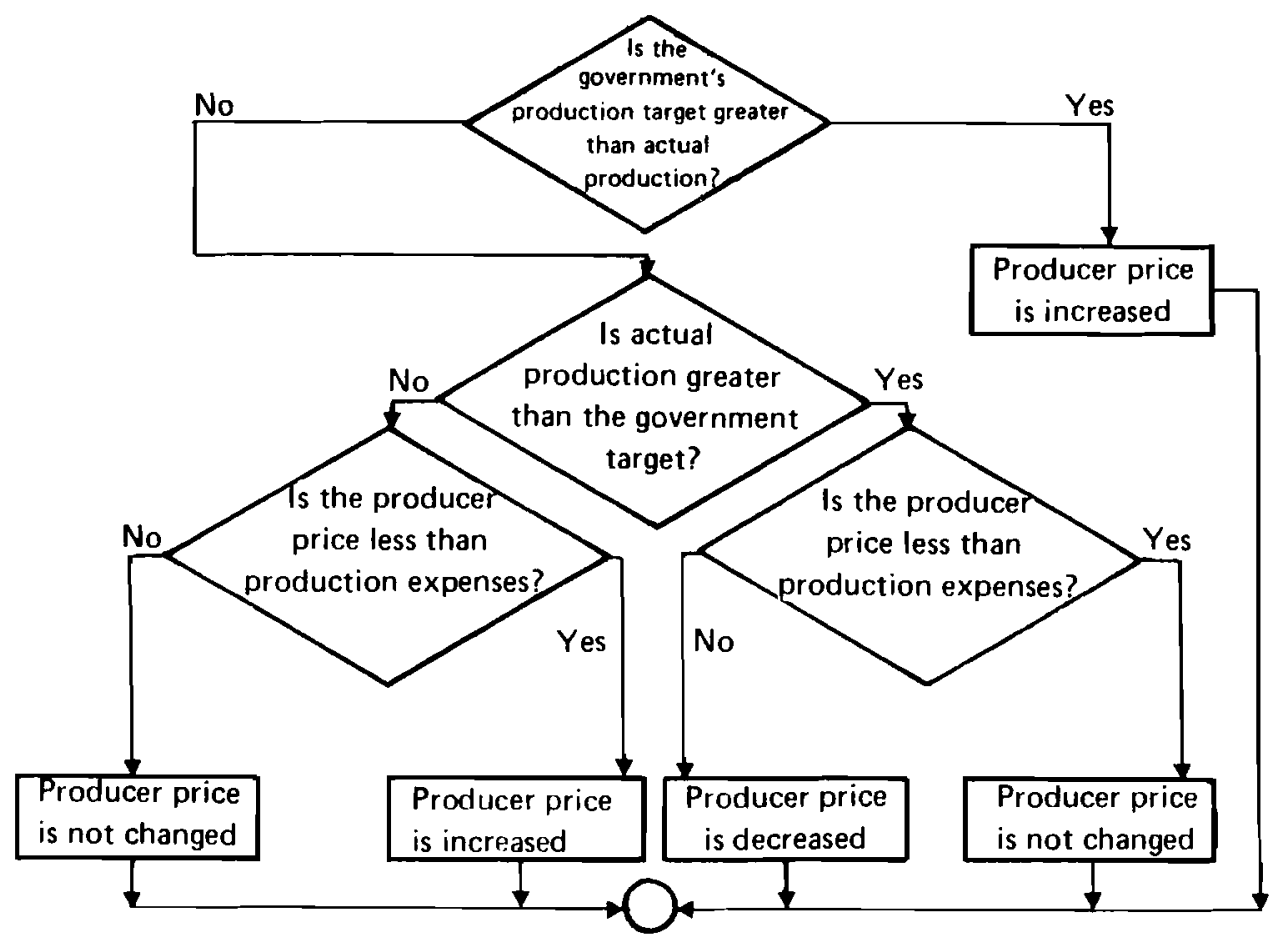

FIGURE 5 Adjustment of producer prices in agriculture.

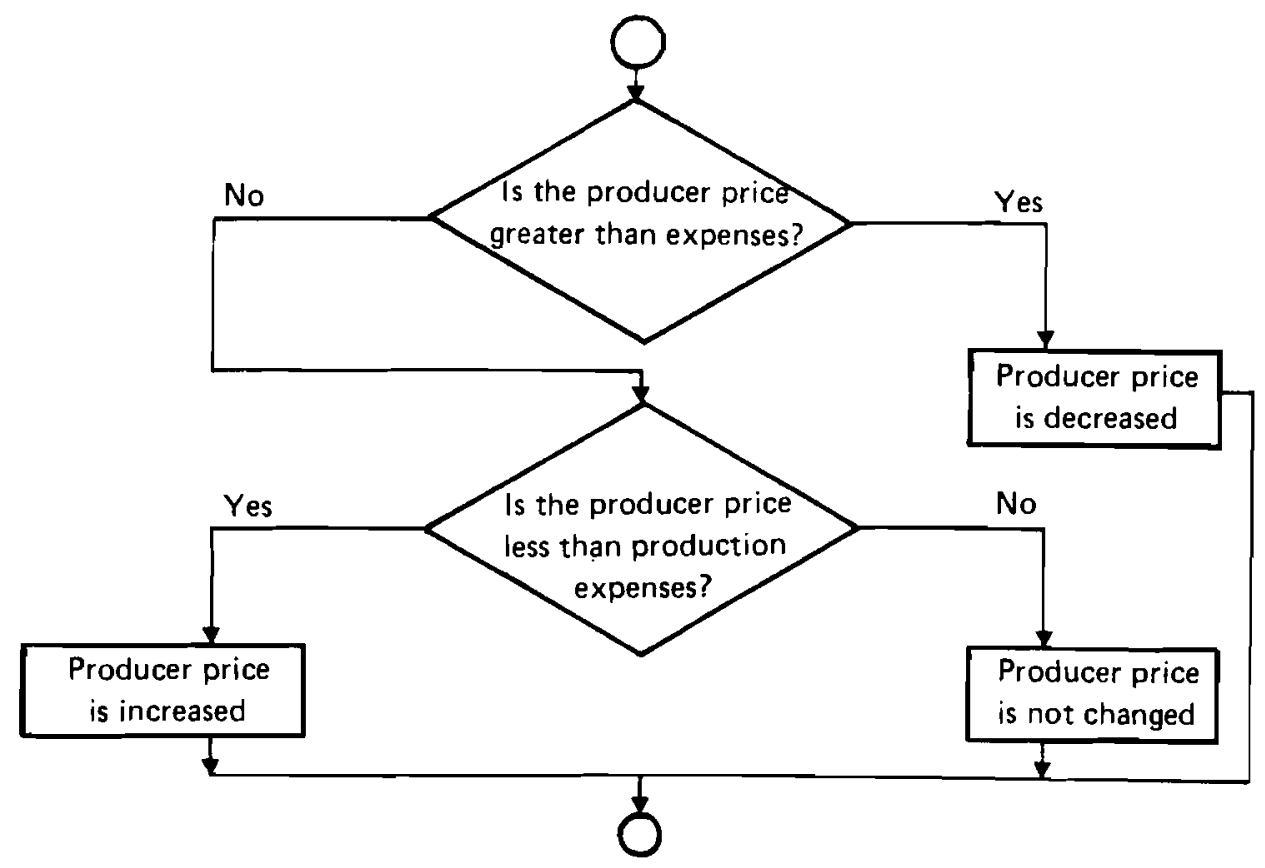

FIGURE 6 Adjustment of producer prices in food processing. 


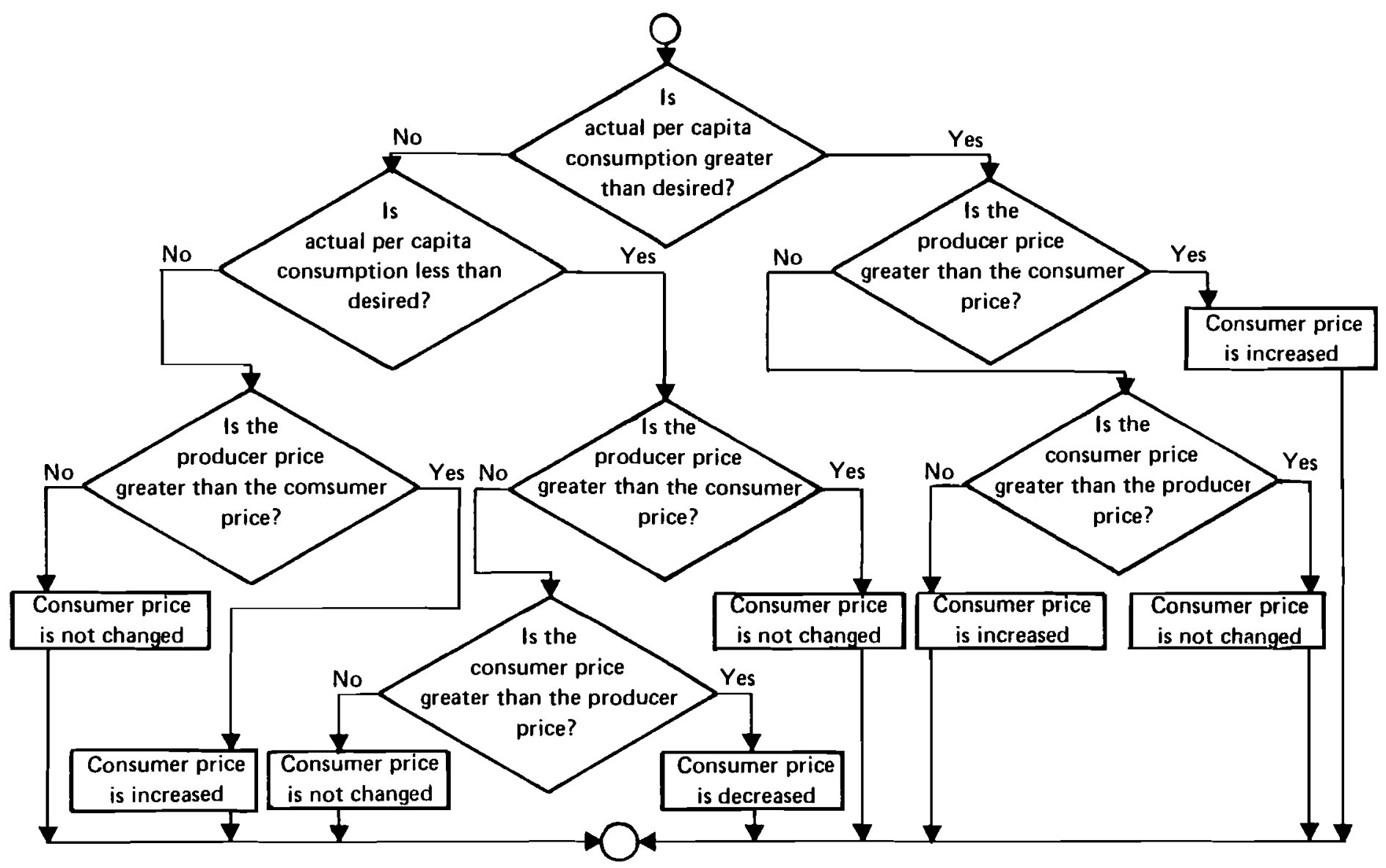

FIGURE 7 Revision of consumer prices. 


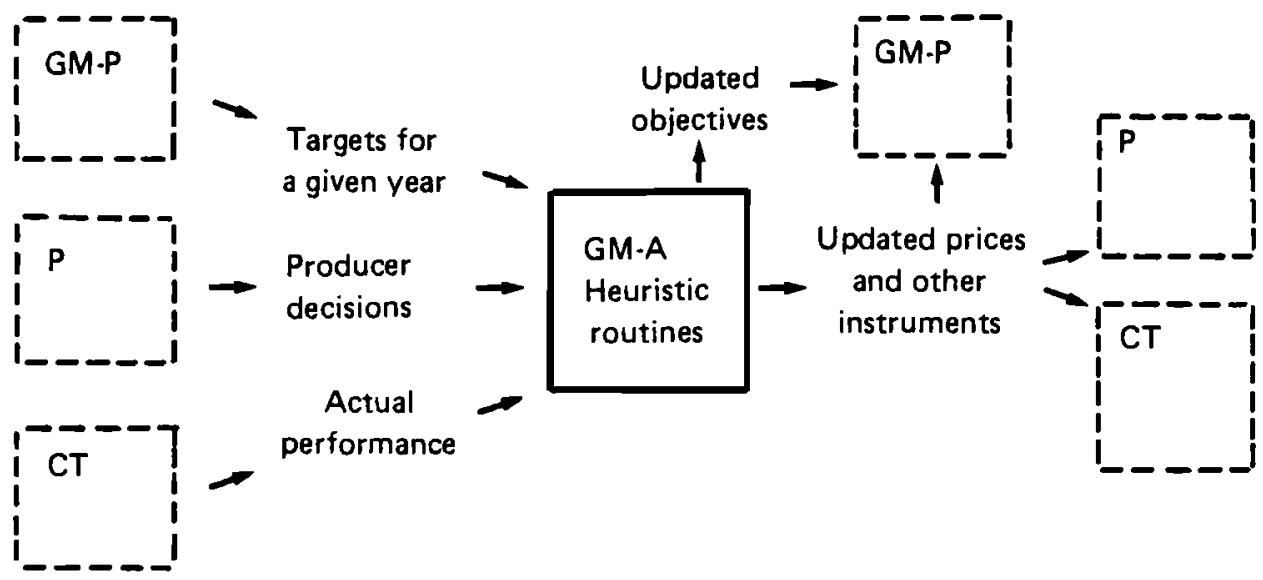

FIGURE 8 Role of government economic analy sis block in HAM.

\section{MATHEMATICAL DESCRIPTION OF HAM MODEL STRUCTURE}

For each model block and module the detailed mathematical structures of the various equations are now described in the order of computation.

\subsection{System of Symbols Used}

The system of symbols used is as follows (the meanings of symbols used in HAM are listed in the Appendix).

\section{Superscripts}

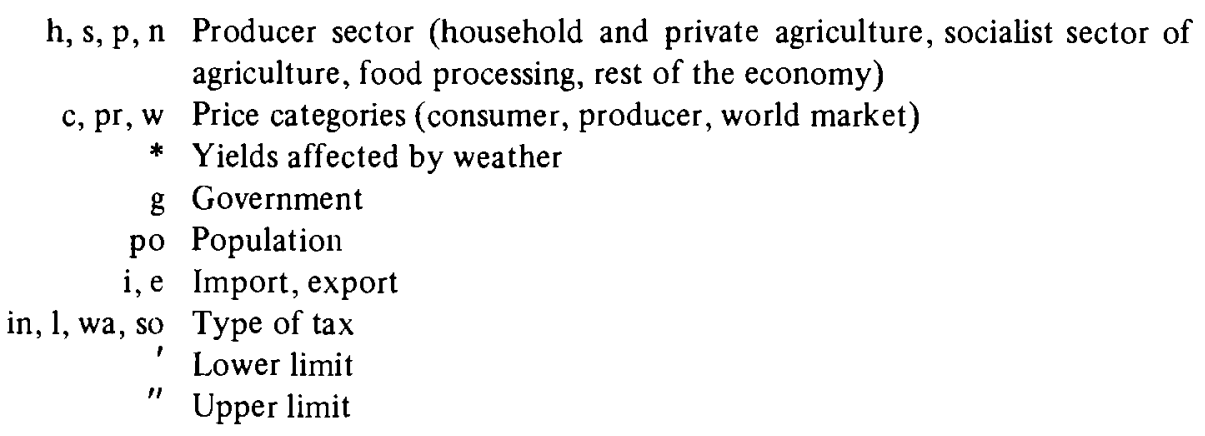

\section{Subscripts}

$i$ Agricultural commodity $i$

$f$ Processed food commodity $f$ 
$n$ The $n$th commodity

1 Land resource

m The additional activities

g General management and overhead activities

An underscore (_) denotes the symbol over which to sum.

\section{In parentheses}

( $t$ ) Time period

$(a, b, \ldots)$ Argument of function

\section{Symbols}

$a, a^{(t)}$ etc. Lower case Roman letters refer to exogenous and policy variables

$\alpha, \beta, \gamma$ etc. Greek letters refer to model coefficients

$S P, L P H N$ etc. Capital letters refer to model variables

\subsection{Modeling of the Government's Economic Planning Activity (GM-P)}

As Fig. 2 shows, the Government Economic Management submodel (GM) is devoted to the simulation of policy making and planning (GM-P), and to economic analysis and the revision of policy instruments (GM-A) by the government of the centrally planned socialist state. Ours is one of the first attempts to present a mathematical description of this very complex area. The final formulation of this submodel, especially those parts related to policy instruments, therefore required detailed analysis of the system.

In Hungary, as in all CMEA countries, the basic franework of economic development is determined by the central planning activity of the government. The first block of HAM therefore has to be devoted to the government's economic planning. As has been mentioned, the basic long-range government objectives are taken as exogenous parameters in HAM. Further government planning activities are represented by the Government Planning Block (GM-P) of HAM which includes four modules: the calculation of major economic goals of government (GM-P-1), the fixing of food consumption targets (GM-P-2), the planning of food production and foreign trade (GM-P-3) and the setting of government investment targets (GM-P-4).

\subsection{Calculation of Major Economic Goals (GM-P-1)}

In the centrally planned economies a certain rate of growth is considered as a minimum requirement for the economy. GM-P-1 is concerned with the determination of these requirements. In HAM the desired level of gross national product of food and agriculture, the desired growth of private consumption and the required positive balance of payments related to agriculture and food processing are fixed based on the exogenous long-range objectives. 
First the desired net national product is fixed and in addition the planned accumulation fund available for food and agriculture is also calculated as follows:

$$
\begin{aligned}
& P N N P^{(t)}=e N N P^{(t-1)} \\
& D G N P^{(t)}=(1+a) G N P^{(t-1)} \\
& D G N P A^{(t)}=(1+b) G N P A^{(t-1)} \\
& D P B A^{(t)}=\sum_{t_{1}=t-3}^{t-1} P B A^{(t)} / 3 \\
& P A F^{(t)}=\left(1-f^{(t)}\right)\left(P N N P^{(t)}+D E S P N^{(t-1)}-P Y O^{(t)}\right) \\
& P A F A^{(t)}=g^{(t)} P A F^{(t)} \\
& P A F N^{(t)}=\left(1-g^{(t)}\right) P A F^{(t)} \\
& P D G I N A^{(t)}=h P A F A^{(t)} \\
& P G I N S^{(t)}=P A F A^{(t)}-P D G I N A^{(t)}
\end{aligned}
$$

As far as the desired positive balance of payments from food and agriculture is concerned, the balance is determined on international dollar and ruble as well as on domestic producer prices. The desired balance of payment in dollar markets is given by

$$
\begin{aligned}
& K A^{(t)}=\left(1+c^{(t)}\right) K A^{(t-1)} \\
& P Y O^{(t)}=\left(1+c^{(t)}\right) Y O^{(t-1)}
\end{aligned}
$$

Finally, based on the desired annual growth rate of private consumption, the target value of total consumption at producer prices is calculated as follows:

$$
\operatorname{PCTOT}^{(t)}=\left(1+i^{(t)}\right)\left(\operatorname{CONP}^{(t-1)}+G P E^{(t-1)}+\operatorname{CONS}^{(t-1)}\right)
$$

\subsection{Plan for Consumption (GM-P-2)}

In the GM-P-2 module a detailed plan for per capita consumption of commodities is elaborated. In connection with this, starting from the desired growth of total consumption, (private and community* consumption) first of all we have to ensure the following.

1. The planned consumption fund must satisfy the minimum consumption growth requirements (adjustment of the $f^{(t)}$ parameter):

$$
P C F^{(t)}=f^{(t)}\left(P N N P^{(t)}+D E S P N^{(t-1)}-P Y O^{(t)}-Y S^{(t-1)}\right)
$$

\footnotetext{
*Consumption of population financed from government budget (e.g. in hospitals, schools etc.).
} 
If the planned consumption fund is not sufficient, then

$$
P C T O T^{(t)}>P C F^{(t)}
$$

$f^{(t)}$ is modified as follows:

$$
f^{(t)}=P C T O T^{(t)} /\left(P N N P^{(t)}+D E S P N^{(t-1)}-P Y O^{(t)}-Y S^{(t-1)}\right)
$$

and

$$
P C F^{(t)}=\operatorname{PCTOT}^{(t)}
$$

2. The endowments of the population (personal income and fund for community consumption) are in accordance with the planned consumption fund (adjustment of $o^{(t)}$ and $\left.e p^{g(t)}\right)$. The income of the population is planned as follows:

$$
\begin{aligned}
& P T P E^{(t)}=\left[\left(1+o^{(t-1)}\right)\left(W E S^{(t-1)}+W E P^{(t-1)}+W E N^{(t-1)}\right)+B S^{(t-1)}+B P^{(t-1)}\right. \\
& \left.+B N^{(t-1)}\right]\left(1-t^{\mathrm{in}, \mathrm{po}}\right)+e S^{\mathrm{g}} G S P^{(t-1)}-A S P^{(t-1)}+\left(1-t^{\mathrm{in}, \mathrm{h}}\right) I N H^{(t-1)}
\end{aligned}
$$

The planned community consumption of commodity $i$ in physical units:

$$
\operatorname{PTCG}_{i}^{(t)}=\left(1+e p^{g(t-1)}\right) P T C G_{i}^{(t-1)}
$$

and the sum in value:

$$
P G P E^{(t)}=\sum_{i} p_{i}^{\mathrm{pr}(t)} P T C G_{i}^{(t)}
$$

If the planned income of the population does not meet the planned value of the consumption fund, the undesired deviations are alleviated by adjusting the targets for increases in wages and community consumption. The adjustment of unit wages for a given period takes place as follows. If

$$
P C F^{(t)}>\left(P T P E^{(t)} / p c i^{(t)}+P G P E^{(t)}\right)\left(1+\epsilon_{1}\right)
$$

then

$$
\begin{aligned}
& o^{t}=\min \left(o^{(t-1)}+\beta_{3} ; o k^{\prime \prime}\right) \\
& e p^{g(t)}=\min \left(e p^{g(t)}+\beta_{4} ; e k^{\prime \prime}\right)
\end{aligned}
$$

If

$$
P C F^{(t)}<\left(P T P E^{(t)} / p c i^{(t)}+P G P E^{(t)}\right)\left(1-\epsilon_{1}\right)
$$

then 


$$
\begin{aligned}
& o^{t}=\max \left(o^{(t-1)}-\beta_{3} ; o k^{\prime}\right) \\
& e p^{g(t)}=\max \left(e p^{g(t-1)}-\beta_{4} ; e k^{\prime}\right)
\end{aligned}
$$

otherwise

$$
\begin{aligned}
& o^{t}=o^{(t-1)} \\
& e p^{g(t)}=e p^{g(t-1)}
\end{aligned}
$$

Obviously the values of $P T P E^{(t)}, P T C G_{i}^{(t)}$ and $P G P E^{(t)}$ have to be recalculated using the adjusted $o^{(t)}$ and $e p^{\mathrm{g}(t)}$ coefficients and

$$
P J O V^{(t)}=P T P E^{(t)} / p c i^{(t)}+P G P E^{(t)}
$$

As the total endowment of the population is determined, the consumers' demands for various commodities are planned. The same method is used for determining expected consumer demand in a given year as for generating the final demand. We assume that the income of the population available after deducting savings and other commitments is spent in buying various commodities. Obviously in this case the planned sum of consumers' incomes is used. The planned consumer demand for a specific commodity is influenced by the consumer prices and the level of income, and is described as follows:

$$
P T C_{i}^{(t)}=\rho_{i}^{(t)} P T P E^{(t)} / p_{i}^{\mathrm{c}(t)}
$$

where $\rho_{i}^{(t)}>0$ and $\Sigma \rho_{i}^{(t)}=1$. The $\rho_{i}^{(t)}$ parameters are determined using C.E.V. Leser's nonlinear demand model.

We assume that planned consumer expenditure on commodity $i$ can be described as

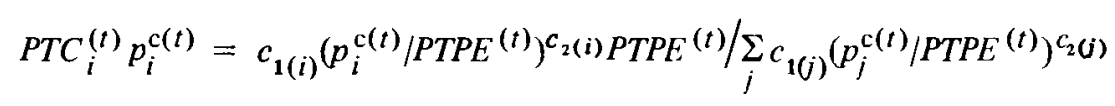

where $c_{1(i)}$ and $c_{2(i)}$ are parameters related to commodity $i$, and therefore

$$
P T C_{i}^{(t)}=c_{1(i)} P_{i}^{\mathrm{c}(t)\left(c_{2(i)-1)} P T P E^{(t)\left(1-c_{2(i)}\right)} / \sum_{j} c_{1(j)} P_{j}^{\mathrm{c}(t)\left(c_{2}(j)\right)} P T P E^{(t)\left(-c_{2}(j)\right)}\right.}
$$

Based on time series of $T C_{i}^{(t)}, p_{i}^{c(t)}$ and $T P E^{(t)}$, the $c_{1}$ and $c_{2}$ parameters were estimated using the least squares method.

$$
\rho_{i}^{(t)}=c_{1(i)}\left(p_{i}^{\mathrm{c}(t)} / P T P E^{(t)}\right)^{c_{2(i)}} / \sum_{j} c_{1(j)}\left(p_{j}^{\mathrm{c}(t)} / P T P E^{(t)}\right)^{c_{2}(j)}
$$

and $\rho_{i}^{(t)}$ expresses the share of commodity $i$ in planned consumer expenditure in period $(t)$.

Finally in the GM-P-2 module the planned consumption fund and total consumption are compared and if

$$
P C F^{(t)}<\sum_{i} p_{i}^{\mathrm{pr}(t)} P T C_{i}^{(t)}+P G P E^{(t)}
$$


the value of planned per capita consumption from the rest of the economy is decreased until

$$
P C F^{(t)}=\sum_{i} p_{i}^{\mathrm{pr}(t)} P T C_{i}^{(t)}+P G P E^{(t)}
$$

\subsection{Government Plan on Food and Agriculture (GM-P-3)}

The most important element of the GM-P block is the third module (GM-P-3), which is actually a linear programming model for fixing central (government) plan targets on food production, exports and imports. These are the basis for the analysis of the performance in a given year.

Commodity balances are given in the GM-P-3 module for each agricultural and processed food commodity considered in the model (listed in Table 2). The foreign trade (exports and imports) and the stock variables are restricted according to the desired level of self-sufficiency and the exogenously given world market constraints (e.g. bilateral agreements). For example the commodity balance for agricultural commodity $i$ is given by

$$
\begin{aligned}
& P P_{i}^{(t)}-\left(\sum_{\underline{i}}^{\sum_{\underline{i}}^{(t)}} P P_{\underline{i}}^{(t)}+\sum_{f} \alpha_{f i}^{(t)} P P_{f}^{(t)}+\alpha_{\mathrm{n} i}^{(t)} P P_{\mathrm{n}}^{(t)}+\sum_{k} \alpha_{k i}^{(t)} R I_{k}^{(t)}+P E_{i}^{(t)}+P S_{i}^{(t)}\right) \\
& +P I_{i}^{(t)}+S_{i}^{(t-1)}=P T C_{i}^{(t)}+P T C G_{i}^{(t)}+P T C S_{i}^{(t)} \\
& c_{i}^{\mathrm{e}(t)^{\prime}} \leqslant P E_{i}^{(t)} \leqslant c_{i}^{\mathrm{e}(t)^{\prime \prime}} \quad d_{i}^{(t)^{\prime}} \leqslant P S_{i}^{(t)} \leqslant d_{i}^{(t)^{\prime \prime}} \quad c_{i}^{\mathrm{i}(t)^{\prime}} \leqslant P I_{i}^{(t)} \leqslant c_{i}^{\mathrm{i}(t)^{\prime \prime}}
\end{aligned}
$$

The planned production of the rest of the economy is calculated as:

$$
P P_{\mathrm{n}}^{(t)}=a P_{\mathrm{n}}^{(t-1)}
$$

In this optimization model only the major physical resources of food production are considered. In the case of resource $k$ in agriculture the constraints are formulated as:

$$
\sum_{i} \alpha_{i k}^{(t)} P P_{i}^{(t)} \leqslant S K A P T_{k}^{(t)}
$$

the resources of the household and private sector are also considered:

$$
\sum_{i} \alpha_{i k}^{(t)} P P_{i}^{(t)} \leqslant S K A P T_{k}^{(t)}+H K A P T_{k}^{(t)}
$$

Production capacities in the household sector are determined based on actual production in the previous period:

$$
H K A P T_{k}^{(t)}=H P_{k}^{(t-1)} / \gamma^{\mathrm{k}}
$$

The land constraints are formulated according to land categories (plowland, plantations, meadows and pastures) as follows:

$$
\sum_{i} \alpha_{i 1}^{(t)} P P_{i}^{(t)} \leqslant L S_{1}^{(t)}+L S_{2}^{(t)}+L S H^{(t)}-H P_{i}^{(t-1)} / A P H_{i}-H P_{i+1}^{(t-1)} / A P H_{i+1}
$$


where commodities $i$ and $i+1$ are the plantations in the household and private sector. The production resources in food processing are modeled according to the major types of processing in the same way as for resources in agriculture:

$$
\sum_{f} \alpha_{f k}^{(t)} P P_{f}^{(t)} \leqslant K A P T_{k}^{(t)}
$$
follows.

The major economic goals fixed by module GM-P-1 appear in the GM-P-3 module as

The required gross national product from food and agriculture is given by

$$
\sum_{i} p_{i}^{\mathrm{pr}(t)} P P_{i}^{(t)}+\sum_{f} p_{f}^{\mathrm{pr}(t)} P P_{f}^{(t)} \geqslant D G N P A^{(t)}
$$

and the required positive balance of payments for food and agriculture by

$$
\sum_{i} p^{\mathrm{w}(t-1)}\left(P E_{i}^{(t)}-P I_{i}^{(t)}\right)+\sum_{f} p_{f}^{\mathrm{w}(t-1)}\left(P E_{f}^{(t)}-P I_{f}^{(t)}\right) \geqslant D B P A^{(t)}
$$

Individual lower and upper limits may also be placed on the production of individual commodities to avoid extreme solutions due to linear programming algorithms. The resource utilization coefficients $\left(\alpha_{i k}^{(t)}, \alpha_{j k}^{(t)}\right)$ are generated from the production block of the previous period in module UD-3. The labor force available is determined based on exogenously given trend coefficients and on the actual labor used in food and agriculture in the previous period.

For module GM-P-3 alternative goal functions can be considered, such as the maximization of the positive balance of payments from food and agriculture, $\max P B P A^{(t)}$. The efficiency of agriucltural foreign trade can also be maximized through the maximization of net foreign exchange returns on domestic production expenditures at domestic currency as follows:

$$
\max \sum_{i}\left(d s p_{i}^{\mathrm{w}(t)}-O K T_{i}^{(t-1)}\right)\left(P E_{i}^{(t)}-P I_{i}^{(t)}\right)
$$

We are aware of the fact that actual agricultural policy objectives are much more complex than the possibilities afforded by an objective function. Several alternative objectives can be considered by changing the objective function.

The Hungarian government operates mainly by indirect economic regulators. The production plan targets generated by module GM-P-3 do not therefore appear directly in the Production block. The government's objectives are transferred mainly through policy variables (prices, subsidies) and a set of assumptions of the production models expressing long-range government requirements towards producers (e.g. cow stock cannot be decreased, or the food processing capacities have to be utilized to the level of available raw materials). Of course, a model may be constructed in which government plan targets appear directly in the Production block.

\subsection{Investment Decisions of the Government: Module GM-P-4}

In Hungary two forms of investments in food and agriculture are differentiated. The development of irrigation systems, infrastructures and some large investments in food 
processing are financed directly by the government. (However, in agriculture most investment decisions are made at the enterprise level.) In the GM-P-4 module, the investment decisions of government are modeled by a heuristic algorithm. The following basic information is used in making these calculations:

- the production facilities in food and agriculture in which the government might invest;

- the planned amount of funds available for direct government investments;

- shadow prices of scarce production facilities are supplied by the GM-P-3 module.

The possible fields of investments are ranked based on shadow prices generated by GM-P-3 LP. The resource with the largest shadow price has priority in the distribution of available funds. For each production facility a so-called investment unit is defined based on economy of scale and previous practice. Firstly one unit of investment is selected for the production facilities, starting with those having the largest shadow prices. After planning one investment unit in the production facility with the lowest positive shadow price, the procedure starts again planning the second investment unit at resource with the highest priority, and so on until all the available funds are utilized.

The algorithm for planning the government's investments is outlined in Fig. 9.

\subsection{Modeling Production: Block P}

The second major block of HAM is devoted to the description of producers' decisions and production itself. The main role of this block is to generate supply in a given unit of time. In contrast to other FAP models, three production sectors of food and agriculture are distinguished in HAM: household and private agriculture, socialist agriculture and food processing.

\subsection{Household and Private Agriculture: Module P-1}

In the formation of the production decision model for the household and private sector, the following main assumptions are made:

- as well as the household plots of cooperative farm members, private types of agricultural production, e.g. private farms and hobby farms, are considered;

- most of the resources for household and private production are given as reminders of former private farming and the extension of production to a given level does not require investment;

- household farming is closely linked with the socialist sector of agriculture in that a given amount of work is required by cooperative farms, most of the basic production operations of household crop production are executed by the machinery of cooperative farms and the socialist agricultural sector supplies feed regularly for animal husbandry in the household and private sector;

- some of the food products from the household and private farms are directly consumed by the owners of these farms. 


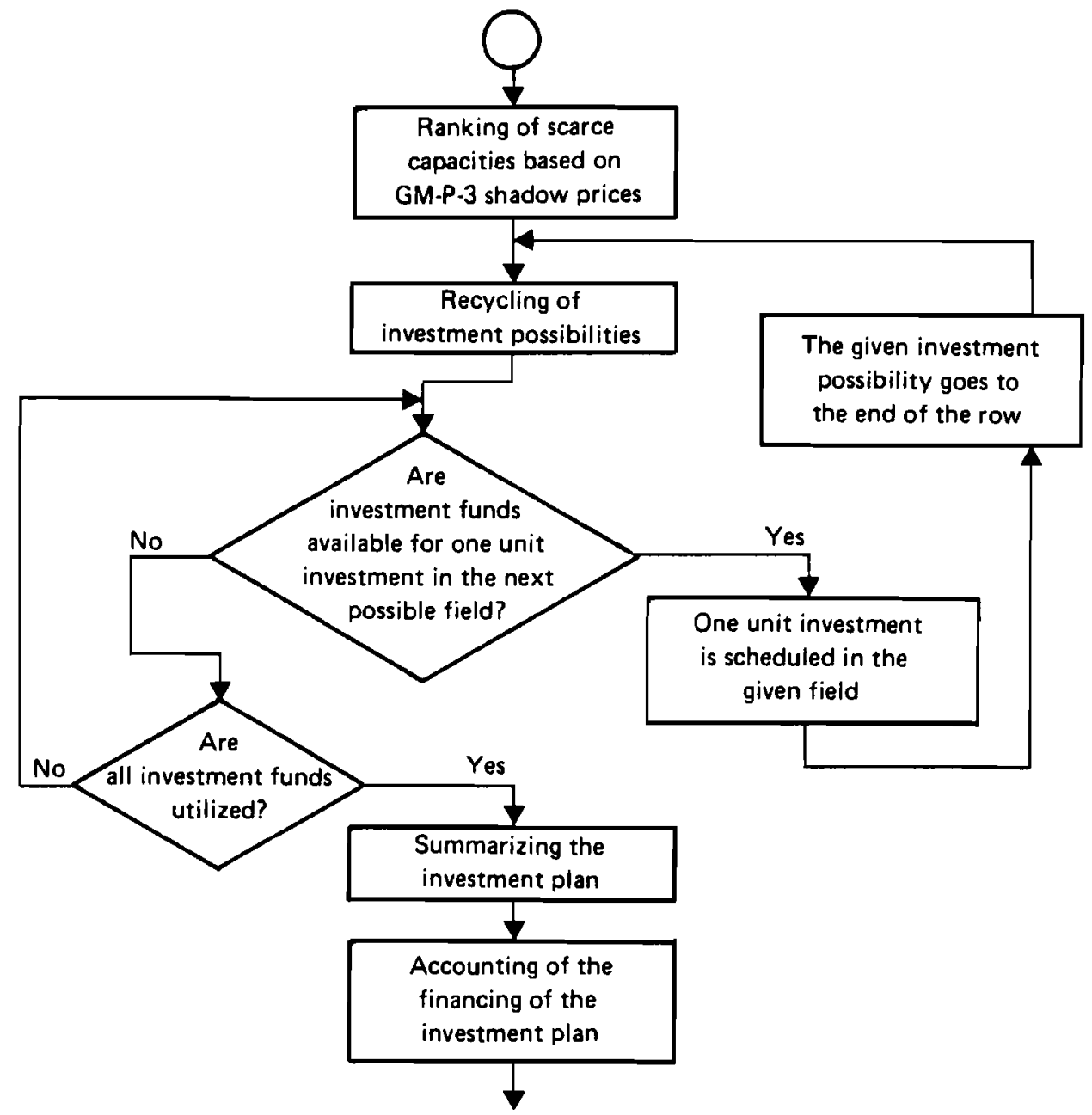

F1GURE 9 Procedure for planning government investments.

The most important part of the P-1 module describes the decisions on the product mix. The expected supplies of crops and animal products are determined by supply functions. To establish the most appropriate methodology for describing the behavior of household and private agriculture, several alternatives were investigated; these were linear programming, nonlinear optimization, trend interpolation and supply functions. The supply functions seemed to fit our objectives and the available data base most appropriately.

The supply of crop products is determined first. We assume that the supply of commodity $i$ is a function of available land, producer prices and yields. The actual shares of various commodities in the total land available are determined using supply functions as follows:

$$
h \rho_{i}^{(t)}=c_{3(i)}\left(1 / p_{i}^{\mathrm{pr}(t)} A P H_{i} L S H^{(t)}\right)^{c_{*}(i)} / \sum_{j} c_{3(j)}\left(1 / p_{j}^{\mathrm{pr}(t)} A P H_{j} L S H^{(t)}\right)^{c_{4}(j)}
$$


The actual supply can be described as:

$$
H P_{i}^{(t)}=h \rho_{i}^{(t)} L S H^{(t)} A P H_{i}^{(t)}
$$

The crop production is not constrained by labor availability. Household and private agriculture is based on work done mostly by cooperative farm members and workers in industry and elsewhere in addition to their main occupations and by women staying at home. The total amount of labor availability for this additional agricultural activity is modeled by a trend function reflecting a trend diminishing in time (see module UD-1). We assume always that the labor force over and above that needed for crop production is used for keeping animals in the household and the private sectors.

The total labor requirement of crop production is given by

$$
T W H V^{(t)}=\sum_{i} H P_{i}^{(t)} W H_{i}^{(t)}
$$

The labor force available for animal husbandry is given by

$$
T W H A^{(t)}=T W H^{(t)}-T W H V^{(t)}
$$

The supply of animal products is influenced by the availability of labor, by producer prices and by the productivity of labor in producing various commodities. In the same way as for crop production, the share of available labor for various commodities of animal husbandry is determined as follows:

$$
h \rho_{i}^{(t)}=c_{3(i)}\left(W H_{i}^{(t)} / p_{i}^{\mathrm{pr}(t)} T W H A^{(t)}\right)^{c_{4}(i)} / \sum_{i} c_{3(j)}\left(W H_{i}^{(t)} / p_{j}^{\mathrm{pr}(t)} T W H A^{(t)}\right)^{c_{4}(j)}
$$

and for the actual supply:

$$
H P_{i}^{(t)}=h \rho_{i}^{(t)} T W H A^{(t)} / W H_{i}^{(t)}
$$

The $c_{3(i)}$ and $c_{4(i)}$ parameters of supply functions can be estimated by using the least-squares method based on time series.

After projecting the production the intermediate input requirements of household and private agriculture are calculated as follows:

$$
H D_{j}^{(t)}=\sum_{i} H P_{i}^{(t)} \mu_{j i}
$$

These requirements are satisfied by the socialist sector of agriculture. In the case of inputs also produced by the household and private sector, the outgoing demand is obviously decreased by the internal supply:

$$
\left(H B F_{i}^{(t)}-H P_{i}^{(t)}\right)>0 \quad H D_{i}^{(t)}=H B F_{i}-H P_{i}^{(t)}
$$

or if production exceeds internal needs:

$$
\left(H B F_{i}^{(t)}-H P_{i}^{(t)}\right) \leqslant 0 \quad H D_{i}^{(t)}=0
$$


Agricultural production in the household and private sector for consumption within the sector is determined based on exogenously given trends:

$$
\operatorname{TCS}_{i}^{(t)}=(1+h c i) \operatorname{TCS}_{i}^{(t-1)}
$$

The total value of farm products used for self consumption is given by

$$
\operatorname{CONS}^{(t)}=\sum_{i} p_{i}^{\mathrm{pr}(t)} \operatorname{TCS}_{i}^{(t)}
$$

Finally the financial consequences of household and private agricultural production are calculated.

The gross production value is given by

$$
H A P^{(t)}=\sum_{i} p_{i}^{\mathrm{pr}(t)} H P_{i}^{(t)}
$$

Expenses related to the use of production facilities of socialist agriculture and expenses of material inputs are also calculated.

\subsection{Production Decisions in Socialist Agriculture: Module P-2}

Obviously the most important part of the production block is the production and investment decision model of the socialist agricultural sector. As far as the methodology is concerned, two options were considered, namely a nonlinear optimization model with production functions for each commodity and a linear programming model with different technologies for each commodity. Because of the lack of data required for the estimation of production functions and certain features of a farm's decision-making on inputs, a linear programming model is constructed to describe the behavior of state and cooperative farms. The possibilities of a more sophisticated mathematical representation of this sector were investigated, but finally the LP approach was kept.

The LP model is structured according to products. The production of most of the commodities is represented by two production variables which express two possible technologies of production, namely a "typical" present-day technology and a more capitalintensive and advanced so-called future technology. Table 5 gives an overview of the model structure. The irrigated production is not considered as a separate production variable. We assume that certain parts (more in the case of advanced technology) of the land used for a specific commodity are irrigated. The inputs and expenses related to irrigation are considered as part of the total inputs and expenses. The technological coefficients of production variables are updated annually from the exogenously given trend of biological development. The speed of the shift from the present "typical" technology to the "future" technology is restricted for each commodity. In the linear programming model, the additional (mainly construction) activities of state and cooperative farms and the general management and overhead activities are treated using separate variables similar to production variables. The LP describing producers' decisions on the structure of production is the central element of module P-2. 
TABLE 5 Structure of linear programming model for socialist agriculture.

\begin{tabular}{|c|c|c|c|c|c|c|}
\hline & $\begin{array}{l}\text { Constraints/ } \\
\text { variables }\end{array}$ & $\begin{array}{l}\text { Plant } \\
\text { production } \\
S P T_{l j}^{\ell}\end{array}$ & $\begin{array}{l}\text { Annimal } \\
\text { husbandry } \\
S P T_{l j}^{\mathrm{t}}\end{array}$ & $\begin{array}{l}\text { Other } \\
\text { activities } \\
S P T_{l}^{\xi}\end{array}$ & Relation & $\begin{array}{l}\text { Right-hand } \\
\text { side }\end{array}$ \\
\hline 1 & Objective function & $p p^{p(t)} \gamma_{i j}^{\mathrm{s}(t)}$ & $p \mathrm{pr}(t)$ & 1 & $\rightarrow$ & $\max$ \\
\hline 2 & Plowland & 1 & & & $\leqslant$ & $L S_{1}^{t}$ \\
\hline 3 & Pastures, meadows & 1 & & & $\leqslant$ & $L S_{2}^{t}$ \\
\hline 4 & $\begin{array}{l}\text { Other resource } \\
\text { constraints }\end{array}$ & $a_{k l j}^{s(t)}$ & $a_{k i j}^{s(t)}$ & $a_{k i}^{s}(t)$ & $\leqslant$ & $\begin{array}{l}S K A P T k \\
S L F^{\mathrm{t}}\end{array}$ \\
\hline 5 & Commodity balances & $\gamma_{i j}^{s(t)}-a_{i t j}^{s(t)}$ & $-a_{i l j}^{s(t)}$ & $-a_{i t}^{s(t)}$ & $\geqslant$ & $H D_{l}^{t}$ \\
\hline
\end{tabular}

In the linear programming model of the socialist agricultural sector, the resource constraints are formulated first. Various land categories can be considered as follows*:

$$
\sum_{i} \sum_{j} a_{i j 1}^{s(t)} S P T_{i j}^{(t)} \leqslant L S_{i}^{(t)}
$$

Other physical resources (buildings, machinery) constraints are given by

$$
\sum_{i} \sum_{j} a_{i j k}^{\mathrm{s}(t)} S P T_{i j}^{(t)} \leqslant S K A P T_{k}^{(t)}-H D_{k}^{(t)}
$$

The use of the labor force is expressed as follows:

$$
\sum_{i} \sum_{j} b_{i j}^{\mathrm{s}(t)} S P T_{i j}^{(t)}=S L F^{(t)}
$$

The outputs of the socialist sector can be determined by commodity balances, assuming that there is no planned inflow of agricultural raw materials into the socialist sector:

$$
\sum_{j} \gamma_{i j}^{s(t)} S P T_{i j}^{(t)}=S P N_{i}^{(t)}
$$

Individual lower and upper bounds are given on the size of the production variables to avoid an extreme solution and to ensure realistic behavior of the model.

$$
\operatorname{PTS}_{i}^{\prime}(t) \leqslant S P N_{i}^{(t)} \leqslant P T S_{i}^{\prime \prime}(t)
$$

These lower and upper bounds are determined based on the analysis of past changes in the production structure of state and cooperative farms.

The introduction of "future" or advanced technologies is also limited. The full substitution of traditional by future technologies is allowed for only in the last third of the 15 . year time period considered. Assuming that $j$ represents a "typical" technology and $j+1$ a so-called "future" technology, these restrictions are formulated as follows:

*In the description of the P-2 LP model, in subscripts $i$ refers to commodity, $j$ to technology and $k$ to production capacity. 


$$
\begin{aligned}
& S P T_{i j}^{(t-1)} \geqslant S P T_{i j}^{(t)} \\
& S P T_{i j+1}^{(t)} \geqslant z_{i}^{(t)}{ }^{\prime \prime}\left(S P T_{i j}^{(t)}+S P T_{i j+1}^{(t)}\right)
\end{aligned}
$$

In the objective function of the model, the gross income (production value minus direct production expenses) of farming is maximized:

$\max \sum_{i} \sum_{j} \operatorname{inc}_{i j}^{(t)} S P T_{i j}^{(t)}$

The inc $c_{i j}^{(t)}$ coefficients are updated in each period before solving the L.P model.

Besides the LP model for determining the structure of production, module P-2 consists of calculations for the following purposes:

- to determine total input needs of production;

- to generate the total disposable income of farming;

- to determine the average unit production costs of various commodities.

The input requirements, i.e. fertilizers, pesticides and other industrial inputs and services and industrially processed protein and other feeds are calculated as

$$
\operatorname{IR} A_{k}^{(t)}=\sum_{i} \sum_{j} a_{i j k}^{(t)} S P T_{i j}^{(t)}
$$

Next the disposable income is calculated as follows.

Gross production value:

$$
S A P^{(t)}=\sum_{i} p_{i}^{\mathrm{pr}(t)} S P N_{i}^{(t)}
$$

Amortization:

$$
D E S^{(t)}=\sum_{k} R S_{k}^{(t)} d r s_{k}
$$

Direct production expenses except industrial inputs and services are calculated as follows. Land tax:

$$
L T S^{(t)}=\sum_{i} \sum_{j} t^{(t)} S P T_{i j}^{(t)}
$$

Inputs of agricultural origin:

$$
\operatorname{MESS}^{(t)}=\sum_{i} \sum_{j} p_{i}^{\mathrm{pr}(t)} a_{i j} S P T_{i j}^{(t)}
$$

Inputs of food processing origin:

$$
\operatorname{MESP}^{(t)}=\sum_{i} \sum_{j} p_{i}^{\left.\mathrm{pr}(t)\right|_{i j} S P T_{i j}^{(t)}}
$$

General management and overhead expenses:

$$
S G M N^{(t)}=\operatorname{enSGMN}(t-1)
$$




$$
\begin{aligned}
& S G M A^{(t)}=e a S G M A^{(t-1)} \\
& S G M M^{(t)}=e m S G M M^{(t-1)} \\
& S G M^{(t)}=S G M N^{(t)}+S G M A^{(t)}+S G M M^{(t)}
\end{aligned}
$$

Expenses on industrial inputs and services:

$$
M E S I^{(t)}=\sum_{k} p_{k}^{\mathrm{pr}(t)} I R A_{k}^{(t)}+S G M N^{(t)}+H M I^{(t)}
$$

Labor expenses and taxes on wages:

$$
\begin{aligned}
& A D M S^{(t)}=(1+e d) A D M S^{(t-1)} \\
& S L F^{(t)}=S L F^{(t)}+A D M S^{(t)}+H W E S^{(t)} / w^{\mathrm{s}(t)} \\
& W E S^{(t)}=S L F^{(t)} w^{\mathrm{s}(t)} \\
& L E S^{(t)}=\left(1+t^{\mathrm{wa}(t)}\right) W E S^{(t)}
\end{aligned}
$$

Total production expenses:

$$
T E S^{(t)}=M E S S^{(t)}+M E S P^{(t)}+M E S I^{(t)}+L E S^{(t)}+D E S^{(t)}+L T S^{(t)}
$$

Disposable net income of socialist agriculture:

$$
I N C S^{(t)}=S A P^{(t)}-T E S^{(t)}+I K T O^{(t)}
$$

Most of the commodities are represented by two technological variables in this module. In order to be able to compare production expenses with producer prices the average unit production costs of commodities are also calculated as follows (in the description of the procedure, $i$ refers to commodity, $k$ to production capacity and $j$ to technology).

$$
\begin{gathered}
B A R M I_{i}^{(t)}=\sum_{k} S P T_{i k}^{(t)}\left(M E S S_{i k}^{(t)}+M E S P_{i k}^{(t)}+M E S I_{i k}^{(t)}+L T S_{i k}^{(t)}+L E S_{i k}^{(t)}\right) \\
O K T_{i}^{(t)}=\left(B A R M I_{i}^{(t)} / S P N_{i}^{(t)}\right)+\left(p_{i}^{\mathrm{pr}(t)} S G M^{(t)} / S A P^{(t)}\right)
\end{gathered}
$$

Special rules might be needed to calculate the unit costs of some of the products (e.g. beef, lamb, poultry meat) as follows:

$$
X T_{e}^{(t)}=B A R M I_{e}^{(t)}+\left(p_{e}^{\mathrm{pr}(t)} S P N_{e}^{(t)}+p_{e+1}^{\mathrm{pr}(t)} S P N_{e+1}^{(t)} / S A P^{(t)}\right) S G M^{(t)}
$$




$$
O K T_{e}^{(t)}=X T_{e}^{(t)} / S P N_{e}^{(t)}
$$

\subsection{Calculation of Final Outputs of Agriculture: Module P-3}

The agricultural commodities available are calculated from the producers' decision models (P-1, P-2) with consideration of the random effects of weather conditions on yields of annual and perennial crops. Our main assumptions in introducing weather uncertainties into HAM are as follows:

- no random effects are considered on the yields of nonmarketable feeds (e.g.green feeds, scraps), pastures and meadows;

- only the outputs are modified by random effects, therefore the inputs are unaffected;

- the methodology used for projecting the effects of weather on agriculture is similar to that applied in other national agricultural policy models at IIASA and will be specified later;

- for commodities that can be either directly consumed, exported or processed, after the calculation of agricultural output the quantity available for processing is also determined here.

The weather effects on yields and the final output of agriculture are calculated in the P-3 module.

The random effects of weather on the yields of commodity $i$ are given by

$$
\begin{aligned}
& \gamma_{i}^{\mathrm{h}(t)^{*}}=\gamma_{i}^{\mathrm{h}(t)} \theta_{i}^{\mathrm{h}(t)} \\
& \gamma_{i j}^{\mathrm{s}(t)^{*}}=\gamma_{i j}^{\mathrm{s}(t)} \theta_{i j}^{\mathrm{s}(t)}
\end{aligned}
$$

where $\gamma_{i}^{\mathrm{h}(t)^{*}}$ and $\gamma_{i j}^{\mathrm{s}(t)^{*}}$ are the actual yields in period $(t)$ and $\theta_{i}^{\mathrm{h}(t)}$ and $\theta_{i j}^{\mathrm{s}(t)^{*}}$ express the effects of weather on yield.

Based on $\gamma_{i}^{\mathrm{h}(t)^{*}}$ and $\gamma_{i j}^{\mathrm{s}(t)^{*}}$, the final outputs of agriculture $\left(S P N_{i}^{(t)}, B P A_{i}^{(t)}\right.$ and $H P^{(t)}$ ) can be calculated.

\subsection{Food Processing: Module P4}

In the fourth module of the Production block the production of food processing is scheduled. In the first version of HAM a linear programming model was used for this purpose. We finally decided to substitute the LP model with a simulation algorithm. Because the structure of food processing is almost completely determined by available resources and raw materials, little space being left for optimization, the use of a simulation procedure seemed to be more appropriate. The basic principles of these algorithms are as follows:

- production facilities are considered according to major branches of the Hungarian food processing industry and are given mostly according to processed commodities in our commodity list;

- alternative usages of production facilities are not considered. 
The production costs, income and income utilization of food processing are also calculated in relation to a given production program of food processing.

\subsection{The Rest of the Economy: Module P-5}

The nonfood production part of the economy is modeled in an aggregated way. In HAM the so-called $n$th commodity represents the rest of the economy including industrial production and all types of services. The scale of the $n$th sector is determined by the available labor and assets as follows:

$$
p_{n}^{(t)}=\alpha_{6}\left(N L F^{(t)}\right)^{\alpha_{7}}\left(R N^{(t)}\right)^{\alpha_{\mathrm{s}}}
$$

The available labor force is calculated as the rest of the total working population:

$$
\begin{aligned}
& L A F^{(t)}=S L F^{(t)}+P L F^{(t)} \\
& N L F^{(t)}=w p^{(t)}-L A F^{(t)}
\end{aligned}
$$

In connection with the scale of activities in the rest of the economy, the related production expenses are also calculated:

$$
\begin{aligned}
& W E N^{(t)}=w^{\mathrm{n}(t)} N L F^{(t)} \\
& L E N^{(t)}=\left(1+t^{\mathrm{wa}}\right) W E N^{(t)} \\
& D E N^{(t)}=d r n R N^{(t)} \\
& M E N^{(t)}=p_{n}^{\mathrm{pr}(t)} \alpha_{n n}^{\mathrm{n}(t)} p_{n}^{\mathrm{n}(t)}
\end{aligned}
$$

\subsection{Investment Decisions of Producing Enterprises: Module P-6}

The investment programs of agricultural and food-processing firms are determined here. Similar principles are applied in the case of government investments, but the replacement of equipment which has deteriorated is also considered. The simulation algorithm of module P-6 includes the following procedures.

1. First the replacement of aged production facilities is carried out. Replacement is scheduled if the utilization of the given resource exceeds the desired level and if funds for replacements are available. 
In agriculture: if $S K A P I G_{k} / S K A P T^{(t)}>$ ups and the value of the depreciated equipment is equal to $d d s_{k} R S_{k}^{(t)}$, then

$$
P O T_{k}^{(t)}=d d s_{k} R S_{k}^{(t)}
$$

Investment is scheduled if INS ${ }^{(t)} \geqslant P O T_{k}^{(t)}$. Obviously, available funds are adjusted after scheduling each type of replacement:

$$
I N S^{(t)}=I N S^{(t)}-P O T_{k}^{(t)}
$$

(The outline of the procedure can be seen in Fig. 9.)

In food processing: if $K A P I G_{k}^{(t)} / K A P T_{k}^{(t)}>u p p$ and the value of the depreciated equipment is equal to $d d p_{k}>R F_{k}^{(t)}$, then

$$
\operatorname{POT}_{k}^{(t)}=d d p_{k} R F_{k}^{(t)}
$$

Investment is scheduled if $I N P^{(t)} \geqslant P O T_{(k)}^{(t)}$. Available funds are updated in a similar way as for agriculture as follows:

$$
I N P^{(t)}=I N P^{(t)}-P O T_{(k)}^{(t)}
$$

2. The new investments in agriculture are scheduled on the basis of shadow prices generated by the producers' decision LP model in module P-2. Therefore, only those resources fully utilized are considered as candidates for new investments. The resources with greater shadow prices have priority when the investment funds are distributed. In a similar way as for government investment, for each investment option the scale of the investment is fixed as a preliminary measure and at first only one unit is scheduled. The allocation of investment funds continues in this way, one additional investment unit being scheduled each time until all the available funds are utilized. (An overview of the calculations is given in Fig.9.)

3. The new investments in food processing are scheduled on the basis of the rate of resource utilization. New investments might be planned if

$$
K A P I G_{k}^{(t)} / K A P T_{k}^{(t)} \geqslant u i p
$$

then:

$$
\operatorname{SPRI}_{(k)}^{(t)}=K A P I G_{k}^{(t)} / K A P T_{k}^{(t)}
$$

The resource with the larger $S P R I_{(k)}^{(t)}$ coefficient has priority. In a similar way as for agricultural investments, the investments in food processing are planned by investment units starting from the resource with the highest priority, scheduling one unit each time until all the available funds are utilized.

As far as financial funds are concerned, the firm's investments are based on the enterprise's own resources and government subsidies. Because of fixed domestic producer prices, it is possible to calculate the enterprise's own investment funds before solving CT block. 
The amount of government subsidies generated in the GM-P block is subject to further adjustment in the CT block as a means by which to reach balance of trade equilibrium. Investments planned according to target values for government subsidies should therefore also be further modified. To avoid this additional step, module P-6 has actually been solved as a part of block CT in HAM-2 when the final amounts of government subsidies are available and the final investment program can be calculated immediately.

\subsection{Consumption and Trade Block: Block CT}

The Consuinption and Trade Block plays a very important role in the operation of the whole system. The private and government consumption as well as the country's reactions to changing world market conditions are modeled by three modules.

\subsection{Committed Demand: Module CT-1}

The first step in module CT-1 is, on the basis of former model elements, to calculate the so-called committed expenditures which cannot be further modified during the simulation of one specific year. A simple calculation is required to determine:

- the gross production value, income and income untilization of the producing sectors (socialist agriculture, food processing, rest of the economy) including the total intermediate demands of production;

-.. the earnings and committed expenditure, including household farming, of the population;

- the governments's income from the population and producing firms and the committed expenditure of the government.

The major elements of committed demands may be broken down as follows:

Income and income utilization of socialist agriculture

$$
I N C S^{(t)}=S A P^{(t)}-\left(L E S^{(t)}+\operatorname{MES} S^{(t)}+D E S^{(t)}+L T S^{(t)}\right)+I K T O^{(t)}
$$

If $\operatorname{LNCS}{ }^{(t)}<0$ then

$$
\begin{aligned}
& D E F^{(t)}=-I N C S^{(t)} \\
& I N C S^{(t)}=0
\end{aligned}
$$

Taxes paid by socialist agriculture:

$$
T X S^{(t)}=t^{\text {in }, \mathrm{s}(t)} I N C S^{(t)}+t^{\text {wa }} W E S^{(t)}+L T S^{(t)}
$$

Bonus paid by socialist agriculture to employee:

$$
B S^{(t)}=\nu^{s} I N C S^{(t)}
$$


Investment funds of socialist agriculture:

$$
I F E S^{(t)}=\left(1-\left(t^{\mathrm{in}, \mathrm{s}(t)}+v^{s}\right)\right) I N C S^{(t)}+\left(1-d c^{\mathrm{s}(t)}\right) D E S^{(t)}+\operatorname{IFES^{(t-1)}}
$$

Income and income utilization of food processing industry

$$
I N C P^{(t)}=P A P^{(t)}-\left(L E P^{(t)}+M E P^{(t)}+D E P^{(t)}\right)
$$

If $I N C P^{(t)}<0$ then

$$
\begin{aligned}
& D E P^{(t)}=D E F^{(t)}-I N C P^{(t)} \\
& I N C P^{(t)}=0
\end{aligned}
$$

Taxes paid by food processing firms:

$$
T X P^{(t)}=t^{\text {in }, \mathrm{p}(t)}+t^{\mathrm{wa}} W E P^{(t)}
$$

Bonus paid by food processing firms to employee:

$$
B P^{(t)}=v^{\mathrm{p}} I N C P^{(t)}
$$

Investment fund of food processing firms:

$$
\operatorname{IFEP} P^{(t)}=\left(1-\left(t^{\mathrm{in}, \mathrm{p}(t)}+v^{\mathrm{p}}\right)\right) I N C P^{(t)}+\left(1-d c^{\mathrm{p}(t)}\right) D E P^{(t)}+I F E P^{(t-1)}
$$

Income and income utilization of the rest of the economy

$$
I N C N^{(t)}=p_{n}^{\mathrm{pr}(t)} p_{n}^{\mathrm{n}(t)}-\left(M E N^{(t)}+L E N^{(t)}+D E N^{(t)}\right)
$$

If $\operatorname{LNCN}(t)<0$ then

$$
\begin{aligned}
& D E P^{(t)}=D E F^{(t)}-I N C N^{(t)} \\
& I N C N^{(t)}=0
\end{aligned}
$$

Taxes paid by the rest of the economy:

$$
T X N^{(t)}=t^{\mathrm{in}, \mathrm{n}(t)} I N C N^{(t)}+t^{\mathrm{wa}} W E N^{(t)}
$$

Bonus paid by the rest of the economy to employee:

$$
B N^{(t)}=v^{\mathrm{n}} I N C N^{(t)}
$$

Investment fund:

$$
\operatorname{IFEAN}(t)=\left(1-\left(t^{\mathrm{in}, \mathrm{n}(t)}+v^{\mathrm{n}}\right)\right) I N C N^{(t)}+\left(1-d c^{\mathrm{n}(t)}\right) D E N^{(t)}+I F E A N^{(t-1)}
$$


Income and income utilization of population

$$
\begin{aligned}
& I N C P O^{(t)}=W E S^{(t)}+W E P^{(t)}+W E N^{(t)}+B S^{(t)}+B P^{(t)}+B N^{(t)} \\
& T X P O^{(t)}=t^{\mathrm{in}, \mathrm{po}} I N C P O^{(t)}+t^{\mathrm{in}, \mathrm{h}} I N H^{(t)}
\end{aligned}
$$

Endowment of private consumers available for buying goods:

$$
\begin{aligned}
& T P E^{(t)}=I N C P O^{(t)}-T X P O^{(t)}-A S P^{(t)}+\left(1-t^{\mathrm{in}, \mathrm{h}}\right) I N H^{(t)}+G S P^{(t)} \\
& C P E^{(t)}=\left(1 / \mathrm{t}_{\mathrm{p}}^{(t)}\right) T P E^{(t)}
\end{aligned}
$$

Savings function of population:

$$
A S P^{(t)}=\operatorname{aspi} I N C P O^{(t)}
$$

Population social benefits (e.g. pension) from government:

$$
G S P^{(t)}=e s^{g} G S P^{(t-1)}
$$

Government's income from taxes and centralized amortization funds

$$
\begin{aligned}
& G T^{(t)}=T X S^{(t)}+T X P^{(t)}+T X N^{(t)}+T X P O^{(t)}+T X H^{(t)} \\
& G D^{(t)}=d c^{\mathrm{s}(t)} D E S^{(t)}+d c^{\mathrm{p}(t)} D E P^{(t)}+d c^{\mathrm{n}(t)} D E N^{(t)}
\end{aligned}
$$

Finally, the gross and net national product for a given year can be calculated as follows:

$$
\begin{aligned}
& G N P A^{(t)}=S A P^{(t)}+P A P^{(t)}+H A P^{(t)} \\
& G N P^{(t)}=G N P A^{(t)}+p_{n}^{\mathrm{pr}(t)} p_{n}^{(t)} \\
& D E S P N^{(t)}=D E S^{(t)}+D E P^{(t)}+D E N^{(t)} \\
& A G F^{(t)}=M E S^{(t)}+M E P^{(t)}+M E N^{(t)}+M E H^{(t)}-I K T O^{(t)} \\
& N N P^{(t)}=G N P^{(t)}-A G F^{(t)}-D E S P N^{(t)}
\end{aligned}
$$

Growth rate of net national product:

$$
e f^{(t)}=N N P^{(t)} / N N P^{(t-1)}
$$

\subsection{Modeling of Consumers' Demands: Module CT-2}

Module CT-2 is an important part of this model block and the complete model as well, describing private consumption. The role of module CT-2 is to determine the per 
capita consumer demands assuming that the endowment of consumers after deduction of savings is spent on various commodities.

The consumer demand for a specific commodity is influenced by the prices and the level of endowment. In HAM the demand for commodity $i$ is described as follows:

$$
\begin{aligned}
& C P_{i}^{(t)}=\rho_{i}^{(t)} C P E^{(t)} / p_{i}^{\mathrm{c}(t)} \\
& \rho_{i}^{(t)}>0 \quad \text { and } \quad \sum_{i} \rho_{i}^{(t)}=1
\end{aligned}
$$

where $C P_{i}^{(t)}$ is the per capita demand for commodity $i$ in period $(t), C P E^{(t)}$ is the per capita endowment of consumers in period $(t)$ and $p_{i}^{\mathrm{c}(t)}$ is the consumer price of commodity $i$ in period $(t)$. The $\rho_{i}^{(t)}$ parameters are determined in the model for each simulated year by using C.E.V. Leser's nonlinear demand model. The demand system used here is the same as those in module GM-P-2. Here, instead of plan targets on consumers' incomes, the final endowment of the population is considered.

\subsection{Exchange Module: Module CT-3}

Module CT-3 is a crucial part of the whole model, where the final level of private and government consumption as well as stocks satisfying balance of trade equilibrium conditions are determined. It is very important to underline that the reaction mechanism of domestic demands to new world market conditions (prices) is described here.

After some unsuccessful at tempts with linear programming based on Michiel Kayzer's suggestion, a relatively simple method was developed to solve module CT-3.

In this module the so-called noncommitted demands, which can be the subjects of further adjustment, are determined. The noncommitted demand for a specific commodity consists of various elements; therefore, let $q_{i h}$ express the $h$ th type of demand for commodity $i$. To reach a solution first we define a target level of the $h$ th demand for commodity $i\left(q_{i h}^{(t)}\right)$ and introduce a vector $\lambda$ which indicates the extent to which the targets are realized. Obviously the realization levels are constrained between two bounds:

$$
\lambda^{*} \leqslant \lambda \leqslant \lambda^{* *}
$$

Let us assume that $y$ is the vector of supply after the deduction of committed expenditures, $p_{i}^{\mathrm{w}(t)}$ is the world market price of commodity $i$, and $k$ is the preliminary fixed balance of foreign trade.

The solution of module CT-3 is equal to the determination of the values of vector $\lambda$ which satisfy

$$
p^{\mathrm{w}} \mathrm{Q} \lambda=p^{\mathrm{w}} y+k
$$

with

$$
\lambda^{*} \leqslant \lambda \leqslant \lambda^{* *}
$$

and where $Q$ is a matrix of noncommitted demands. 
During the solution procedure a strict preference ordering of various types of demands is followed. In the event of changes in the world market prices a new $\lambda$ vector has to be calculated. If no solution can be obtained, the $\lambda^{*}$ and $\lambda^{* *}$ vectors have to be adjusted so that a solution can be reached. The calculation of vector $\lambda$ is easily programmed. It is worthwhile to consider unity as an initial value of $\lambda_{i}$. It is obvious that in the event that the target is realized, $\lambda_{i}=1$, and always $\lambda_{i}^{*}<1$ and $\lambda_{i}^{* *}>1$.

The target values of noncommitted demands are determined as follows.

- As far as stocks are considered, so-called optimal stocks are taken as target values. These optimal stocks are fixed exogenously.

- As the target value of direct government investments in food and agriculture the value of PDGINA ${ }^{(t)}$ (planned direct government investments in food and agriculture), as determined in module GM.P-1, is used. The target value of $\operatorname{GINN}^{(t)}$ is calculated based on the value of $P A F N^{(t)}$ (planned capital accumulation of the rest of the economy) determined in module GM-P-1 and $I F E A N^{(t)}$ (firm's investment fund in the rest of the economy).

- Targets on government subsidies to investments in agriculture and in food processing (PGINSA ${ }^{(t)}$, PGINSP( $\left.{ }^{(t)}\right)$ are determined in the GM-P-4 module as a part of determining government's investment.

- The targets on consumption $P T C^{(t)}$ are fixed in the GM-P-2 module based on commodity-specific trends.

- As targets on private consumption, the values of $T C_{i}^{(t)}$ related to consumer price for the given year and endowments calculated in module CT-1 determined by the nonlinear demand system are used.

$\lambda^{*}$ and $\lambda^{* *}$ express the extent of allowed deviation from target levels. For the various elements of $\mathbf{Q}$ different $\lambda^{*}$ and $\lambda^{* *}$ values are given, expressing the government objectives and policies in demand adjustment. Vector $\lambda$ is determined using the algorithm mentioned above and the final values of variables included in matrix $\mathbf{Q}$ can be calculated. On the basis of the elements of the $\mathbf{Q}$ matrix the export-import vector is calculated:

$$
\begin{aligned}
& E I_{i}^{(t)}=\sum_{i} q^{i j(t)}-y_{i}^{(t)} \\
& \text { If } E I_{i}^{(t)} \leqslant 0 \text { then } I_{i}^{(t)}=-E I_{i}^{(t)} \text { and } E_{i}^{(t)}=0 \\
& \text { If } E I_{i}^{(t)} \geqslant 0 \text { then } E_{i}^{(t)}=E I_{i}^{(t)} \text { and } I_{i}^{(t)}=0 \\
& \text { If } E I_{i}^{(t)}=0 \text { then } E_{i}^{(t)}=0 \text { and } I_{i}^{(t)}=0
\end{aligned}
$$

The final values of government investment subsidies PGINSA ${ }^{(t)}$ and $P G I N S P^{(t)}$ are also calculated. Based on the latter information the investment program of the given year is finalized. In fact, as has already been mentioned, module P-6 is solved only at this point in full and final knowledge of the investment funds available. 


\subsection{Financial Account of a Given Year: Module CT 4}

As the state satisfying the balance of payments equilibrium condition has been reached in module CT -3 , in module CT 4 the government budget and domestic financial consequences of the given product utilization structure are calculated.

Exports, imports and consumer prices are calculated as follows:

$$
\begin{aligned}
& \operatorname{TREP}(t)=\sum_{i}\left(d s p_{i}^{(t)}-p_{i}^{\mathrm{pr}(t)}\right) E_{i}^{(t)} \\
& \operatorname{TRIP^{(t)}}=\sum_{i}\left(p_{i}^{\mathrm{pr}(t)}-d s p_{i}^{\mathrm{w}(t)}\right) I_{i}^{(t)} \\
& \operatorname{TRCP^{(t)}}=\sum_{i}\left(p_{i}^{\mathrm{c}(t)}-p_{i}^{\mathrm{pr}(t)}\right) T C_{i}^{(t)} \\
& \text { If } T R E P^{(t)}<0 \text { then } G E S^{(t)}=-T R E P^{(t)} \text { and } T R E P^{(t)}=0 \text { and } G E S^{(t)}=0 \\
& \text { If } T R I P^{(t)} \leqslant 0 \text { then } G I S^{(t)}=-T R I P^{(t)} \text { and } T R E P^{(t)}=0 \\
& \text { If } T R C P^{(t)}<0 \text { then } G C S^{(t)}=-T R C P^{(t)} \text { and } T R C P^{(t)}=0
\end{aligned}
$$

The total tariff receipts of government:

$$
G T R P^{(t)}=T R E P^{(t)}+T R I P^{(t)}+T R C P^{(t)}
$$

The total amount of price subsidies of government:

$$
G \boldsymbol{P}^{(t)}=G E S^{(t)}+G I S^{(t)}+G C S^{(t)}
$$

Financial consequences of changes in stocks:

$$
\begin{aligned}
& S D S^{(t)}=\sum_{i} p_{i}^{\mathrm{pr}(t)}\left(S_{i}^{(t)}-S_{i}^{(t-1)}\right) \\
& S D P^{(t)}=\sum_{f} p_{f}^{\mathrm{pr}(t)}\left(S_{f}^{(t)}-S_{f}^{(t-1)}\right) \\
& S D N^{(t)}=p_{n}^{\mathrm{pr}(t)}\left(S_{n}^{(t)}-S_{n}^{(t-1)}\right)
\end{aligned}
$$

Total amount of investments in a given year:

$T I N^{(t)}=S D S^{(t)}+S D P^{(t)}+S D N^{(t)}+T I N S^{(t)}+T I N P^{(t)}+P D G I N A^{(t)}+P A F N^{(t)}$

Income of government:

$$
G I^{(t)}=G T^{(t)}+G D^{(t)}+G T R P^{(t)}
$$

Expenditures of government:

$$
G E^{(t)}=G P E^{(t)}+G S P^{(t)}+G P^{(t)}+G I N A^{(t)}+G I N N^{(t)}+D E F^{(t)}
$$


Balance of government budget:

$$
G I S X^{(t)}=G I^{(t)}-G E^{(t)}
$$

Balance of payments related to food and agriculture:

$$
P B A^{(t)}=\sum_{i} p_{i}^{\mathrm{w}(t)} E I_{i}^{(t)}
$$

\subsection{Analysis of Results and Revision of Policy Instruments: Block GM-A}

After the final results are obtained for a given year based on an analysis of the performance of the whole system, some of the basic policy variables and instruments in the model are revised in block GM-A (Economic Analysis of Government). By this stage of the model, at tempts have been made to describe one of the most complex elements of centrally planned food and agriculture systems. This is one of the first approaches ever developed for modeling the sphere of agricultural policy in a centrally planned economy. Based on interviews with high-level officials and on analysis of present-day practice, the basic policy structure and principles used in revising overall objectives and policy instruments have been outlined. These structures and principles are taken as given in the model and only their implementation is really modeled. Changes in structure or in principles can be dealt with only by modifying the structure of the model.

\subsection{Revision of Policy Variables Influencing the Whole System: Module GM-A-1}

First the overall performance of the system is analyzed in order to revise instruments controlling the growth of the whole economy as well as that of its main branches. We assume that the major government objectives to reach a desired economic growth rate are basically realized by changing the rate of investment of national income and the shares of the major sectors in total investments.

We assume that the desired path of growth (lower and upper bounds within which the actual growth is considered to be satisfactory) is given exogenously. The procedure described in module GM-A-1 starts with the calculation of the actual growth rates for the given period as follows.

Growth of food and agriculture:

$$
b f_{1}^{(t)}=\left\{\left(\sum_{i} p_{i}^{\mathrm{pr}(t-1)} S P N_{i}^{(t)}+\sum_{i} p_{i}^{\mathrm{pr}(t-1)} F P N_{i}^{(t)}+\sum_{i} p_{i}^{\mathrm{pr}(t-1)} H P_{i}^{(t)}\right) / G N P A^{(t-1)}\right\}-1
$$

Growth of the rest of the economy:

$$
b f_{2}^{(t)}=\left(p_{\mathrm{n}}^{\mathrm{pr}(t-1)} p_{\mathrm{n}}^{(t)} / p_{\mathrm{n}}^{\mathrm{pr}(t-1)} p_{\mathrm{n}}^{(t-1)}\right)-1
$$

Share of food and agriculture in total output:

$$
r_{1}^{(t-1)}=G N P A^{(t-1)} / G N P^{(t-1)}
$$




$$
r_{2}^{(t-1)}=1-r_{1}^{(t-1)}
$$

Growth of the whole economy:

$$
a f^{(t)}=r_{1}^{(t-1)} b f_{1}^{(t)}+r_{2}^{(t-1)} b f_{2}^{(t)}
$$

The revision of instruments influencing overall growth depends on the relation of actual to desired growth. We have to distinguish between situtation in which the overall growth is within the desired boundaries and those in which actual growth is less or greater than desired. If the overall growth remains within the previously fixed lower and upper bounds, the growth of the economy is considered satisfactory and instruments are not revised. Otherwise adjustment takes place, the actual development of food and agriculture and the rest of the economy being considered in addition to their relation. As a whole, the GM-A-1 module consists of six basic cases of adjustments (Fig. 10 gives an overview of these cases).

\section{Case 1}

In case 1 overall growth is higher than desired and the development of the rest of the economy is also faster than desired. In this case, our objective is to decrease the growth of the rest of the economy, maintaining or increasing the rate of development in food and agriculture.

If actual investments exceed plan targets, the income tax rates $\left(t^{\mathrm{m}, \mathrm{n}(t)}\right)$ and the centralized part of the depreciation $\left(d c^{n(t)}\right)$ are increased. If development in agriculture is slower than desired the share of food and agriculture in total investments $\left(g^{(t)}\right)$ is also increased.

If actual investments meet targets or remain below the target level, the share of consumption in national income $\left(f^{(t)}\right)$ is increased. In the case of unsatisfactory growth of food and agriculture, investments in this sector $\left(g^{(t)}\right)$ are also increased.

\section{Case 2}

In case 2 overall growth is higher than desired and similarly for food and agriculture. Meanwhile the rate of development in the rest of the economy is satisfactory or less than desired. As for case 1, the overall growth of the economy has to be decreased, maintaining or increasing the rate of growth in the rest of the economy.

If actual investments in food and agriculture exceed plan targets, related income tax rates $\left(t^{\mathrm{in}, \mathrm{s}(t)}\right.$ and $\left.t^{\mathrm{in}, \mathrm{p}(t)}\right)$ and the rates of centralized depreciation $\left(d c^{\mathrm{s}(t)}\right.$ and $\left.d c^{\mathrm{p}(t)}\right)$ are increased. In the case of unsatisfactory development of the rest of the economy, investment in food and agriculture $\left(g^{(t)}\right)$ is decreased.

If actual investments meet targets or are below the target level, the share of consumption in national income $\left(f^{(t)}\right)$ is increased. In the case of unsatisfactory growth of the rest of the economy, the share of food and agriculture in total investments $\left(g^{(t)}\right)$ is decreased.

\section{Case 3}

In case 3 overail growth is higher than desired and both food and agriculture and the rest of the economy develop faster than desired. Growth in both major sectors therefore has to be limited. 
If actual investments exceed targets in both major sectors, income tax rates $\left(t^{\mathrm{in}, \mathrm{s}(t)}\right.$, $\left.t^{\mathrm{in}, \mathrm{p}(t)} t^{\mathrm{in}, \mathrm{n}(t)}\right)$ and centralized parts of depreciation $\left(d c^{\mathrm{s}(t)}, d c^{\mathrm{p}(t)}, d c^{\mathrm{n}(t)}\right)$ are increased.

If actual investments are below the target level the share of consumption $\left(f^{(t)}\right)$ in national income is increased.

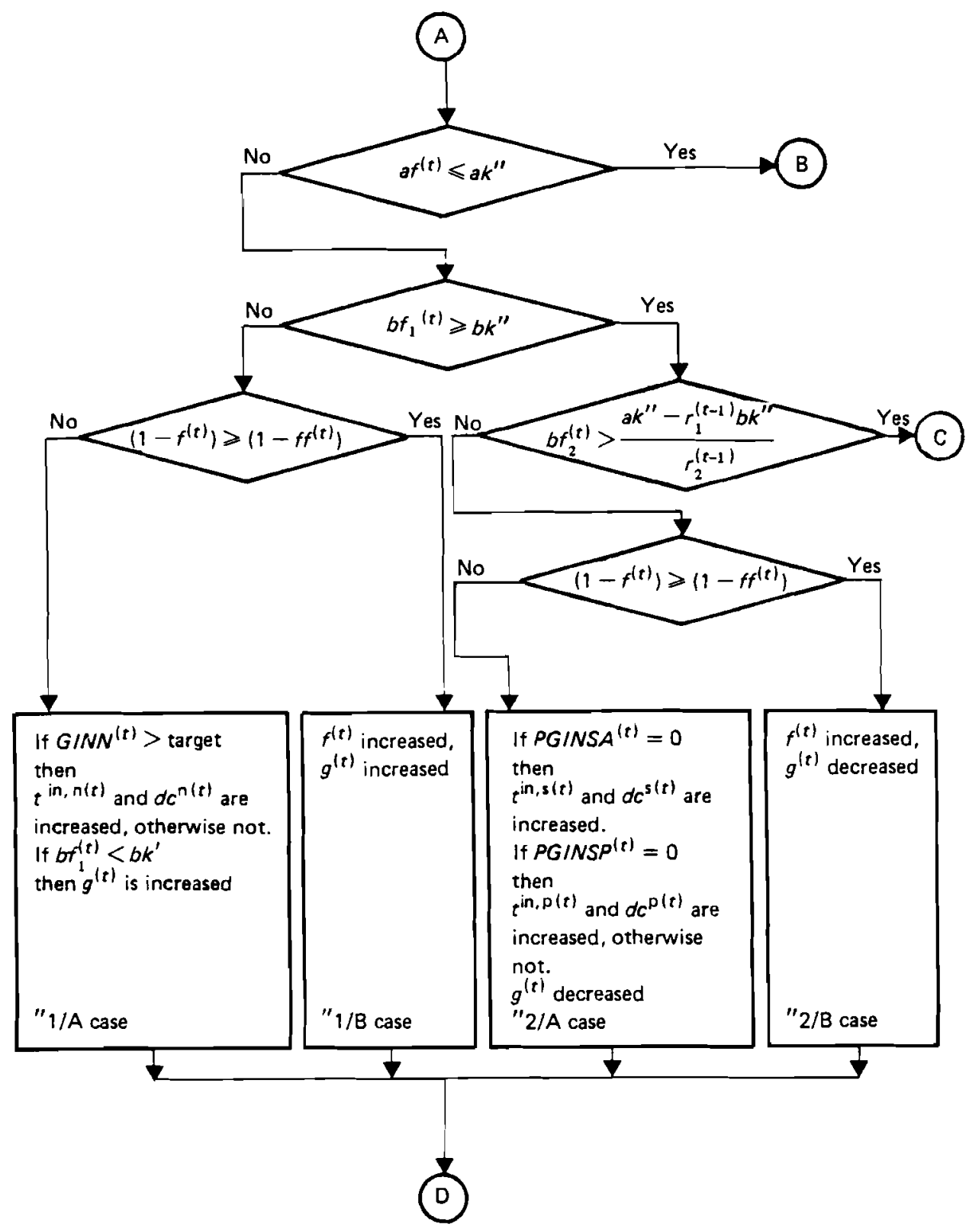



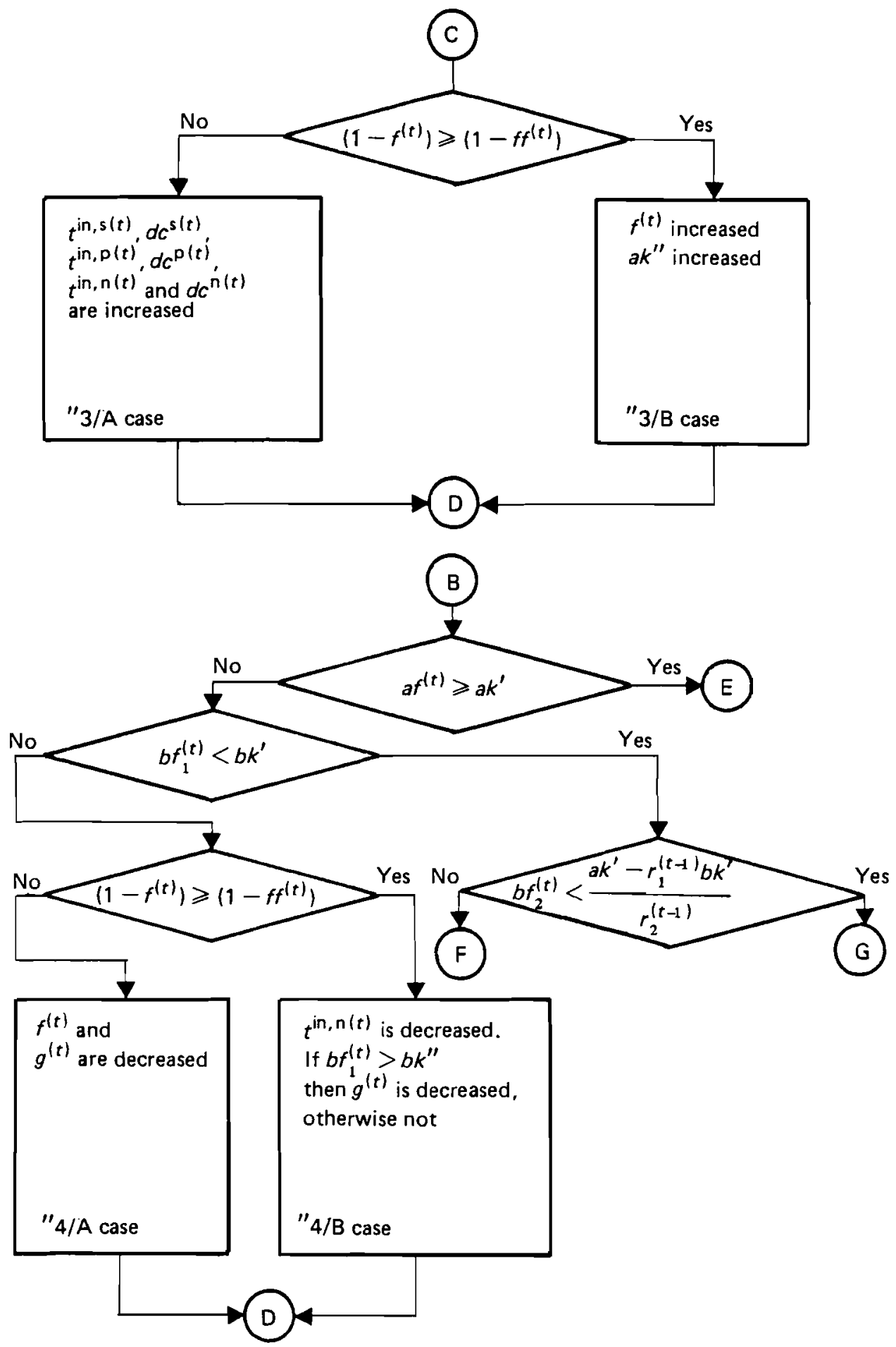


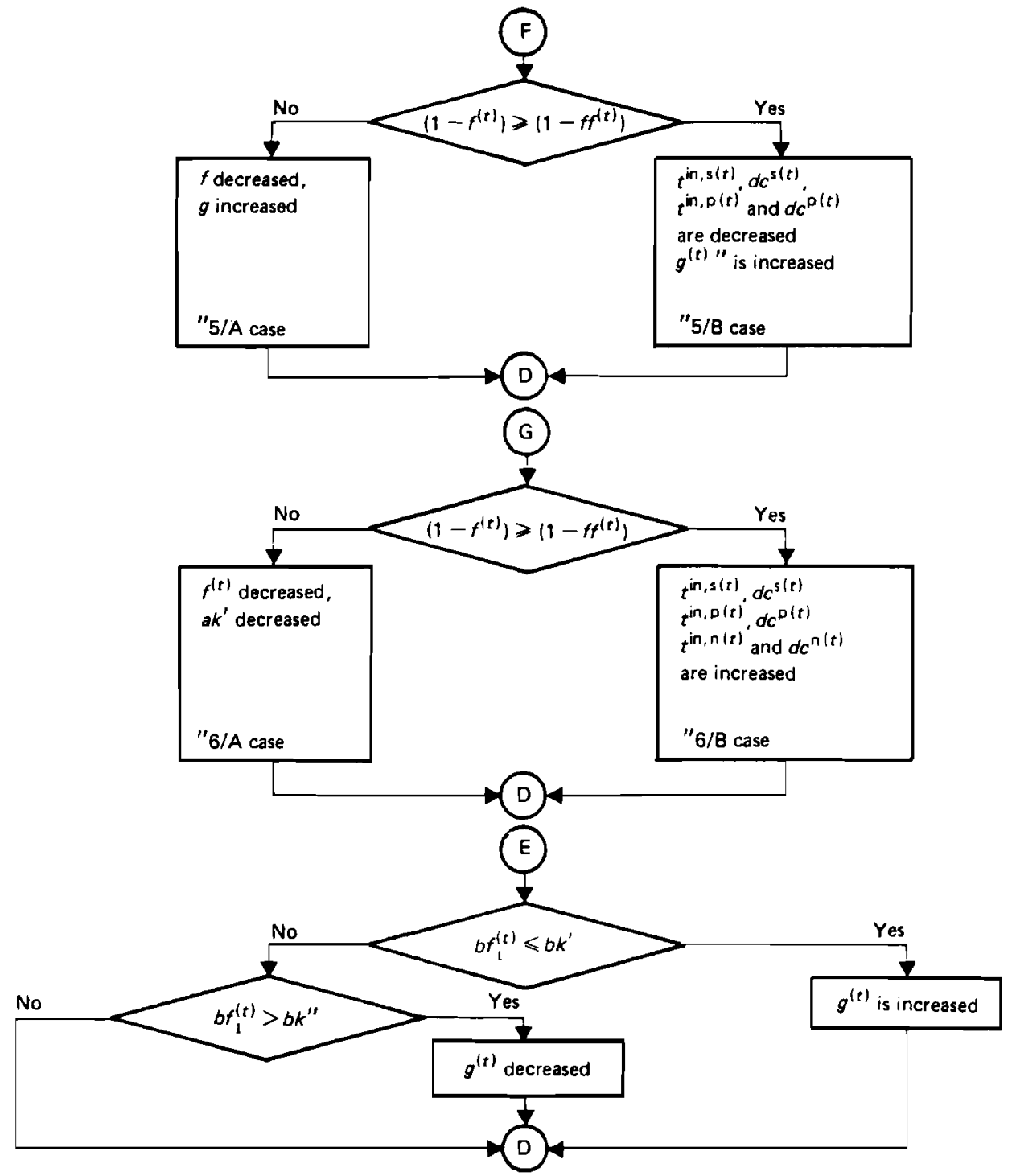

FIGURE 10 Revision of basic policy variables.

\section{Case 4}

In case 4 overall growth is below the desired level and the rest of the economy also develops slowly, but the rate of growth in food and agriculture is satisfactory or higher than desired. In this situation the growth of the rest of the economy is stimulated by increasing investments. 
If actual investment exceeds targets, the share of investment in national income is increased $\left(f^{(t)}\right.$ is decreased) and the share of the rest of the economy in total investment is also increased $\left(g^{(t)}\right.$ is decreased).

If actual investment in the rest of the economy does not reach the target level the income tax rate $\left(t^{\mathrm{in}, \mathrm{n}(t)}\right)$ and the centralized part of the depreciation $\left(d c^{\mathrm{n}(t)}\right)$ in the $n$th sector is decreased and the share of food and agriculture in total investments $\left(g^{(t)}\right)$ might also be decreased.

Case 5

In case 5 the rate of overall growth is less than desired, similarly for the rates for food and agriculture, but the growth in the rest of the economy is satisfactory or faster. In this situation, obviously, investments in food and agriculture are encouraged at the expense of consumption and the rest of the economy.

If actual investments exceed the target levels overall, the consumption fund $\left(f^{(t)}\right)$ is decreased and the share of food and agriculture in investments $\left(g^{(t)}\right)$ is increased.

If actual investments are below the target level, income tax rates $\left(t^{\mathrm{in}, \mathrm{s}(t)}, t^{\mathrm{in}, \mathrm{p}(t)}\right)$ and centralized depreciation $\left(d c^{\mathrm{s}(t)}, d c^{\mathrm{p}(t)}\right)$ are decreased. The share of food and agriculture in investments $\left(g^{(t)}\right)$ is increased.

Case 6

In case 6 , in addition to slow overall growth, the rate of development both in the rest of the economy and in food and agriculture is below the desired level. In this situation, investment possibilities are enlarged for both sectors.

If actual investments are above the target levels, the total investment fund is increased at the expense of consumption $\left(f^{(t)}\right.$ is decreased).

If actual investments do not reach the target levels, in addition to increasing the total investment fund, investment possibilities at the firm level (tax rates $t^{\text {in }, \mathrm{n}(t)}, t^{\mathrm{in}, \mathrm{s}(t)}$ and $t^{\mathrm{in}, \mathrm{p}(t)}$ are increased and centralized depreciation $d c^{\mathrm{n}(t)}, d c^{\mathrm{s}(t)}$ and $d c^{\mathrm{p}(t)}$ are decreased) might also be increased.

The diagram presented in Fig. 10 outlines the simulation procedure applied in module GM-A-1; the symbols used are explained in the Appendix.

\subsection{Revision of Prices: Module GM-A-2 and GM-A-3}

Domestic prices in Hungary are not directly related to international prices, but certain impacts of world market prices upon producer and consumer prices cannot be avoided. To develop module GM-A-2 and 3 the rather complex system of pricing employed in Hungary at present was studied. The pricing procedure included in HAM, we believe, explains the basic principles and logic of the Hungarian pricing system. However, we are aware of the fact that actual pricing is very largely commodity specific and influenced by the current economic situtation.

The revision of producer prices in HAM is based on the comparison of plan targets settled in module GM-P-3 with actual production results for the given year. Price revision depends on the length of time prices are to apply. The production expenses are also considered in the price modification. (The simplified process of producer price revision is shown in Fig. 11.) Production targets in the GM-P-3 module are actually determined on 
the basis of world market prices in the objective function, while actual production follows the domestic producer prices. World market prices have an impact on domestic producer prices by this indirect means.

In revising consumer prices (GM-A-3) the so-called desired structure of food consumption is used as a starting point. We assume that in changing consumer prices the government

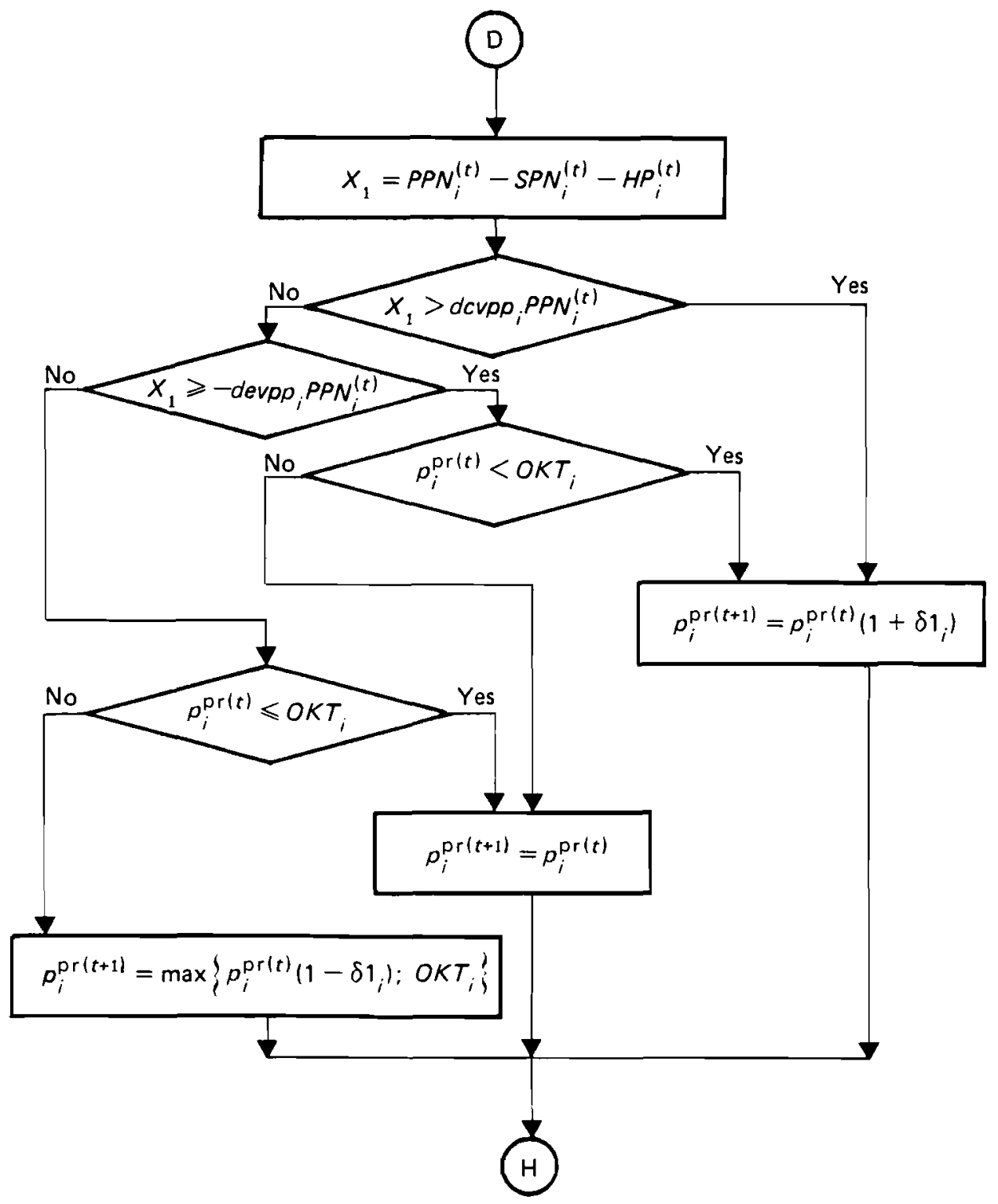




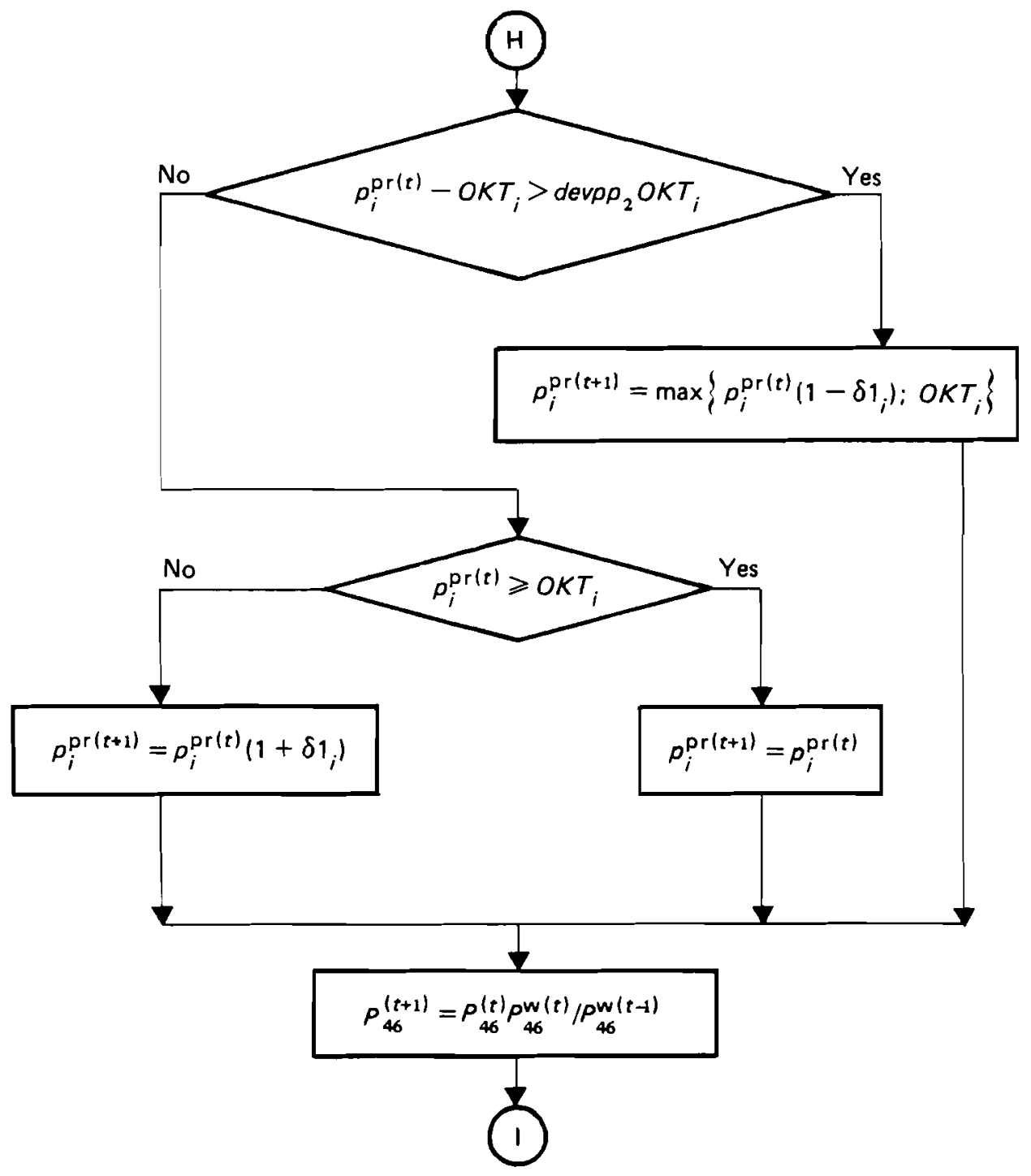

FIGURE 11 Process of revision of producers' prices.

aims at altering the actual structure to the desired structure. The desired structure of consumption is generated using exogenously given trends. Consumer prices might be modified if the actual consumption of a given commodity deviates substantially from the desired level of consumption. In modifying consumer prices the producer prices are also considered in order to keep the difference between the consumer and producer prices of a given commodity within a certain limit. The process of revising consumer prices is outlined in Fig. 12. 


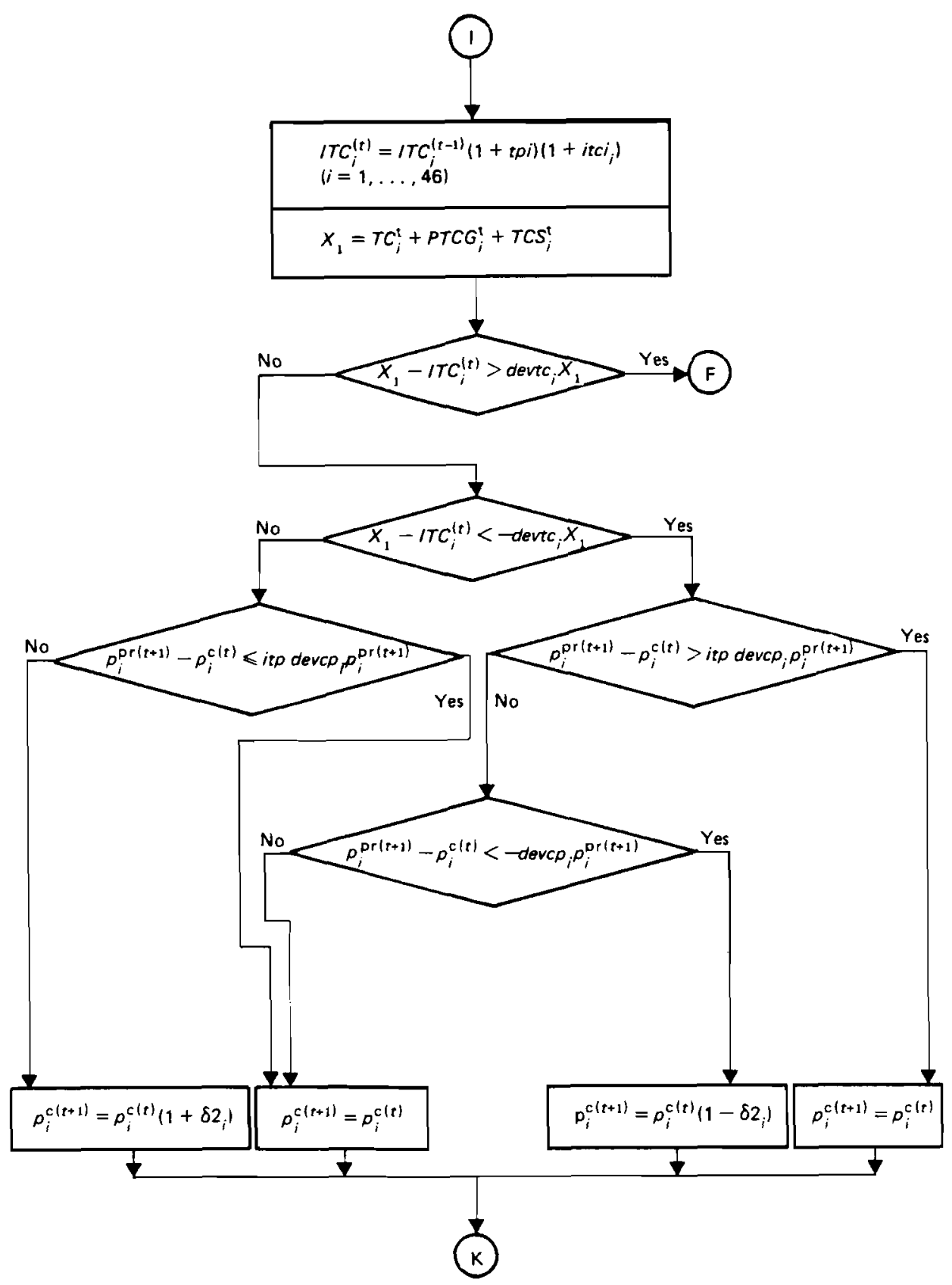




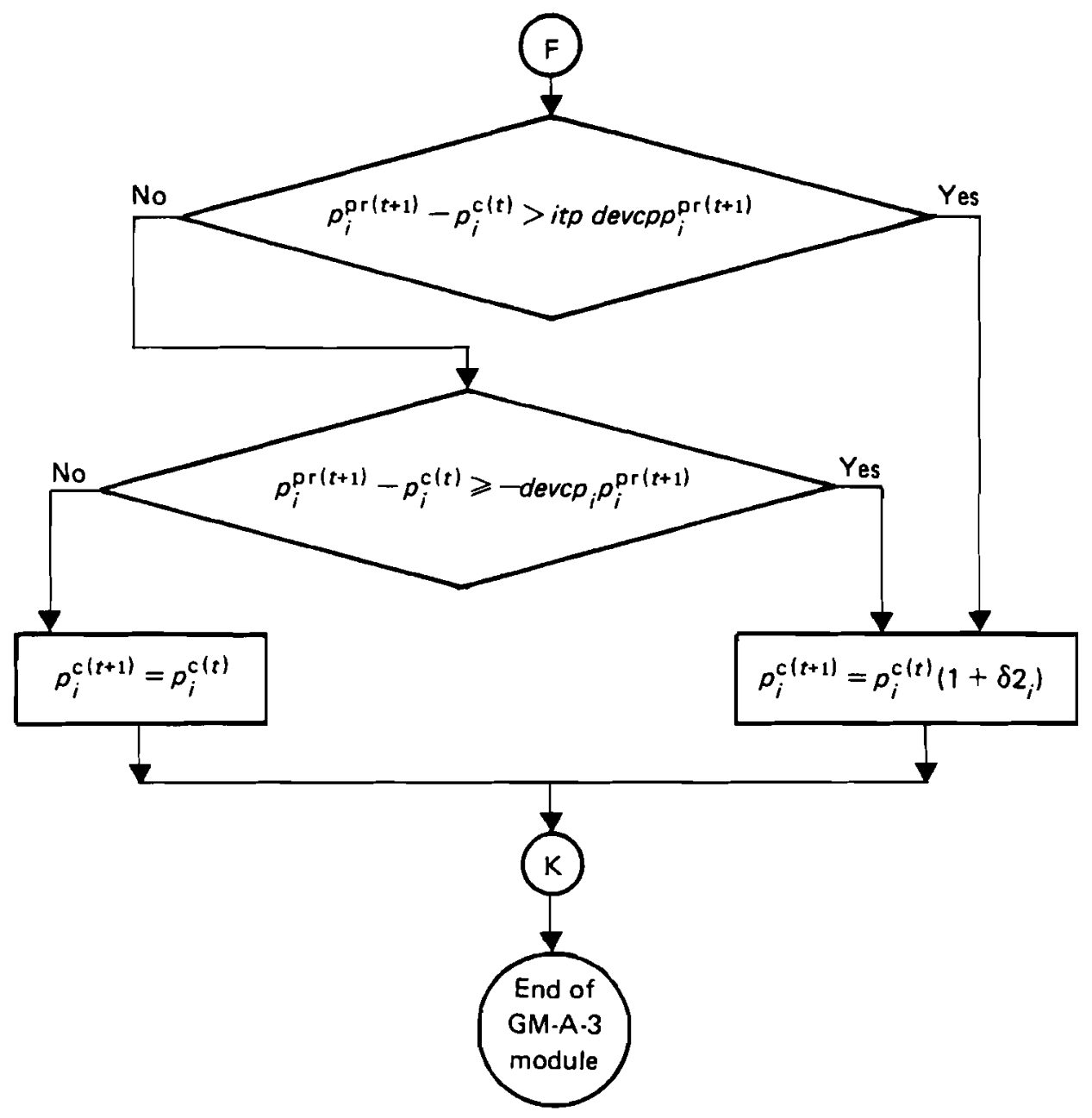

FIGURE 12 Revision of consumer prices.

\subsection{Updating Parameters: Block UD}

The last block of HAM-2 serves for the updating of parameters of the other model blocks - the last task during the modeling of a given time period. The UD block incorporates four modules:

- calculation of demographic changes (UD-1);

- updating of available land and physical resources (UD-2);

- calculation of new parameters for GM-P-3 module (UD-3);

- updatings of parameters for the Production block (UD-4). 


\subsubsection{Demographic changes: module UD-1}

HAM does not include a demographic subnodule. The available labor force and changes in population are calculated from a demographic prognosis elaborated by the Hungarian Central Statistical Bureau. The period of large-scale migration within the country ended in the late 1960s. Only a projected maximum decrease of the agricultural labor force is therefore considered. The available labor force in the household and private sector is forecast based on past trends.

The updating of the available labor force takes place based on the following three equations:

$$
\begin{aligned}
& w p^{(t+1)}=w p^{(t)}(1+w p i) \\
& t p^{(t+1)}=t p^{(t)}(1+t p i) \\
& T W H^{(t+1)}=T W H^{(t)}(1+w i)
\end{aligned}
$$

\subsubsection{Land and physical resources: module UD-2}

The land available for agricultural purposes is modeled according to the socialist agriculture and household and private sectors. The regular decrease in the amount of plowland and meadows due to industrialization and urbanization is considered:

$$
\begin{aligned}
& L S_{1}^{(t+1)}=L S_{1}^{(t)}\left(1+l s i_{1}\right) \\
& L S_{2}^{(t+1)}=L S_{2}^{(t)}\left(1+l s i_{2}\right) \\
& L S H^{(t+1)}=L S H^{(t)}(1+l h)
\end{aligned}
$$

The increase in physical resources is based on the investments of producing sectors as well as of the government. Obsolete production facilities are accounted for.

Fixed assets in the rest of the economy:

$$
R N^{(t+1)}=R N^{(t)}-d d n R N^{(t)}+P A F N^{(t)}
$$

Production facilities in agriculture:

$$
\begin{aligned}
& R S_{i}^{(t+1)}=R S_{i}^{(t)}\left(1-d d s_{i}\right)+P O T_{i}^{(t)}+I N V_{i}^{(t-a t i(i))} \\
& S K A P T_{i}^{(t+1)}=S K A P T_{i}^{(t)}\left(1-d d s_{i}\right)+\left(P O T_{i}^{(t)}+I N V_{i}^{(t-a t i(i))}\right) / p k s_{i}^{t}
\end{aligned}
$$

Production facilities in food processing:

$$
\begin{aligned}
& X_{i}^{(t)}=P O T_{i+1}^{(t)}+I N V_{i}^{(t-a t i(i))} \\
& R F_{i}^{(t+1)}=R F_{i}^{(t)}\left(1-d d p_{i}\right)+X_{l}^{(t)} \\
& K A P T_{i}^{(t+1)}=K A P T_{i}^{(t)}\left(1-d d p_{i}\right)+X_{l}^{(t)} / p k p_{i}^{\mathrm{t}}
\end{aligned}
$$




\subsubsection{Updating GM-P-3 model parameters: module UD-3}

Food and agriculture is described in an aggregated way by the GM-P-3 model. Technical coefficients of variables representing the production of different food and agricultural commodities are calculated based on the Production block of the previous period as a weighted average of the various production options. The available resource and production facility capacities are taken from the UD-2 module.

\subsubsection{Generation of the producers' decision model parameters: module UD-4}

In agriculture the yields and output coefficients are calculated from functions estimated based on time series expressing biological development in plant production and animal husbandry. These functions are given according to technologies. The inputs are determined from the projected yields and outputs. The fertilizer use is calculated from fertilizer response functions.

The output coefficients of food processing are updated according to trends. The method of updating input coefficients is similar to those applied for adjusting agricultural parameters.

The parameters related to investment decisions are updated based on time trends. 



\section{PART TWO}

Toward the Development of a Detailed National Policy Model - First Version of the Hungarian Agricultural Model (HAM-1) 


\section{OBJECTIVES IN DEVELOPING HAM-1}

HAM is the first system simulation model to describe the Hungarian food and agriculture sector. The earlier modeling work provided much useful experience but in several cases HAM applies entirely new approaches and the development of HAM requires the analysis of several possible alternative methodological solutions. To avoid the difficulties of immediately working with a large-scale system we therefore decided first to develop a more aggregated, relatively simplified model version (HAM-1).

The main objective of HAM-1 was to gain methodological experience for the further refinement of our model structure and for the construction of the final model version through the following:

- testing the operation of the whole model system, investigating alternative methodological solutions for some of the model modules (e.g. using nonlinear optimization instead of linear programming);

- performing a sensitivity analysis of the crucial model parameters;

-- studying the reaction of the system to changing external conditions (e.g. to changing world market prices);

- calculating the impacts of changes within the system (e.g. modifications of pricing mechanisms or decision-making rules) on the performance of the whole system.

HAM 1 is also very important from the point of view of computation of the final model version. Through the implementation of HAM-1 at IIASA and the computer of the Hungarian National Planning Bureau we intended to develop and test a computer program which could serve as a solid basis for the computation of the final model.

Our further objective with HAM-1 was to demonstrate that our model structure is suitable for investigations connected with the development of Hungarian food and agriculture in the following way.

-- Based on the model, the realization of major policy goals and plan targets and their main alternatives can be investigated. For example, the key factors and bottlenecks of production, the considerations for faster growth, the expected labor outflow from agriculture and the feasibility of the goals may be analyzed.

- HAM is suitable for studying the adjustments and reactions of the Hungarian food and agriculture system to a changing international market. For example, the export and import structure, the desired level of specialization or self-sufficiency, and the reaction of the domestic to the world market may be investigated.

- Finally, HAM is designed to be useful for the further development of the Hungarian economic management system, since the model can analyze the efficiency of policy instruments, the impact of the new instruments, and areas of additional control requirements.

Finally, the investigation of data availability and the development of data collecting system for further work can also be mentioned as important objectives of the HAM-1 experiment. 


\section{DESCRIPTION OF HAM-1}

HAM-1 describes the Hungarian food and agricultural sector in a rather aggregated way, but it has all the basic features of the HAM model structure described in Part One, namely:

- the model is dynamic and is descriptive in character;

- the food consumption sphere is incorporated;

- the nonfood production sectors of the economy are represented by assuming that they produce only one aggregated commodity;

- the economic, technical and biological aspects of food production are covered;

- both the production of agricultural raw materials and food processing are modeled;

- the whole agricultural production and food processing areas are represented;

- financial equilibrium is maintained.

Compared with our objectives as stated in the general description of the HAM structure, the aggregated and simplified features of HAM-1 mean the following:

- HAM-1 has a rather aggregated commodity coverage;

- different sectors of agricultural production (state farms, cooperative farms, household plots) are not conside red - only the so-called socialist agricultural production (state and cooperative farms together) is modeled;

- random weather effects on agricultural production are not directly included;

- in some cases (e.g. the savings function) less sophisticated mathematical formula. tion is applied;

- the description of the government's policy instrument revision activities (e.g. pricing) can be considered as the first preliminary approach;

- no separate CMEA market is considered.

\subsection{Commodity Coverage and Data Sources}

The Hungarian food and agriculture system is described in HAM-1 on a relatively high level of aggregation. Hungarian food and agriculture is represented by five agricultural and four processed food commodities, the tenth commodity being related to the rest of the economy.

As is shown in Table 6, practically all the model commodities represent a relatively wide range of products. Altogether, almost the entire Hungarian food and agriculture and the national economy also are covered. The computed results of HAM-1 can therefore be compared with the actual indicators of Hungarian food and agriculture, and the national economy. Of the 10 commodities, six - wheat, pork, beef, sugar, processed meat and the $n$th commodity $\cdots$ are consumed by the population.

HAM-1 is based on official Hungarian statistics. The methodological character of the HAM-1 experiment allowed us to be less exacting and sophisticated in data preparation. Most of the model parameters were calculated using the data of the Hungarian National Statistical Bureau and the Ministry of Food and Agriculture. The consumers' demand system was estimated at IIASA based on time series. 
TABLE 6 Commodity coverage of the first version of HAM.

\begin{tabular}{|c|c|c|}
\hline & Product & Product content \\
\hline 1 & Sugar beet & Sugar beet and other crop products to be processed \\
\hline 2 & Corn & Coarse grains and other feed products \\
\hline 3 & Wheat & Food grains and other directly consumed crop products \\
\hline 4 & Swine & Swine (pigs) \\
\hline 5 & Cattle & Cattle and other livestock products \\
\hline 6 & Sugar & Sugar and other processed crop products \\
\hline 7 & Pork & Pork meat \\
\hline 8 & Processed meat & Processed meats \\
\hline 9 & Beef & Beef and other meats \\
\hline 10 & $n$th product & Product of the rest of the economy \\
\hline
\end{tabular}

\subsection{Structure of HAM-1}

HAM-1 is actually a system of models structured as it was planned in the general HAM outline. Figure 13 shows the structure of HAM-1. Some of the most important linkages and the operation of the model are shown in Figs. 14 to 16. Figure 14 shows how the overall government objectives on the growth of the economy are realized. The government production control mechanism and the government influence on comsumption are outlined in Figs. 15 and 16 respectively.*

\subsection{Government Economic Planning Submodel}

The GM-P submodel incorporates three modules. The calculation of major economic goals (GM-P-1) and government targets on consumption (GM-P-2) are executed as stated in the general model outline. A linear programming model is applied to fix government targets on food and agriculture (GM-P-3).

The GM-P-3 module contains 34 variables and 45 rows, including the objective function describing the maximization of the balance of payments in food and agriculture. The whole GM-P-3 model for the first year is shown in Appendix 2. The model coefficients are updated in each simulated year based on P-3 and P-5 modules, as described later.

\subsection{Production Block}

The Production block of HAM-1 consists of three major elements. The rest of the economy is modeled (module P-1) by a Cobb - Douglas-type production function as follows:

$$
p_{n}^{(t)}=290.3\left(L A N^{(t)}\right)^{0.3}\left(R V N^{(t)}\right)^{0.75}
$$

*Figures 14-16 were designed by Professor Ferenc Rabar. 


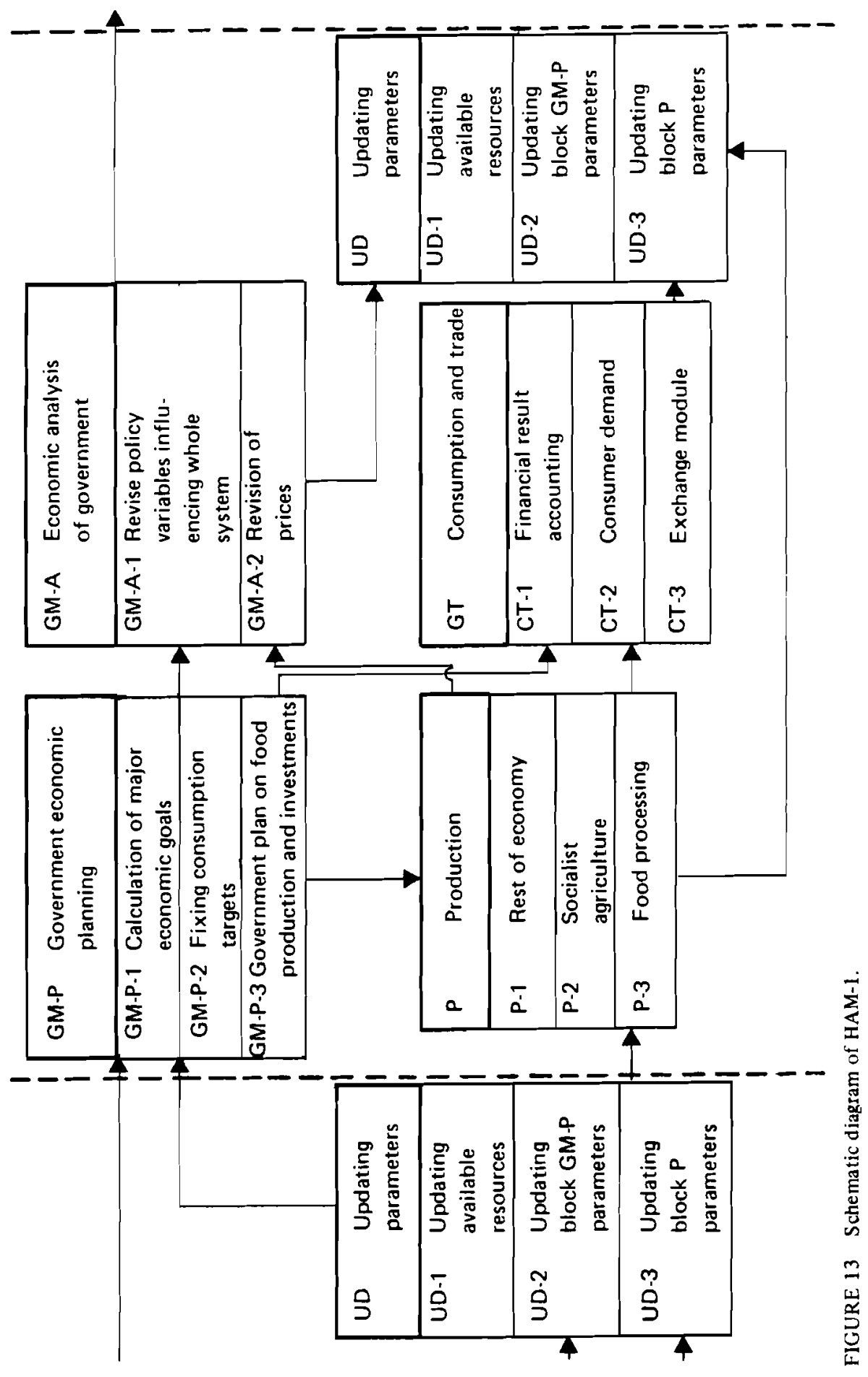




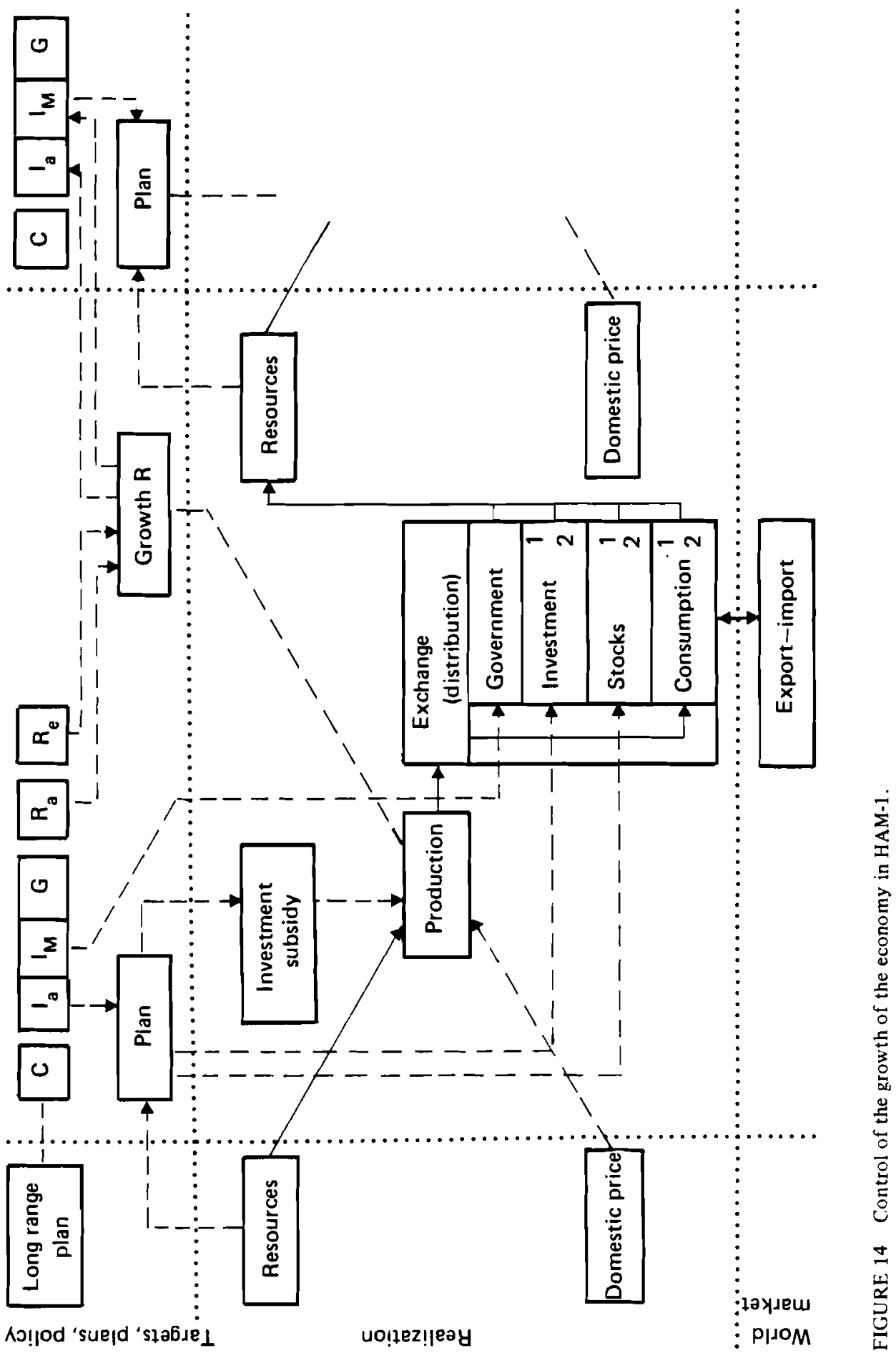









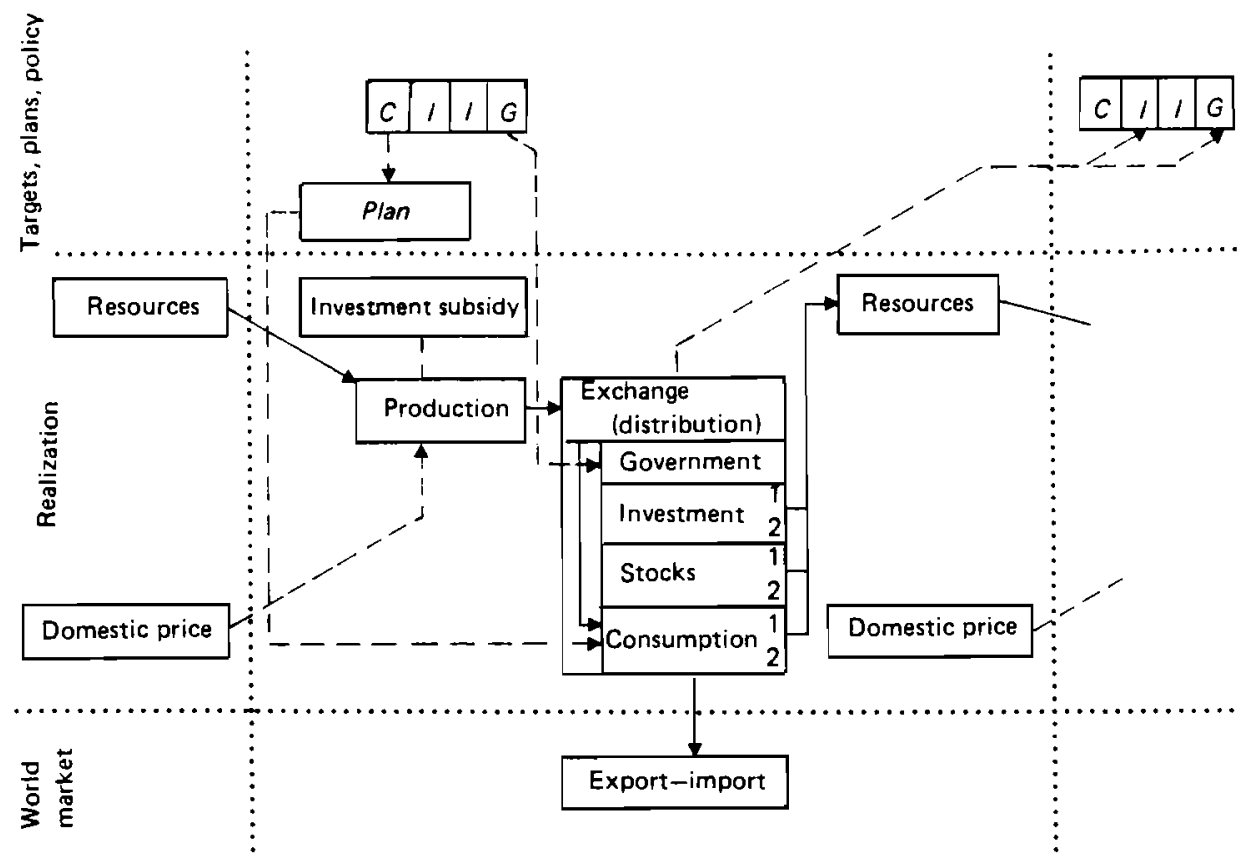

FIGURE 16 Government influence on consumption in HAM-1.

where $P_{n}^{(t)}$ is the production of the rest of the economy in period $(t), L A N^{(t)}$ is the labor force of the rest of the economy in period $(t)$, and $R V N^{(t)}$ is the available assets of the rest of the economy in period $(t)$.

Agricultural production and food processing are modeled by two separate linear programming models (module P-3 and P-5) determining first the agricultural production. As has been mentioned, random weather effects are not considered.

In the P-3 module the production of the five agricultural commodities is represented by two or three production technologies and a relatively wide range of input factors is considered. Module P-3 contains 22 columns and 31 rows including the objective function. Obviously, the P-3 model parameters are subject to annual updating according to the trends of biological and technical development as well as to domestic price changes.

Model P-5 is used to describe the production decisions of the food processing industry. The relatively small case linear programming model has 15 columns and 19 rows, and the results are to a large extent determined by available raw materials and processing capacities.

As can be seen from the description of the P-3 and P-5 modules, the investment decisions are included in production decision models in both cases and most of the investments have no time lag. 


\subsection{Consumption and Trade Block}

The Consumption and Trade block of HAM-1 plays a very important role in the operation of the whole system. Some revision of the original structure of this model block was required during the work on it, but its basic content has not been changed from that of the general model outline.

The consumer demand is modeled according to our general model outline. The parameters of demand system used in HAM-1 are shown in Table 7.

TABLE 7 Parameters of the demand system used in HAM-1.

\begin{tabular}{lrr}
\hline Commodity & $c 1$ & \multicolumn{1}{c}{$c 2$} \\
\hline 1 Wheat & 465.570 & 0.47800 \\
2 Sugar & 2.929 & 0.00535 \\
3 Pork & 240.550 & 0.57560 \\
4 Processed meat & 191.000 & 0.62140 \\
5 Beef & 19.463 & 0.13200 \\
$6 n$th product & 6.138 & 0.24500 \\
\hline
\end{tabular}

The demands related to noncommitted expenditures are formulated as in Table 8 .

$$
S_{i}^{(t)}, S_{f}^{(t)} \text { and } S_{n}^{(t)} \text { are stocks in period }(t)
$$

$T C_{i}^{(t)}, T C_{f}^{(t)}$ and $T C_{n}^{(t)}$ are the total consumptions by the population of the various $G P E^{(t)}$ is the government public expenditure in period $(t)$;

$D G I N A^{(t)}$ is the direct government investment in food and agriculture in period $(t)$;

$G I N N^{(t)}$ is the government investment in the rest of the economy;

$p_{n}^{\mathrm{pr}(t)}$ is the producer price of the $n$th commodity in period $(t)$.

$\pi=1 / p_{n}^{\mathrm{pr}(t)}$

TABLE 8 Demands related to noncommitted expenditures.

\begin{tabular}{llllllll}
\hline (agricultural commodities) & 0 & $S_{l}^{(t)}$ & 0 & 0 & 0 & 0 & $T C_{l}^{(t)}$ \\
$f$ (processed food commodities) & 0 & $S\}^{(t)}$ & 0 & 0 & 0 & 0 & $T C C^{(t)}$ \\
n (rest of the economy) & $S_{n}^{(t)}$ & 0 & $\pi G P E^{(t)}$ & $\pi D G I N A^{(t)}$ & $\pi G I N N^{(t)}$ & $T C_{n}^{(t)}$ & 0 \\
\hline
\end{tabular}

The structure of matrix $\mathbf{Q}$ expresses the preference ordering of adjustment as it is stated in the model outline, namely: 
- adjustment of stocks of the $n$th commodity;

- stock adjustment of agricultural and processed food commodities;

- modification of government public expenditure;

- adjustment of direct government investment in food and agriculture;

- modification of government investments in the rest of the economy;

- adjustment of private consumption of the $n$th product;

- modification of private consumption of food and agricultural commodities.

This is the order of demand adjustment.

As has been mentioned in Part One, $\lambda^{*}$ and $\lambda^{* *}$ express the extent of allowed deviation from target levels. For the various elements of $Q$ different $\lambda^{*}$ and $\lambda^{* *}$ are given, expressing the government objectives and policies in demand adjustment. Table 9 contains $\lambda^{*}$ and $\lambda^{* *}$ vectors of HAM-1. Three sets of $\lambda^{*}$ and $\lambda^{* *}$ are used in HAM-1, in which the extent of possible adjustment is increased continuously going from the first set to the third. Using the algorithm mentioned earlier, vector $\boldsymbol{\lambda}$ is determined and we ob tain the final values of variables included in matrix $Q$ as given in Table 9 .

TABLE 9 Values of $\lambda^{*}$ and $\lambda^{* *}$ used in HAM-1.

\begin{tabular}{|c|c|c|c|c|c|c|}
\hline \multirow{2}{*}{$\begin{array}{l}\text { Parameter to which } \lambda^{*} \text { and } \\
\lambda^{* *} \text { are related }\end{array}$} & \multicolumn{3}{|l|}{$\overline{\lambda^{*}}$} & \multicolumn{3}{|l|}{$\lambda^{* *}$} \\
\hline & 3 & 2 & 1 & 1 & 2 & 3 \\
\hline$S_{n}^{(t)}$ & 0 & 0.3 & 0.5 & 2 & 5 & 10 \\
\hline$s_{l}^{(t)}, s_{f}^{(t)}$ & 0.4 & 0.5 & 0.6 & 2 & 3 & 4 \\
\hline$G P E^{(t)}$ & 0.6 & 0.7 & 0.8 & 1.2 & 1.3 & 1.5 \\
\hline$D G I N A^{(t)}$ & 0 & 0.3 & 0.5 & 1.2 & 1.5 & 2 \\
\hline$G I N N^{(t)}$ & 0 & 0.3 & 0.5 & 3 & 4 & 5 \\
\hline$T C_{n}^{(t)}$ & 0.85 & 0.9 & 0.95 & 1.05 & 1.15 & 1.25 \\
\hline$T C_{l}^{(t)}, T C_{f}$ & 0.95 & 1.0 & 1.0 & 1 & 1.05 & 1.05 \\
\hline
\end{tabular}

\subsection{Economic Analysis of Government}

The revision of the government policy instruments in HAM-1 is somewhat simpler than the procedures described in the general model outline. The actual values used in government policy instruments are determined in this module. These values have a great impact on the performance and operation of the whole system.

- Firstly the desired share of investment accumulation in net national product is updated for the next period. The procedure is based on the comparison of the actual growth of gross national product and those exogenous coefficients expressing the bounds of desired growth, as is shown in Fig. 17.

- The annual increase in unit wages is calculated based on the growth of net national product and the desired share of investment accumulation in net national product, as can be seen from Fig. 17. 


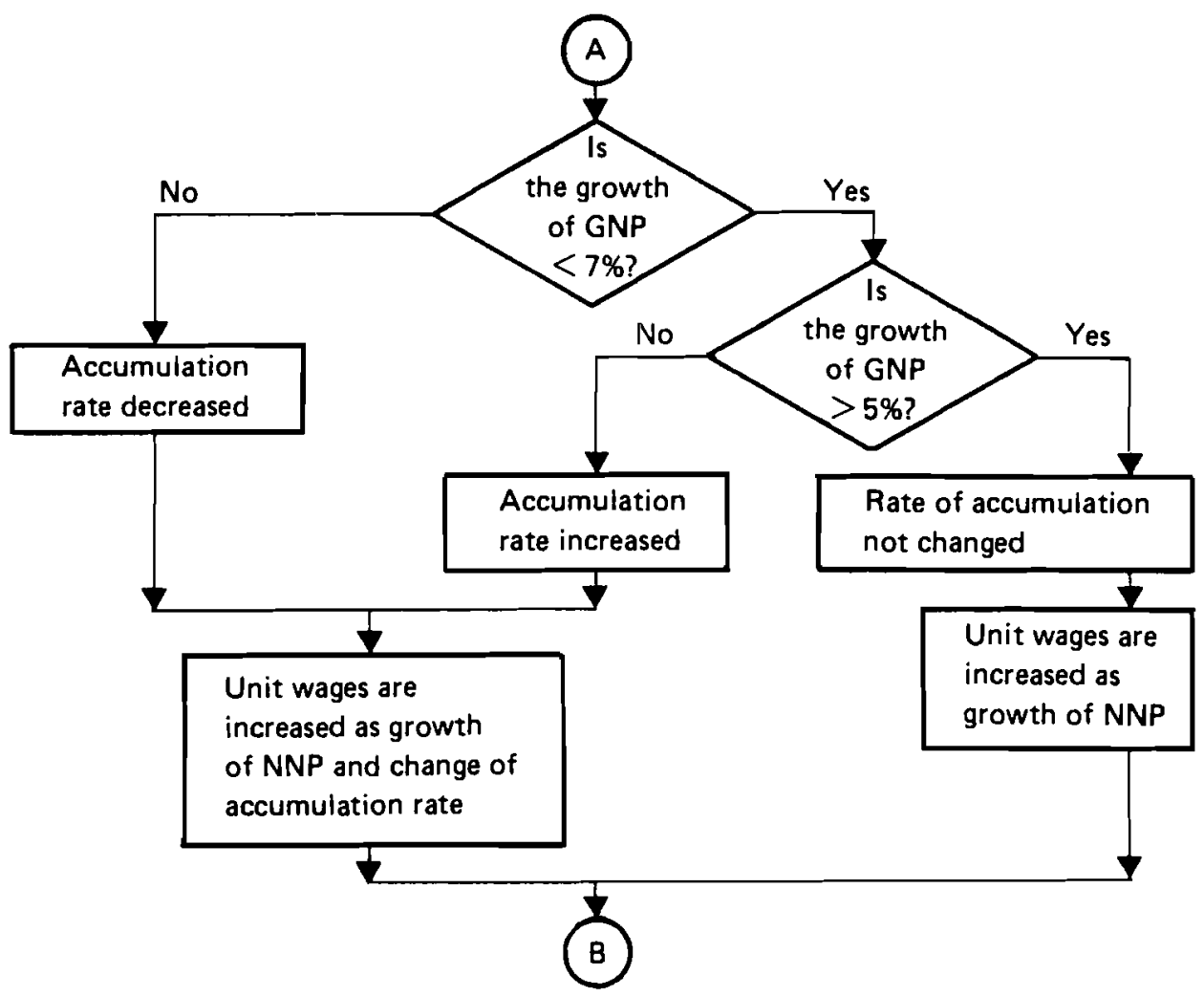

FIGURE 17 Revision of basic policy variables in HAM-1.

- The desired share of food and agriculture in total investment accumulation is revised based on the actual growth of gross production value of food and agriculture (see Fig. 18).

- The income tax rates are changed if the actual income rates are above or below certain given bounds, as shown in Fig. 18.

- Finally the producer and consumer prices are also revised. In HAM-1 this procedure is based on a comparison of target and actual figures of production, as shown in Fig. 19.

\subsection{Ujảating Parameters}

The last block of HAM-1 is devoted to the updating of parameters of other model blocks. The demographic changes are given exogenously based on a prognosis elaborated by the Hungarian Central Statistical Bureau. In HAM-1 only plowland is considered and some annual decrease of total land is projected as

$$
L S^{(t)}=0.9995 L S^{(t-1)}
$$

$L S^{(t)}$ is the total available plowland in period $(t)$. 


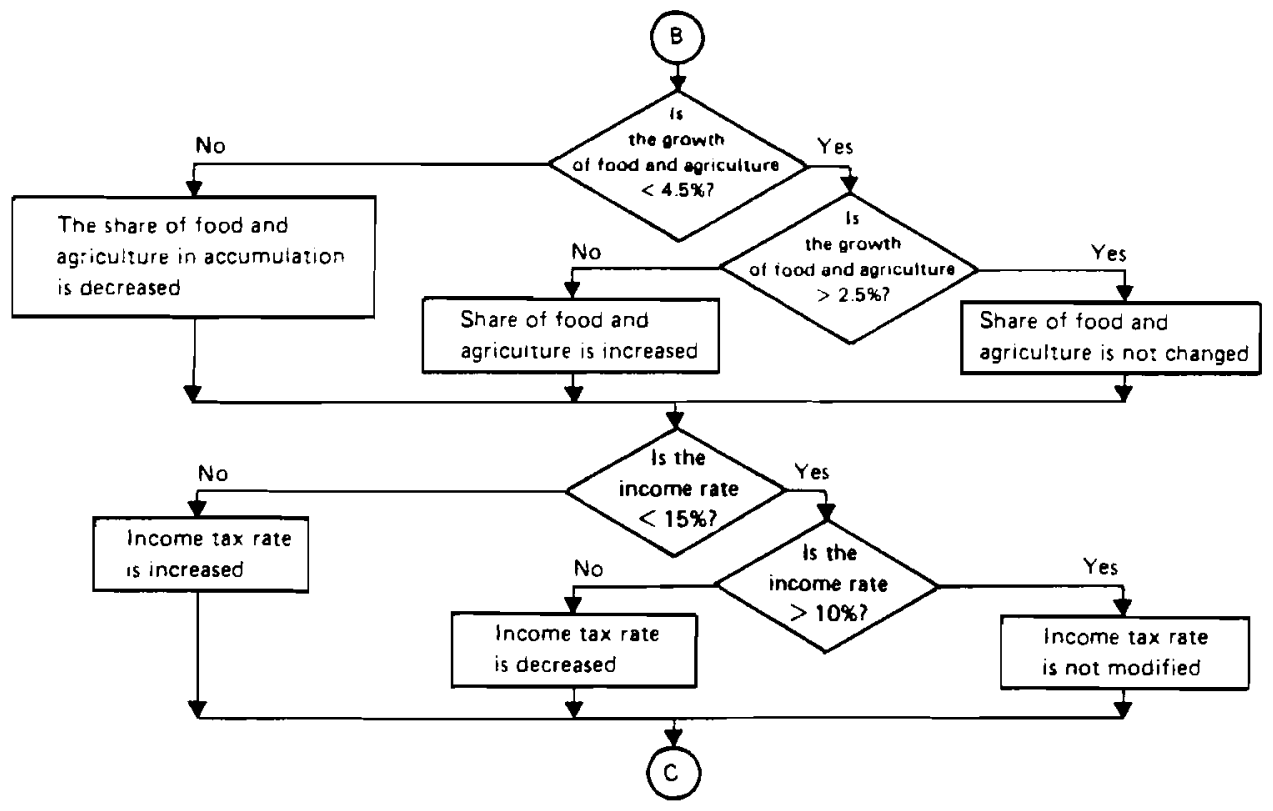

FIGURE 18 Revision of the desired share of food and agriculture in total investment and the income tax rate in HAM-1.

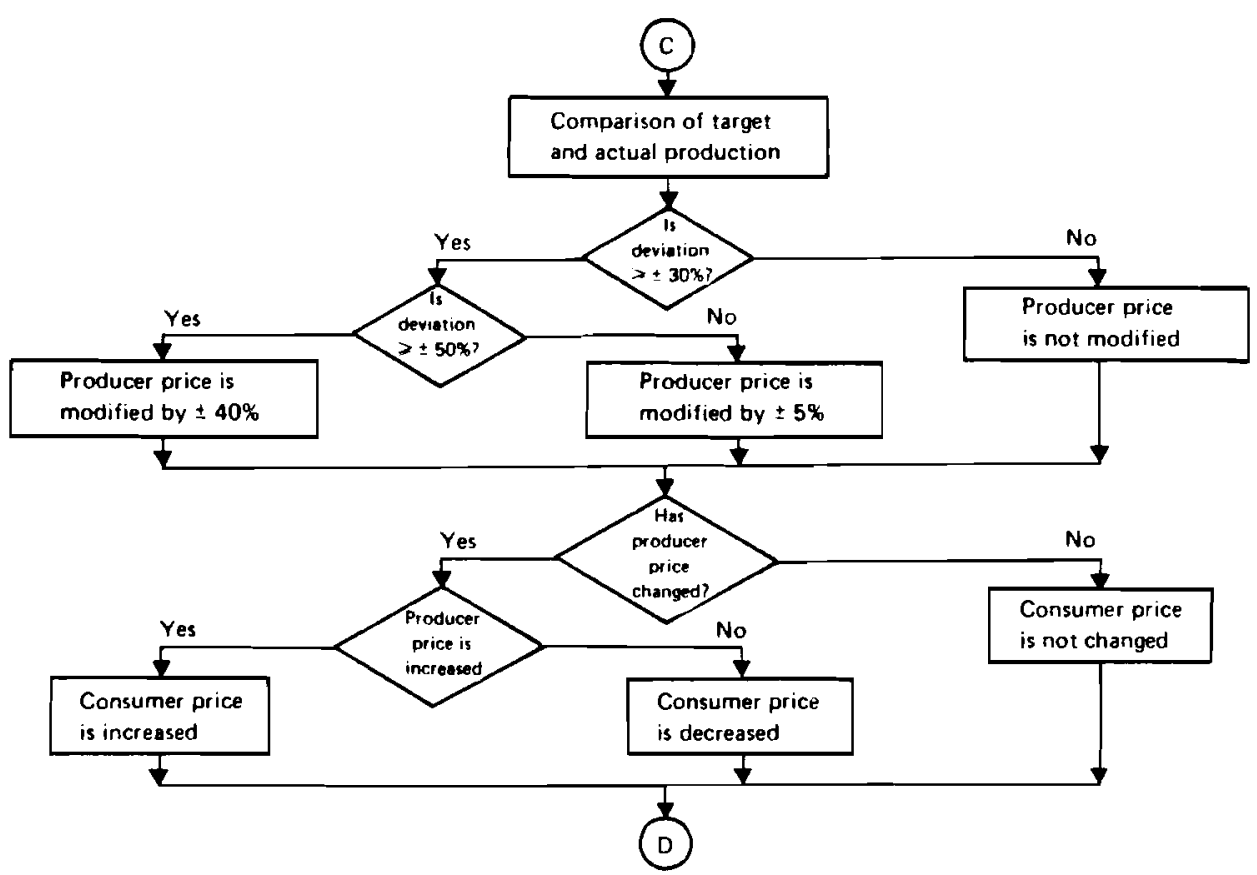

FIGURE 19 Revision of domestic prices in HAM-1. 
TABLE 10 Initial values and updating of physical resources ${ }^{a}$.

\begin{tabular}{|c|c|c|c|}
\hline Resource & Unit & $\begin{array}{l}\text { Initial } \\
\text { value } \\
\left(R S_{l}^{(0)},\right. \\
R P_{l}^{(0)}\end{array}$ & Updating \\
\hline Tractors & $1000 \mathrm{~s}$ & 440 & $R S_{1}^{(t)}=0.86 R S_{1}^{(t-1)}+R I S_{1}^{(t-1)}$ \\
\hline Additional equipment & Millions of Hungarian forints & 30000 & $R S_{2}^{(t)}=0.87 R S_{2}^{(t-1)}+R I S_{2}^{(t-1)}$ \\
\hline Pig barns & 1000 head & 9000 & $R S_{3}^{(t)}=0.95 R S_{3}^{(t-1)}+R I S_{3}^{(t-1)}$ \\
\hline Cattle barns & 1000 head & 3000 & $R S_{4}^{(t)}=0.97 R S_{4}^{(t-1)}+R I S_{4}^{(t-1)}$ \\
\hline Other fixed assets & Millions of Hungarian forints & 50000 & $R S_{s}^{(t)}=0.95 R S_{s}^{(t-1)}+R I S_{5}^{(t-1)}$ \\
\hline Sugar processing & 1000 tonnes & 3600 & $R P_{1}^{(t)}=0.95 R P_{1}^{(t-1)}+R I P_{1}^{(t-1)}$ \\
\hline Slaughtering capacity & 1000 tonnes & 2000 & $R P_{2}^{(t)}=0.95 R P_{2}^{(t-1)}+R I P_{2}^{(t-1)}$ \\
\hline Meat processing plants & 1000 tonnes & 300 & $R P_{\mathbf{3}}^{(t)}=0.95 R P_{\mathbf{3}}^{(t-1)}+R I P_{\mathbf{3}}^{(t-1)}$ \\
\hline
\end{tabular}

${ }^{a} R I S_{i}^{(t)}$ and $R I P(t)$ are increases in physical resources due to new investments in period $(t)$.

TABLE 11 GM-P-3 module coefficients determined based on P-3 module in HAM-1.

\begin{tabular}{|c|c|c|c|c|c|}
\hline & $\begin{array}{l}\text { Sugar beet } \\
\text { production }\end{array}$ & $\begin{array}{l}\text { Corn } \\
\text { production }\end{array}$ & $\begin{array}{l}\text { Wheat } \\
\text { production }\end{array}$ & $\begin{array}{l}\text { Pig } \\
\text { production }\end{array}$ & $\begin{array}{l}\text { Cattle } \\
\text { production }\end{array}$ \\
\hline & $P P_{1}$ & $P P_{2}$ & $P P_{3}$ & $P P_{4}$ & $P P_{s}$ \\
\hline & 2 & 3 & 4 & 5 & 6 \\
\hline 4 Tractor & $e_{42}$ & $e_{43}$ & $e_{44}$ & & \\
\hline 5 Other equipment & $e_{52}$ & $e_{s 3}$ & $e_{54}$ & & \\
\hline 6 Pig bams & & & & $e_{65}$ & \\
\hline 7 Cattle barns & & & & & $e{ }^{26}$ \\
\hline 8 Other fixed assets & $e_{82}$ & $e_{83}$ & $e_{84}$ & & \\
\hline 12 Labor & $e_{12.2}$ & $e_{12.3}$ & $e_{12,4}$ & $e_{12.5}$ & $e_{12.6}$ \\
\hline 14 Land & $e_{14.2}$ & $e_{14.3}$ & $e_{14.4}$ & & \\
\hline 30 Corn & & 1 & & $-E_{4}$ & $-E_{s}$ \\
\hline
\end{tabular}


In agricultural production the fixed assets are represented by five types. In food processing three basic production resources are considered. Table 10 shows the method of updating and the initial stock of these resources.

The coefficients of module GM-P-3 are calculated based on P-3 and P-5 modules. If only one production technology is considered in food processing, the parameters of P-5 are simply used in the GM-P-3 module. In the case of agricultural production, the GP-P-3 linear programming model parameters are determined based on the previous year's P-3 module. Table 11 contains a section of the GM-P-3 model and in Table 12 the altered part of the previous year's P-3 module is shown. The parameters for the GM-P-3 module are calculated as:

$$
\left.\begin{array}{rl}
e_{42}= & \left(\alpha_{20.2} S P_{11}^{(t-1)}+\alpha_{20.3} S P_{12}^{(t-1)}+\alpha_{20.4} S P_{13}^{(t-1)}\right) / \\
& \left(\gamma_{11} S P_{11}^{(t-1)}+\gamma_{12} S P_{12}^{(t-1)}+\gamma_{13} S P_{13}^{(t-1)}\right) \\
e_{43}= & \left(\alpha_{20.5} S P_{21}^{(t-1)}+\alpha_{20.6} S P_{22}^{(t-1)}\right) /\left(\gamma_{21} S P_{21}^{(t-1)}+\gamma_{22} S P_{22}^{(t-1)}\right) \\
e_{44}= & \left(\alpha_{20.7} S P_{31}^{(t-1)}+\alpha_{20.8} S P_{32}^{(t-1)}\right) /\left(\gamma_{31} S P_{31}^{(t-1)}+\gamma_{32} S P_{32}^{(t-1)}\right) \\
e_{52}, e_{53}, e_{54} & e_{65}
\end{array}\right\}
$$

In the objective function of the GM-P-3 module, the balance of payments in food and agriculture is maximized using the previous year's world market prices.

In modeling agricultural producers' decisions in HAM-1 the following coefficients are updated using the simulated time horizons:

-. yields, expressing the trends of biological development;

- fertilizer use, related to yields;

- feed input coefficients in pork production;

- upper limits of future technologies in the production of agricultural commodities;

- prices and unit wages.

Functions used to update yields and fertilizer inputs are shown in Table 13. The unit pork feed input coefficients are calculated as follows. 


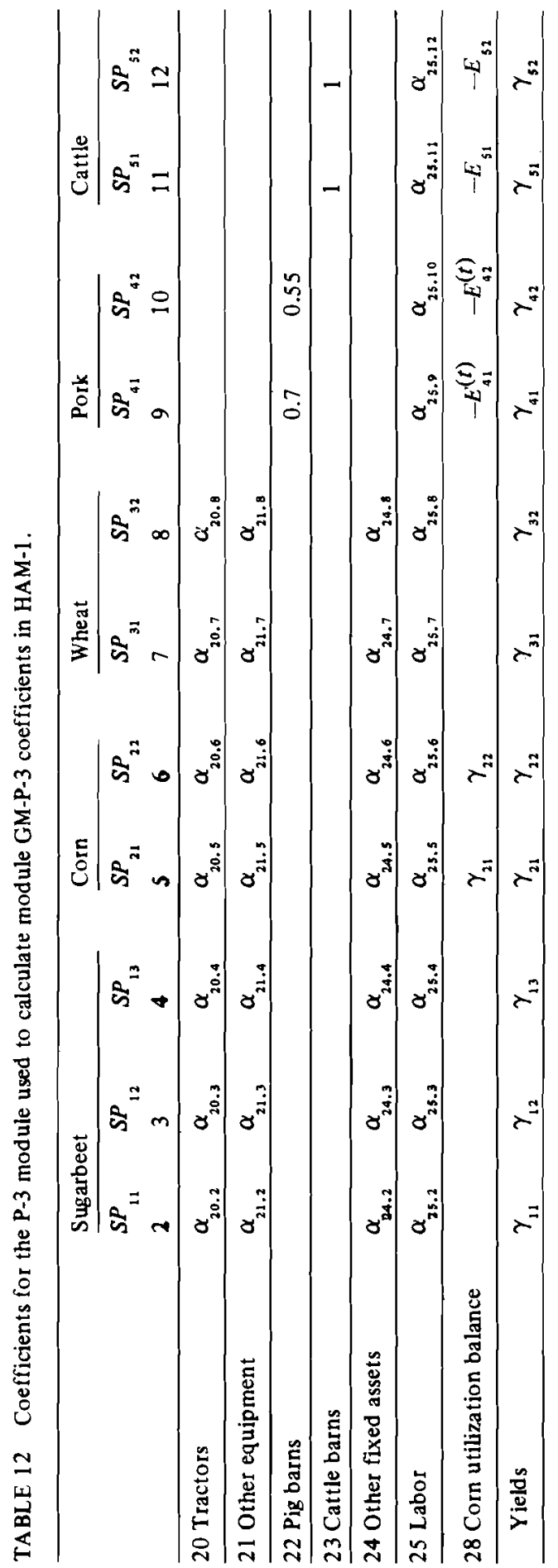


TABLE 13 Yield and fertilizer response functions in HAM-1 ${ }^{a}$.

\begin{tabular}{|c|c|c|c|c|}
\hline Crop & Symbol & Yield function & $\begin{array}{l}\text { Initial } \\
\text { yield } \\
\text { tonnes/ha }\end{array}$ & Fertilizer response function \\
\hline \multicolumn{5}{|l|}{ Sugarbeet } \\
\hline - present technology & $\gamma_{11}$ & $\gamma_{11}^{(t)}=\gamma_{11}^{(t-1)}+0.547$ & 31.8 & $\alpha_{41.11}^{(t)}=0.01365 f_{11}^{(t)}-0.01607$ \\
\hline -- future technology & $\gamma_{12}$ & $\gamma_{12}^{(t)}=\gamma_{12}^{(t-1)}+0.533$ & 42.0 & $\alpha_{41.12}^{(t)}=0.01587 \gamma_{12}^{(t)}-0.0635$ \\
\hline - irrigated production & $\gamma_{13}^{(t)}$ & $\gamma_{13}^{(t)}=\gamma_{13}^{(t-1)}+0.60$ & 44.0 & $\alpha_{41.13}^{(t)}=0.01875 f_{13}^{(t)}-0.205$ \\
\hline \multicolumn{5}{|l|}{ Corn } \\
\hline - present technology & $\gamma_{21}$ & $\gamma_{21}^{(t)}=\gamma_{21}^{(t-1)}+0.132$ & 4.5 & $c_{41.21}^{(t)}=0.0625_{\gamma_{21}}^{(t)}-0.08375$ \\
\hline - future technology & $\gamma_{22}$ & $\gamma_{22}^{(t)}=\gamma_{21}^{(t-1)}+0.152$ & 5.5 & $\alpha_{41.22}^{(t)}=0.05782 \gamma_{22}^{(t)}-0.149$ \\
\hline \multicolumn{5}{|l|}{ Wheat } \\
\hline - present technology & $\gamma_{31}$ & $\gamma_{31}^{(t)}=\gamma_{31}^{(t-1)}+0.073$ & 3.3 & $\alpha_{41,31}^{(t)}=0.0909 f_{31}^{(t)}-0.04997$ \\
\hline - future technology & $\gamma_{32}$ & $\gamma_{32}^{(t)}=\gamma_{32}^{(t-1)}+0.087$ & 4.2 & $\alpha_{41.32}^{(t)}=0.08461 f_{32}^{(t)} \ldots 0.05536$ \\
\hline
\end{tabular}

a $\alpha_{41, i j}^{(t)}=$ unit fertilizer input coefficient in period $(t)$. 
- Present technology:

$E_{41}^{(t)}=E_{41}^{(t-1)}-0.00333 \quad\left(E_{41}^{(0)}=0.32\right)$

-. future technology:

$E_{42}^{(t)}=E_{42}^{(t-1)}-0.003 \quad\left(E_{42}^{(0)}=0.30\right)$

The upper limit of future technology $\left(Z_{i}^{(t)}\right)$ is updated as follows:

$$
\begin{array}{lll}
Z_{1}^{(t)}(\text { sugarbeet }) & =Z_{1}^{(t-1)}+0.0375 & \left(Z_{1}^{(0)}=0.25\right) \\
Z_{2}^{(t)}(\text { corn }) & =Z_{2}^{(t-1)}+0.01875 & \left(Z_{2}^{(0)}=0.4\right) \\
Z_{3}^{(t)}(\text { wheat }) & =Z_{3}^{(t-1)}+0.01875 & \left(Z_{3}^{(0)}=0.3\right) \\
Z_{4}^{(t)}(\text { pork }) & =Z_{4}^{(t-1)}+0.035 & \left(Z_{4}^{(0)}=0.3\right) \\
Z_{5}^{(t)}(\text { cattle }) & =Z_{5}^{(t-1)}+0.040 & \left(Z_{5}^{(0)}=0.2\right)
\end{array}
$$

In module P-5 of HAM-1 (food processing) only prices and the wage rate are updated from model coefficients.

\section{COMPUTATION OF HAM-1}

The computer program of HAM-1 was developed in Hungary by the Computer Center of the Hungarian National Planning Bureau under the leadership of Laszlo Zeöld. At present two program versions exist, allowing us to execute runs both on IIASA's PDP 11/45 computer and on the Hungarian Planning Bureau's ICL-System 4/70.

The computer program of HAM-1 consists of four subprograms:

- LOAD is used to change model parameters, to determine the lengths of runs and to start the program;

- MAIN executes the solutions of the GM-P, GM-A, P, and UD blocks of the model;

- CONSUM executes the solution of the Consumption and Trade block;

- TAB stores selected variables after each simulated year and prepares the outputs including time series for the whole simulated period.

At the end of the computation various types of output can be printed out. The output system of HAM-1 consists of the following three major elements.

Annual results provide the analysis of time periods containing very detailed results for each simulated year and for each module of the model including the updated model coefficients.

The summary of results covers time series of the most important indicators, making possible the global analysis of the various runs. 
Plotter output can be prepared for the most important time series, visualizing trends and tendencies projected by HAM-1 and helping in the comparison of various runs.

The summary of results is the most useful type of output and in most cases the information needs on the individual runs can be satisfied on the basis of it. Of course, the more detailed analysis or debugging can only be done using the annual results. The summary of results is structured according to eight tables as follows.

1. Commodity coverage: list of commodities.

2. General indicators: general indicators of production, foreign trade, investment, income development on current and fixed prices for the whole simulated period, and indexes of the development.

3. Dynamics of production and trade: the planned and actual production, and the export or import of individual commodities in physical units.

4. Dynamics of per capita consumption: private consumption by commodities in value.

5. Dynamics of investments: the investments in physical units by types of investment and the share of the rest of the economy in the total investment fund for each year.

6. Dynamics of prices: producer, consumer and world market prices of commodities, and producer and consumer price indexes.

7. Resources and production structure: main physical resources, production structure in physical units and structure of the gross production value of food and agriculture for each or for the desired - e.g. first and last - simulated years.

Figure 20 shows the structure the output system of HAM-1.

\section{EXPERIMENTS WITH HAM-1}

To realize our objectives with HAM-1 as stated in Section 1, numerous runs of HAM-1 were executed. These runs represent three types of investigation, namely:

- testing the operation of the whole system and investigating the model's relation to reality;

- studying the impacts of changes in external conditions;

- investigating how the system reacts to modifications within the model.

The largest number of runs was of the first of the above-mentioned three types. Some of them simply served debugging purposes. In other cases the sensitivity of the crucial parameters was investigated. Finally several runs were required to test our assumptions on various decision making procedures. These runs led us to the so-called basic variant of HAM1 , which can be considered the most appropriate description of the present Hungarian food and agricultural system, obviously on the aggregation level and accepting the methodological framework of HAM-1.

We now present some of the results of the computation, first of all to realize our third objective - to prove that the HAM model structure is suitable to provide useful information for decision making and policy analysis. In our analysis the results of twelve independent runs, $1-5$ and 9-15, are used and compared. These basic model variants are as follows. 


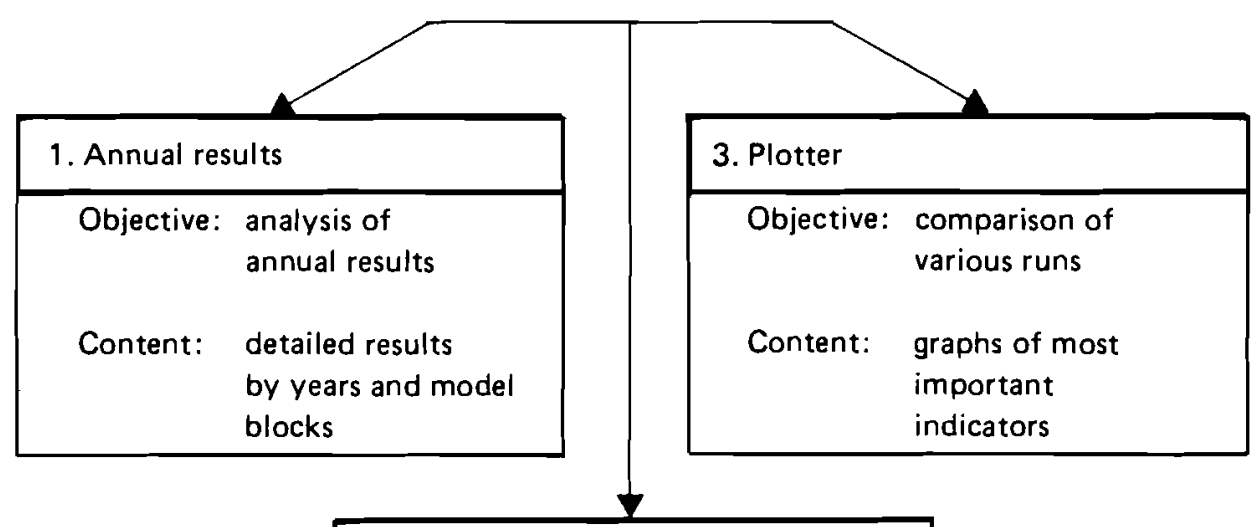

2. Summary of results

Objective: analysis of one run

Content: time series for 15 years

\begin{tabular}{|c|c|}
\hline \multicolumn{2}{|l|}{ HAM output tables } \\
\hline \multicolumn{2}{|c|}{ 1. Commodity coverage } \\
\hline 2. General indicators & $\begin{array}{l}\text { - of production, trade, income } \\
\text { situation on current and } \\
\text { fixed prices } \\
\text { - of development }\end{array}$ \\
\hline $\begin{array}{l}\text { 3. Production and } \\
\text { trade }\end{array}$ & $\begin{array}{l}\text { - by commodities in physical units } \\
\text { - by comparison of target and } \\
\text { actual production }\end{array}$ \\
\hline $\begin{array}{l}\text { 4. Per capita } \\
\text { consumption }\end{array}$ & $\begin{array}{l}\text { - by commodities in physical units } \\
\text { - in value }\end{array}$ \\
\hline 5. Investments & $\begin{array}{l}\text { - investments in physical units } \\
\text { - share of rest of economy in } \\
\text { total investments }\end{array}$ \\
\hline 6. Prices & $\begin{array}{l}\text { - producer, consumer, and world } \\
\text { market prices } \\
\text { - price indexes }\end{array}$ \\
\hline $\begin{array}{l}\text { 7. Resources and } \\
\text { production } \\
\text { structure }\end{array}$ & $\begin{array}{l}\text { - in physical units } \\
\text { - structure of gross production } \\
\text { value }\end{array}$ \\
\hline
\end{tabular}

FIGURE 20 Output system of HAM-l. 
Variant 1: we assume a three-year price cycle for corn on the world market.

Variant 2: we assume a two-year price cycle for corn on the world market.

Variant 3: the world market prices of all food and agricultural commodities of HAM-1 change year by year.

Variant 4: changing world market prices of variant 3 are used also as domestic producer prices using an exchange rate of 1 US $\$=30$ Hungarian forints.

Variant 5: as for variant 4 but using an exchange rate of 1 US $\$=60$ Hungarian forints.

Variant 9:40\% of the amortization funds of enterprises in food and agriculture and $50 \%$ of the same funds from the rest of the economy are centralized by the government.

Variant 10: the initial value of $Z_{i}$ (upper limit of the application of advanced technology) is increased.

Variant 11 : as for variant 10 but also allowing a faster full substitution of traditional technologies.

Variant 12: as for the basic variant but assuming that domestic prices remain unchanged for the entire time horizon covered.

Variant 13: as for variant 3 but assuming that domestic prices remain unchanged for the entire time horizon covered.

Variant 14: the required level of self-sufficiency from food and agricultural commodities is only $70 \%$ instead of $100 \%$.

Variant 15: instead of $100 \%$ there is no required level of self-sufficiency in food and agricultural commodities.

As can be seen in the case of variants 1,2 and 3 , the external conditions are modified; in variants 4-15 it is our assumptions about the system that are changed (the model structure is modified).

The impacts of various government policies and external conditions on the development of the whole Hungarian food and agricultural production, as computed by HAM-1, are shown in Figs. 21,22 and 23. As can be seen in Fig. 21, where the results for the basic variant are compared with those for variant 2 , the cyclical change of corn world market prices does not significantly influence the basic trend of production growth. However, the changes in basic government policies - modification of the producer price system or of the desired level of self-sufficiency -- have a significant impact on projected production growth. In Fig. 22 the basic variant is compared with variants 4 and 14. The reduction of the desired level of self-sufficiency (variant 14) makes possible a faster growth in production, allowing a higher level of specialization in the direction of commodities with the most favorable production indicators. The use of world market prices as producer prices (variant 4) slows down the development of production, but it will be shown later that this policy is the most efficient from the point of view of the balance of payments.

In Fig. 23, where the basic variant is compared with variant 12, the impacts of the use of fully fixed domestic prices on the development of food and agriculture can be seen.

The impacts of various government policies on the projected positive balance of payments for food and agriculture and other general performance indicators of the system can also be analyzed. Figure 24 shows the balance of payments situation for three model variants -- the basic variant and variants 4 and 14 . It is obvious that variant 4 is the most favorable from this point of view. However, the results also indicate that a basic modification of the producer price system - a shift to world market prices - may cause serious difficulties within the system during the first few years. The same result is confirmed by variant 5 , 


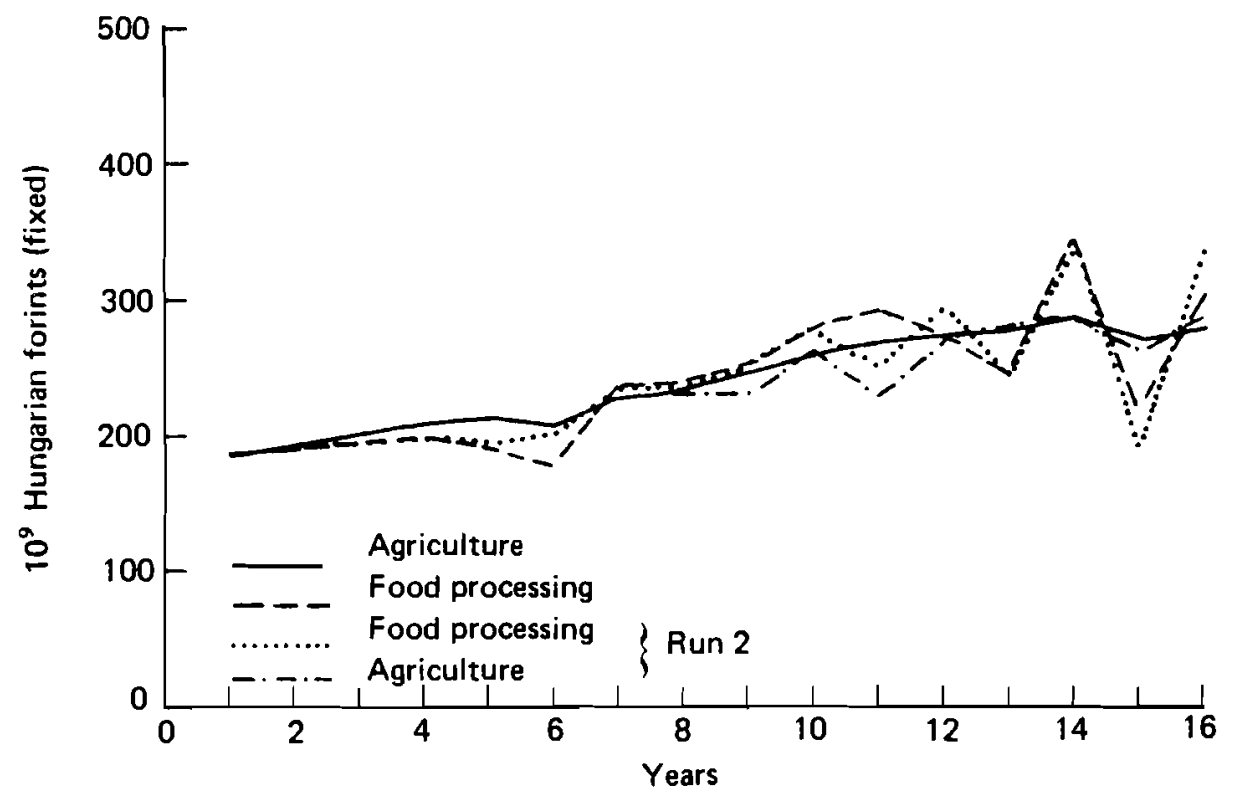

FIGURE 21 Production development projected by HAM-1.

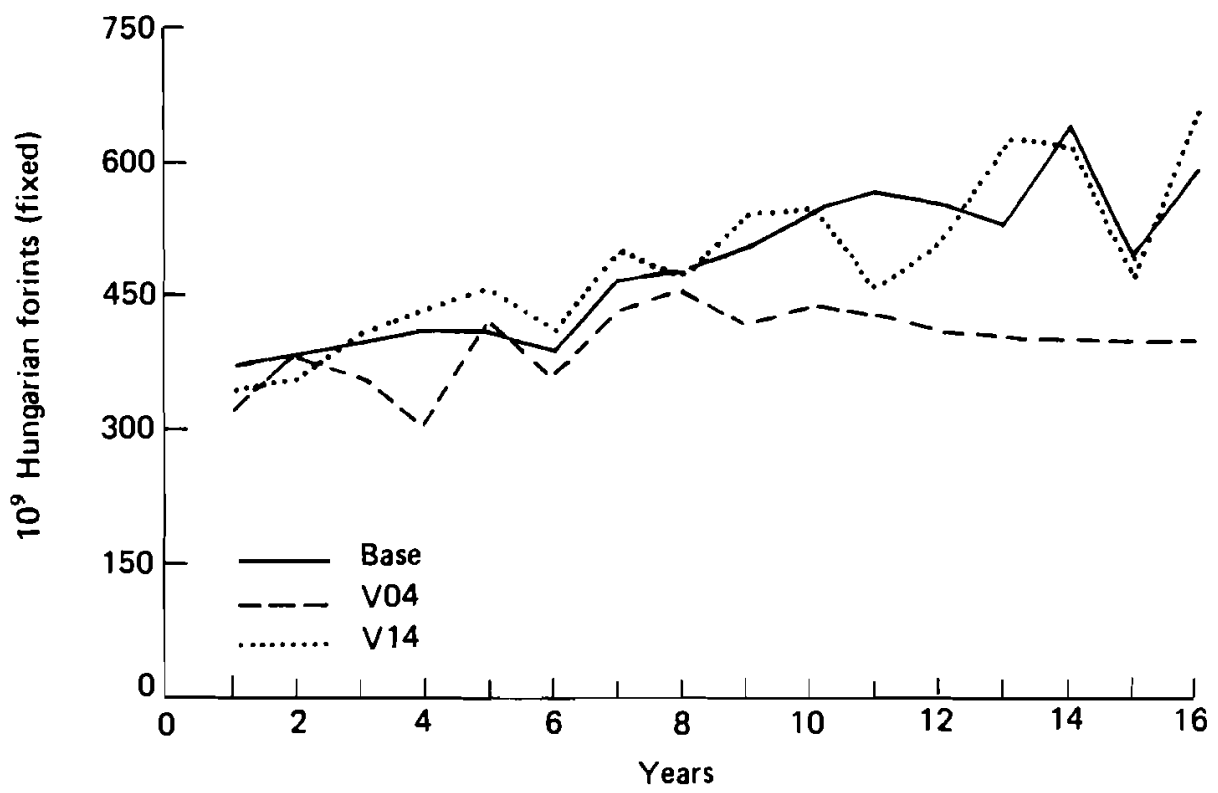

FIGURE 22 GNP in food and agriculture projected by HAM-1. 


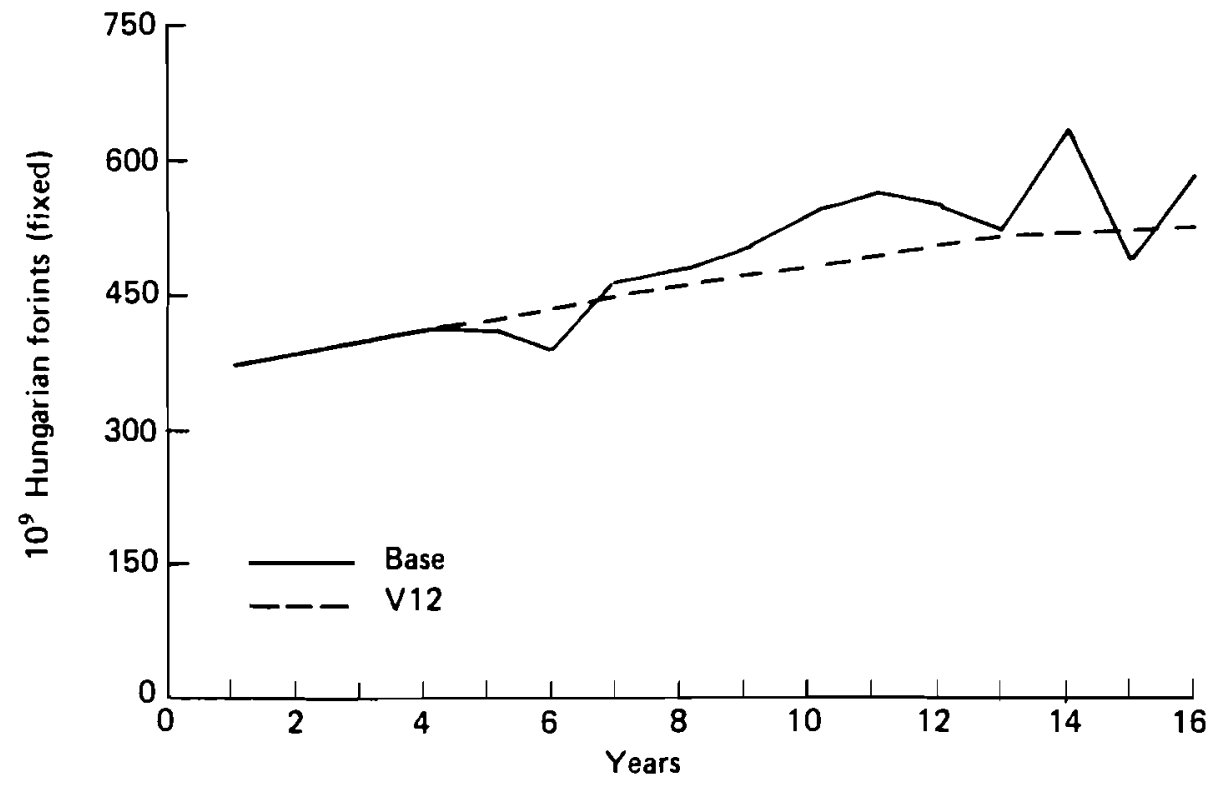

FIGURE 23 GNP in food and agriculture projected by HAM-1.

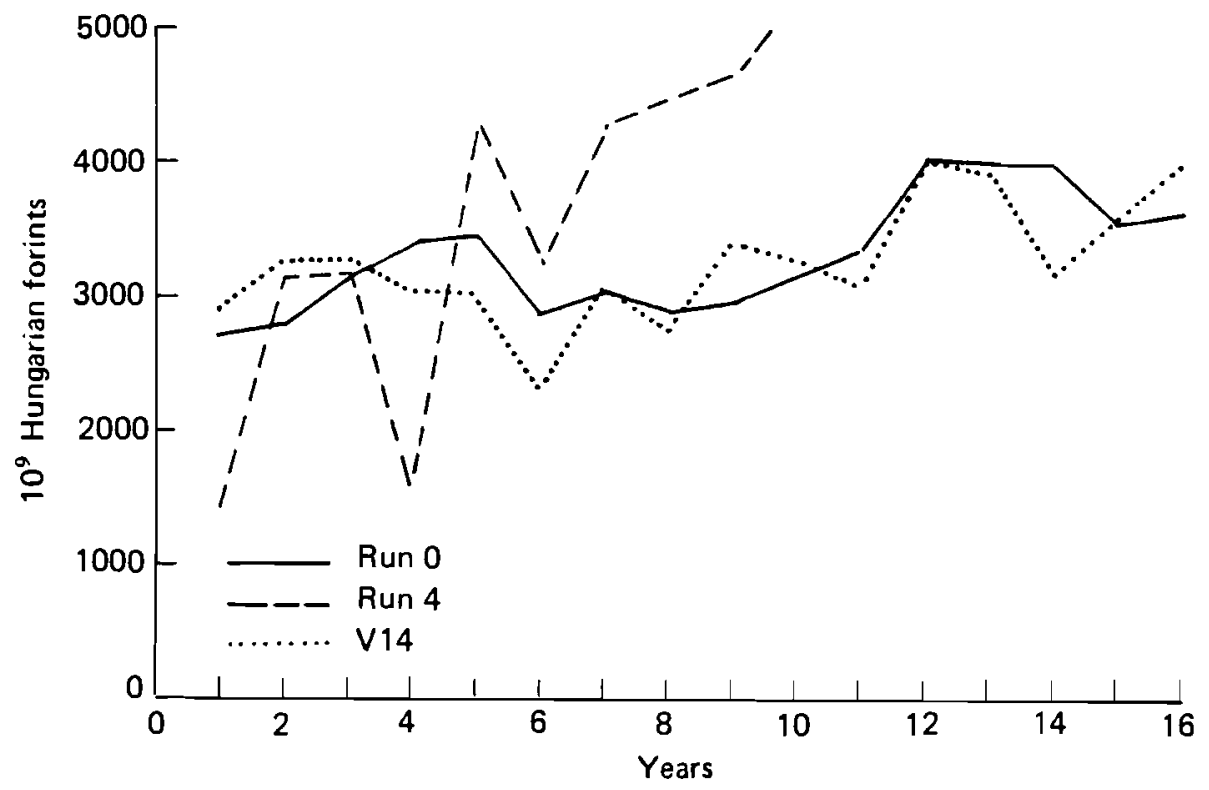

FIGURE 24 Balance of payments projected by HAM-1. 
for which we were unable to obtain a feasible solution, indicating that a drastic producer price change requires the additional modification of other elements of the system. Of course, all other performance indicators of the system can be analyzed in a similar way.

Figure 25 presents a comparison of the present structure with the structure of food and agricultural production at the end of the modeled planning horizon as computed by various model variants. Obviously, the application of different government policies leads to different production structures and the structure is also influenced by changing external conditions, especially world market prices. The main conclusion of Fig. 14 is that a more specialized structure of food and agriculture is desirable from an economic point of view. With various assumptions a large number of possible structural developments can be computed, and by using this information there is no doubt that a model like HAM-1 can be a very useful tool in structural decision making.

The descriptive character of HAM's structure enables the investigation of the efficiency of the whole economic management system as well as of the individual instruments. In Fig. 26 the example of corn shows how actual production is related to government plan targets. Figure 16 illustrates very clearly how world market prices influence the production in the modeled system. There is a two-year lag between world market prices and producers' reactions.

The efficiency of the individual policy instruments of the government may also be analyzed on the basis of HAM. Variants 4, 5, 12 and 13 represent situations in which the domestic pricing mechanism is modified. In Figs. 22,23 and 24 the impacts of these changes on the overall growth and balance of payments situation are clearly discernible.

On the basis of the HAM model structure, a wide range of investigations can be made in connection with the individual commodities. Figure 27 shows the production of corn in relation to world market and producer prices computed by variant 2 . It can be seen that the adjustment mechanism build into HAM-1 is efficient in the case of two-year price cycles (variant 2). Domestic production increases when international market conditions are most favorable and decreases in parallel with world market prices. It is also possible to quantify the extent of price reaction of individual commodities.

The production module of HAM allows us to carry on various investigations in relation to the technological development of food and agriculture. Variants 12 and 13 represent some examples of this kind of investigation. In Fig. 28, the share of advanced technology in total production is shown for the cases of sugar beet and corn for the basic variant. The investment programs associated with various government policies can obviously also be analyzed.

The HAM model structure is suitable for various investigations of consumption by the population. The aggregated commodity coverage of HAM-1 does not allow us to go into detail with regard to the structure of consumption. However, as Fig. 29 shows, the impacts of various government policies on consumption can be analyzed.

The interrelation between indirect and drain effects within the system can also be studied. For example, in Figs. 30 and 31 the wheat and sugarbeet production are shown for the basic variant. The sudden increase in year 6 of the wheat production seems to have been unexpected, especially because the producer price remained unchanged from year 5 to year 6. This can be explained on the basis of comparisons with the developments in sugarbeet production. The production of sugarbeet decreased very sharply from year 5 to year 6 and this crop was partly replaced by the more profitable wheat. This increase is not desired in the national plan; producer prices are thus modified and wheat loses its competitiveness. 

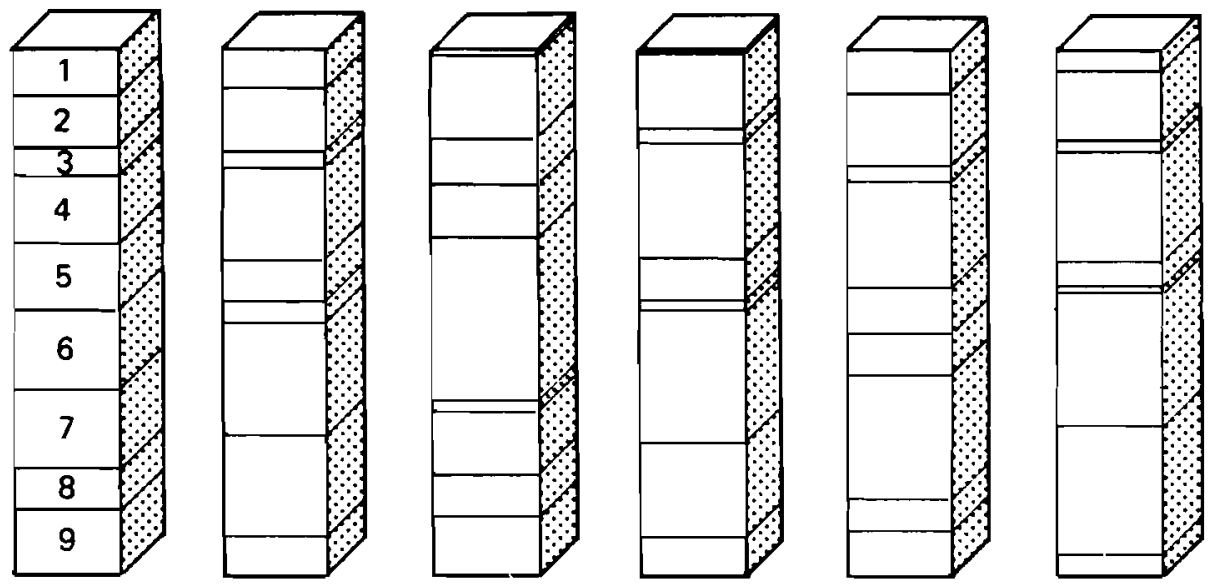

Initial
structure

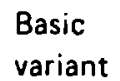

Variant

4
Variant

9
Variant

12
Variant

14

FIGURE 25 Structure of food and agricultural production. 1, sugarbeet; 2, corn; 3, wheat; 4, pigs; 5 , cattle; 6 , sugar; 7 , pork; 8 , processed meat; 9 , beef.

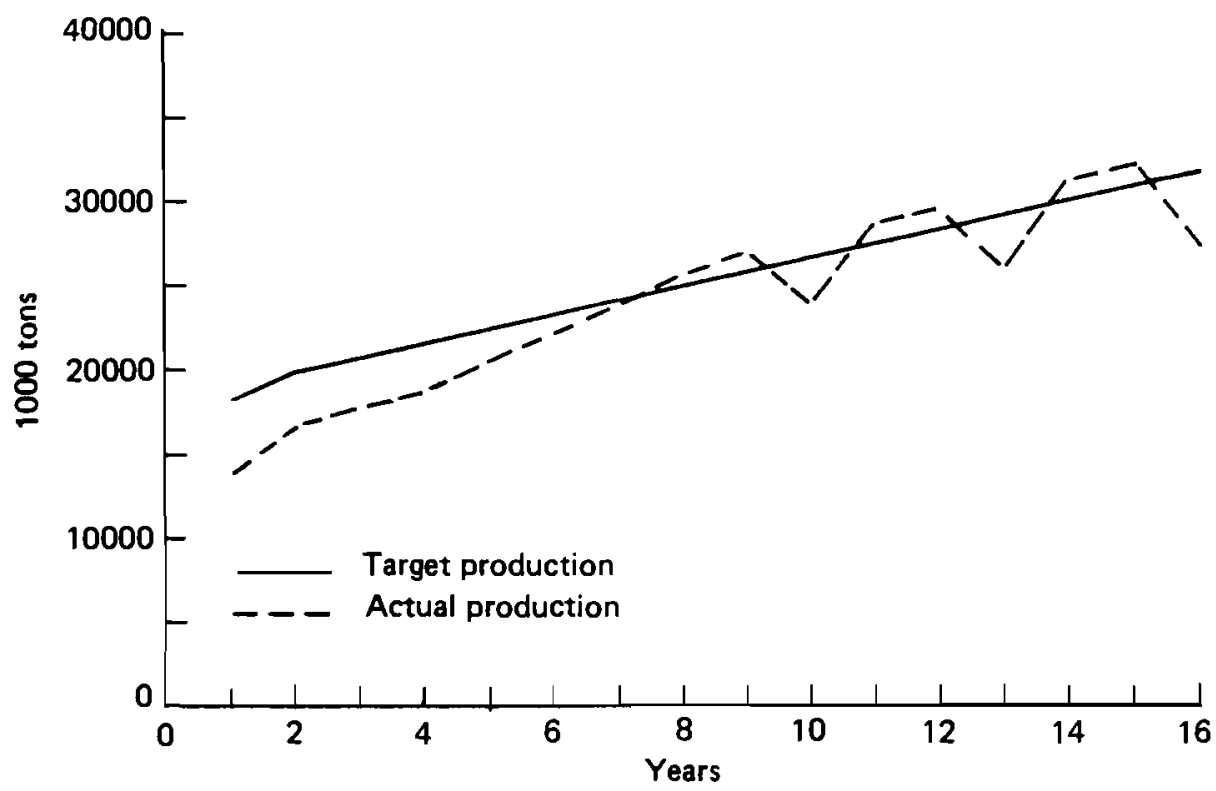

FIGURE 26 Production and trade of corn (run 0). (Results from HAM-1.) 


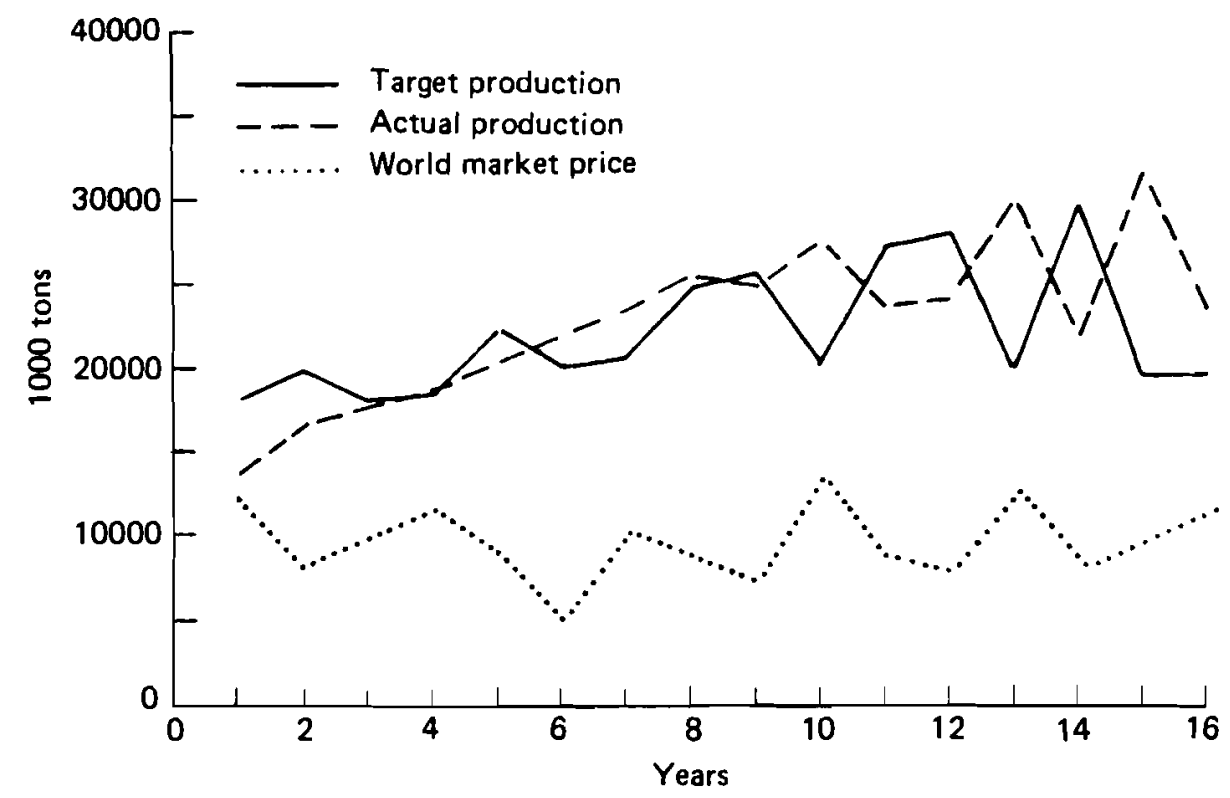

FIGURE 27 Production of corn (run 2). (Results from HAM-1.)

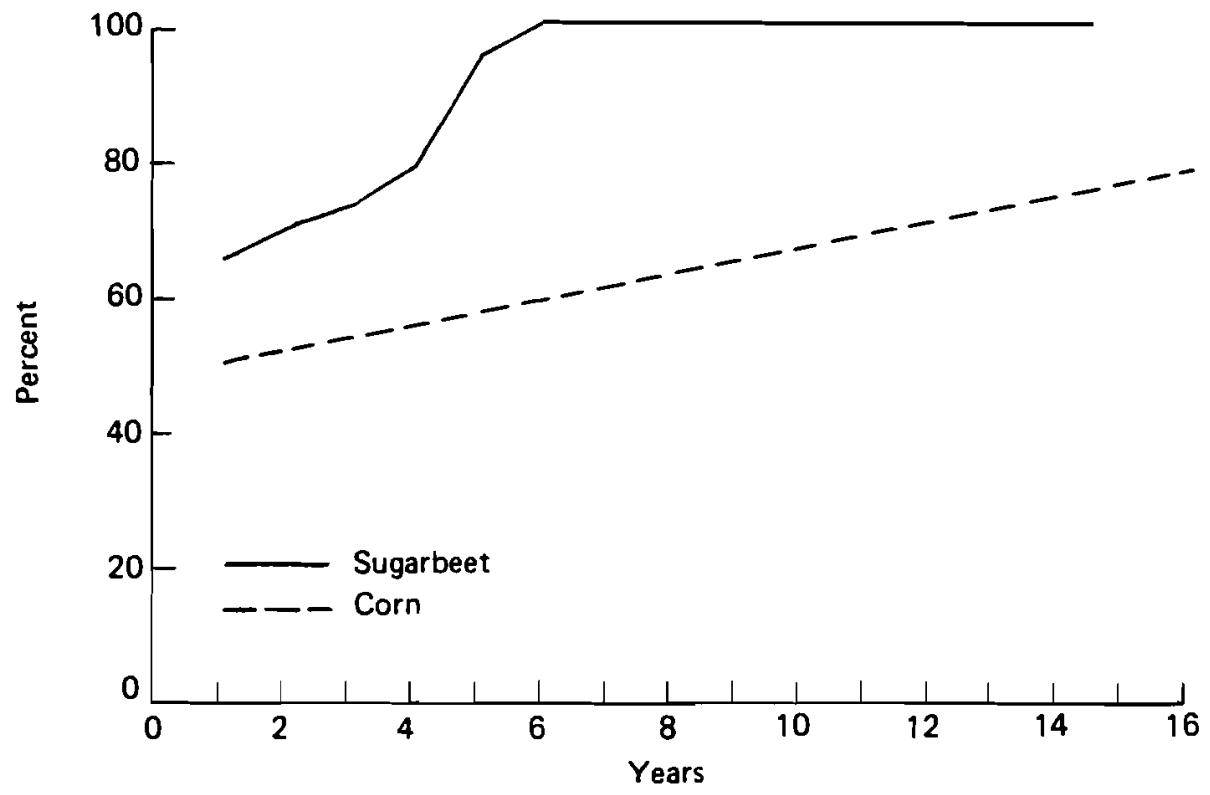

FIGURE 28 Share of advanced technology in total production (run 0). (Results form HAM-1.) 


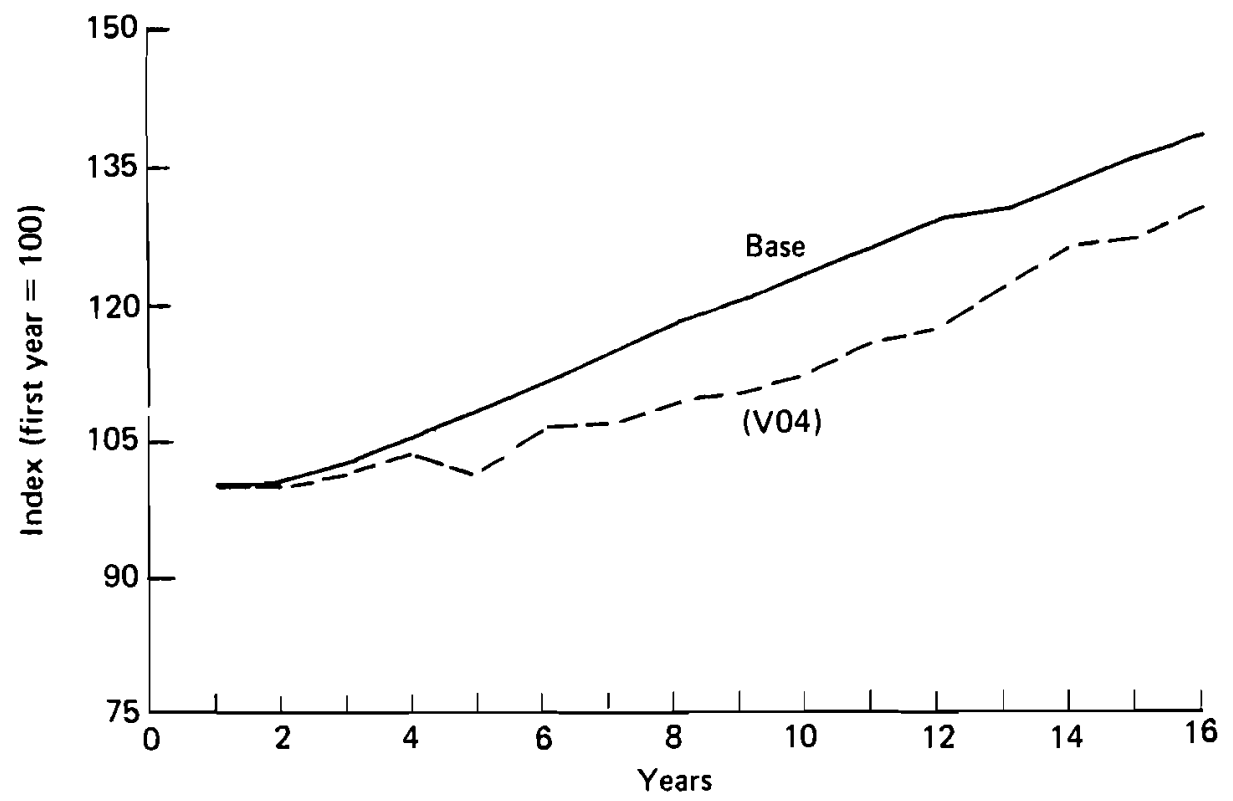

FIGURE 29 Dynamics of consumption projected by HAM-1.

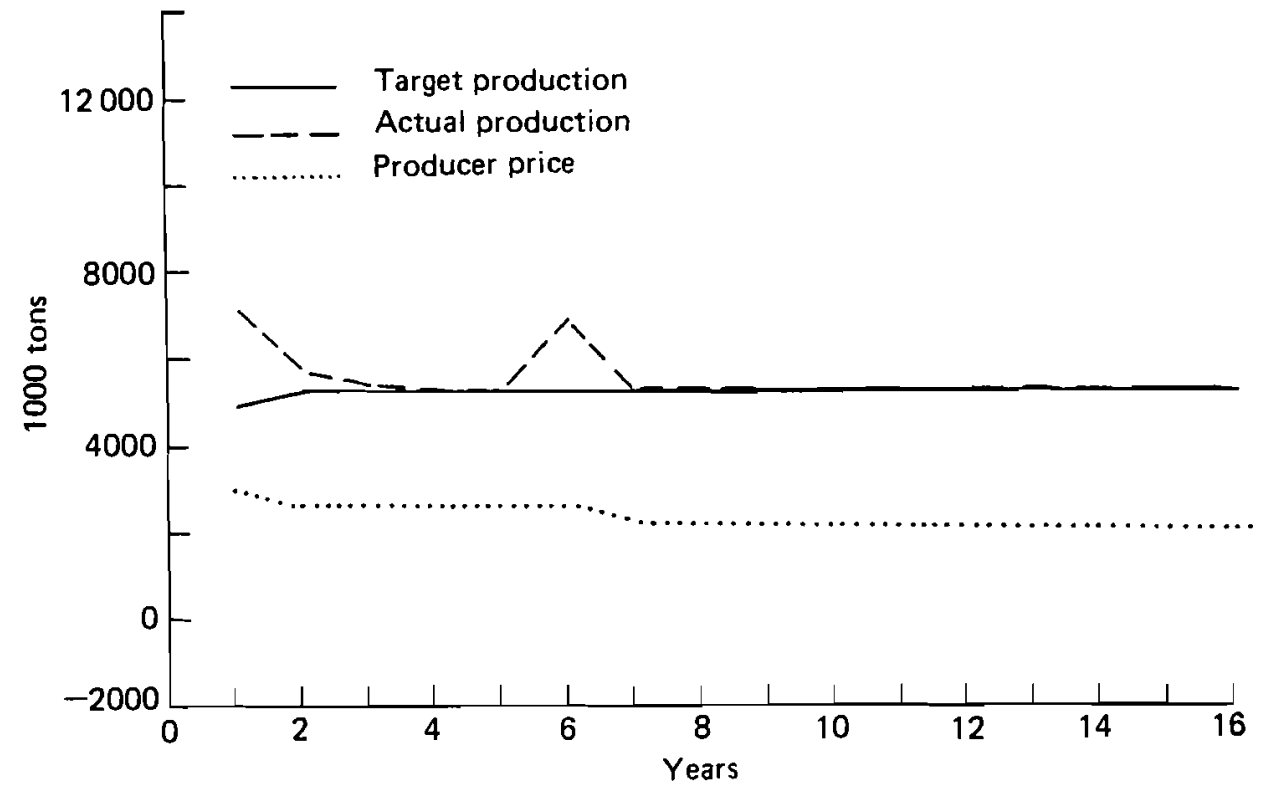

FIGURE, 30 Production of wheat (run 0). (Results from HAM-1.) 


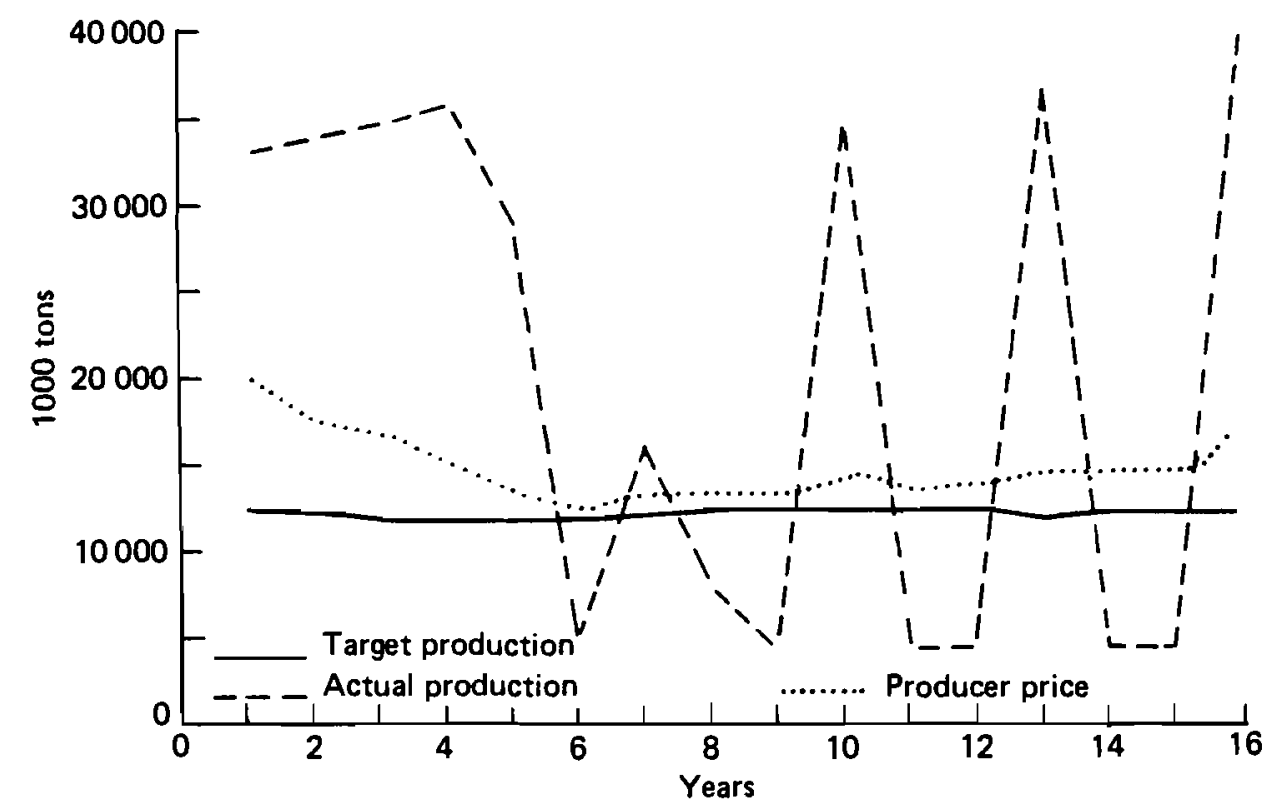

FIGURE 31 Production of sugarbeet (run 0). (Results from HAM-1.)

\section{CONCLUSIONS OF THE HAM-1 EXPERIMENT}

On the whole we felt that the development of HAM-1 was a very useful step in our work towards the final version of HAM. We believe that the results of various runs of HAM-1 were fairly promising. They supported the appropriateness of our approach and they prove that the structure of the HAM model really can contribute to the further development of planning techniques and also to actual decision making. HAM-1 also led us to several methodological conclusions that are very important for the further refinement of the model. The most important ones are as follows.

- A relatively aggregated commodity coverage, as in the case of HAM-1, is also suitable for very valuable investigations, and above a relatively moderate level the disaggregation does not improve the quantity of information generated by macromodels. The commodity aggregation of the final version of HAM, contrary to our original plans, will therefore follow the commodity list of the Food and Agriculture Program at IIASA, having not more than 10-15 additional commodities.

- The GM-A model describing the activity of the government in revising policy instruments is the crucial part of the model from the point of view of further refinement. Further investigations are required to analyze the present practice and in particular the pricing inechanism built into the model has to be revised.

- The use of linear programming in three modules caused less difficulty than we expected. In spite of this, we shall try to substitute the linear programming model 
of agricultural producer decisions with a more sophisticated nonlinear programming approach. The structure of the remaining LPs will also be further developed on the basis of HAM-1.

- More attention has to be given to the dynamic features of agricultural investments. The approach of HAM-1, which is to include these decisions in production models, is not fully satisfactory for some of the investments (e.g. the development of animal husbandry). The application of a separate multistage model for investment decisions seems to be the desired solution.

- The enlargement of the model size requires a well-designed data collection system, but we have to be aware of the fact that owing to insufficient information some of the parameters cannot be estimated by statistical methods. In these cases we intend to use the estimations of experts at various Hungarian research institutions.

- The elaboration of further methods of validation for HAM-1 has to be one of our most important tasks in the future. 
PART THREE

Final Version of the Hungarian Agricultural Model (HAM-2) 


\section{OBJECTIVES, COMMODITY COVERAGE, AND DATA BASE OF HAM-2}

Using the experience gained with HAM-1, a more detailed version of HAM, HAM-2 was developed.

Besides satisfying the common requirements of IIASA's food and agricultural models, HAM-2 was constructed to be useful in investigating major developmental problems in Hungarian food and agriculture. Therefore, in the disaggregation of food and agriculture, the specific requirements of the potential model users were also considered. HAM-2 actually has a more detailed commodity coverage than other F AP models. First, agricultural raw materials and processed food commodities are handled separately according to the two main sectors of food prodcution in the model. Table 14 contains the list of commodities

TABLE 14 Commodity coverage of HAM-2.

\begin{tabular}{ll}
\hline Agriculture & Food processing \\
\hline 1 Food grains & 22 Flour \\
2 Coarse grains except corn & 23 Bran \\
3 Corn & 24 Vegetable oils \\
4 Oil seeds & 25 Oil cake \\
5 Sugarbeet & 26 Beef \\
6 Green fodders & 27 Pork \\
7 Potatoes & 28 Lamb \\
8 Vegetables & 29 Slaughtering wastes/offal \\
9 Other field crops & 30 Processed meat (high moisture content) \\
10 Fruits & 31 Processed meat (low moisture content, \\
11 Grapes & smoked, canned) \\
12 Beef cattle & 32 Poultry meat (processed) \\
13 Dairy cattle & 33 Processed eggs \\
14 Pigs & 34 Slaughtering wastes/offal (poultry) \\
15 Sheep meat & 35 Dairy products \\
16 Wool & 36 Milk powder \\
17 Poultry meat & 37 Protein feeds \\
18 Eggs & 38 Feed mix \\
19 Other animal husbandry & 39 Sugar \\
20 Alfalfa for drying & 40 Canned fruits \\
21 Additional farm activities & 41 Canned vegetables \\
& 42 Wine \\
& 43 Other processed foods \\
& 44 Coffee \\
& 45 Tea, cocoa \\
& Rest of the Economy \\
& $46 n$th commodity \\
& \\
&
\end{tabular}

considered in HAM-2. Hungarian agricultural production is covered by 21 commodities. Most of the agricultural commodities represent a group of products (e.g. food grains or fruits) and under "other field crops" and "other animal husbandry" the rest of the production not individually represented is aggregated. The commodity "additional farm activities" such as construction and servicing done by the farms. These activities do not belong 
naturally with agriculture, but in the Hungarian situation they are so interlinked with agriculture that their aggregation with the rest of the economy would greatly complicate the modeling of agriculture. (They are based on the labor force and resources of agriculture, the income generated by these activities being mostly invested in agriculture.) The commodity coverage of the household and private agriculture module (P-1) is somewhat narrower than that of the socialist agriculture module (P-2).

The 24 processed food commodities in HAM-2 express the present structure of the Hungarian food processing industry. In the selection of commodities the commodity classification of the Hungarian National Planning Bureau was used as the major guideline. (Table 14 lists the processed commodities.) Of the 24 commodities, 22 are related to raw materials domestically produced. Coffee, tea, and cocoa are imported as raw materials and are further processed, mainly only packed.

The 46th commodity is related to the remainder of the economy, aggregating all the rest of the economy including production and services.

The data base of HAM-2 includes various sources. Statistical data availabie from the Central Statistical Bureau and from the Ministry of Food and Agriculture were primarily utilized. We relied on UN Food and Agriculture Organization data tapes for international prices. The trends of biological and technological development, the overall targets for the growth of the economy, and other previous government decisions constraining agricultural development were supplied by experts from the National Planning Bureau and the Research Institute for Agricultural Economics. In estimating technological coefficients the major indicators of existing production systems were considered. Obviously, the level of aggregation in the Production module does not allow us to be very detailed in respect of production technologies. The main data base for parameters in production models was from the annual statistical survey of the Research Institute for Agricultural Economics and the Center for Statistical and Economic Analysis at the Ministry of Food and Agriculture on inputs and expenses of various commodities. Estimates from the Farm Machinery Research Institute were also considered. The algorithm for revising government policy instruments was developed on the basis of interviews with high level officials and information supplied by the Ministry of Finance.

\section{DESCRIPTION OF HAM-2}

HAM-2 describes Hungarian food and agriculture in a rather disaggregated way. HAM-2 is practically structured according to our general model outline discussed in Part 1. In comparison with the general description, only one simplification is applied: random effects of weather on agricultural production are not directly included. Otherwise, HAM2 is formulated as shown in Fig. 1.

\subsection{Government Economic Planning Submodel}

According to the general model structure, the GM-P subinodel of HAM-2 incorporates four modules. The most important element of GM-P block is the third module, which is actually a linear programming model to fix government targets for food and agriculture. 
In the GM-P-3 module of HAM-2 commodities are considered according to Table 3. Production sectors are not treated separately. The LP model actually consists of 75 variables and 63 constraints. In addition to variables representing the production of various commodities, 29 variables are related to exports and 11 to imports of food and agricultural commodities. Of the 63 constraints, 26 are connected with resources, 34 are commodity balances and 3 express overall economic requirements for food and agriculture (e.g. lower bounds for the gross national product of food and agriculture). The maximum efficiency of agricultural foreign trade was considered as a major objective of central planners and this is described by the objective function. The impacts of an alternative objective function, namely the maximization of foreign exchange earnings from food and agriculture, is also investigated. Table 15 gives an overview of the structure of the linear programming model built into the GM-P-3 module of HAM-2.

\subsection{Production Block}

The first module of the Production Block is devoted to the private and household sector of Hungarian agriculture. The parameters of supply functions used to describe the behavior of this sector have been estimated based on the time series of 1964-76. Table 16 gives full information on crops and animal products considered in module P-1 (eleven crop and eight animal products). The suitability of parameters of the supply function was verified by statistical methods.

The calculations related to expenses of household and private agricultural production are based on the following:*

$$
\begin{aligned}
& H D E S^{(t)}=\alpha_{9} H D_{1}^{(t)} I K T_{1}^{(t)}+\alpha_{12} H D_{2}^{(t)} I K T_{2}^{(t)}+\alpha_{15} H D_{3}^{(t)} I K T_{3}^{(t)}
\end{aligned}
$$

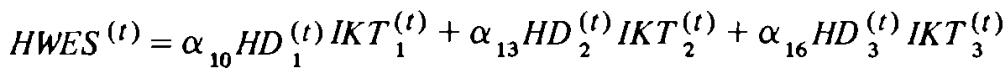

$$
\begin{aligned}
& H M I^{(t)}=\alpha_{11} H D_{1}^{(t)} I K T_{1}^{(t)}+\alpha_{14} H D_{2}^{(t)} I K T_{2}^{(t)}+\alpha_{17} H D_{3}^{(t)} I K T_{3}^{(t)} \\
& I K T O^{(t)}=H D_{1}^{(t)} I K T_{1}^{(t)}+H D_{2}^{(t)} I K T_{2}^{(t)}+H D_{3}^{(t)} I K T_{3}^{(t)}
\end{aligned}
$$

Expenses of material inputs:

$$
\begin{aligned}
M E H I^{(t)}= & \operatorname{PMUTR}^{(t)} H D_{10}^{(t)}+H D_{11}^{(t)} \\
M E H^{(t)}= & I K T O^{(t)}+\left(H D_{6}^{(t)}+H B F_{6}^{(t)}\right) P_{6}^{\mathrm{pr}(t)}+p_{3}^{\mathrm{pr}(t)} H B F_{3}^{(t)}+p_{38}^{\mathrm{pr}(t)} H D_{7}^{(t)} \\
& +p_{8}^{\mathrm{pr}(t)} H D_{1}^{(t)}+p_{7}^{\mathrm{pr}(t)} H D_{9}^{(t)}+p_{11}^{\mathrm{pr}(t)} H B F_{11}^{(t)}+p_{2}^{\mathrm{pr}(t)} H D_{4}^{(t)} \\
& +p_{3}^{\mathrm{pr}(t)} H D_{5}^{(t)}+M E H I^{(t)}
\end{aligned}
$$

*The symbols are explained in the Appendix. 


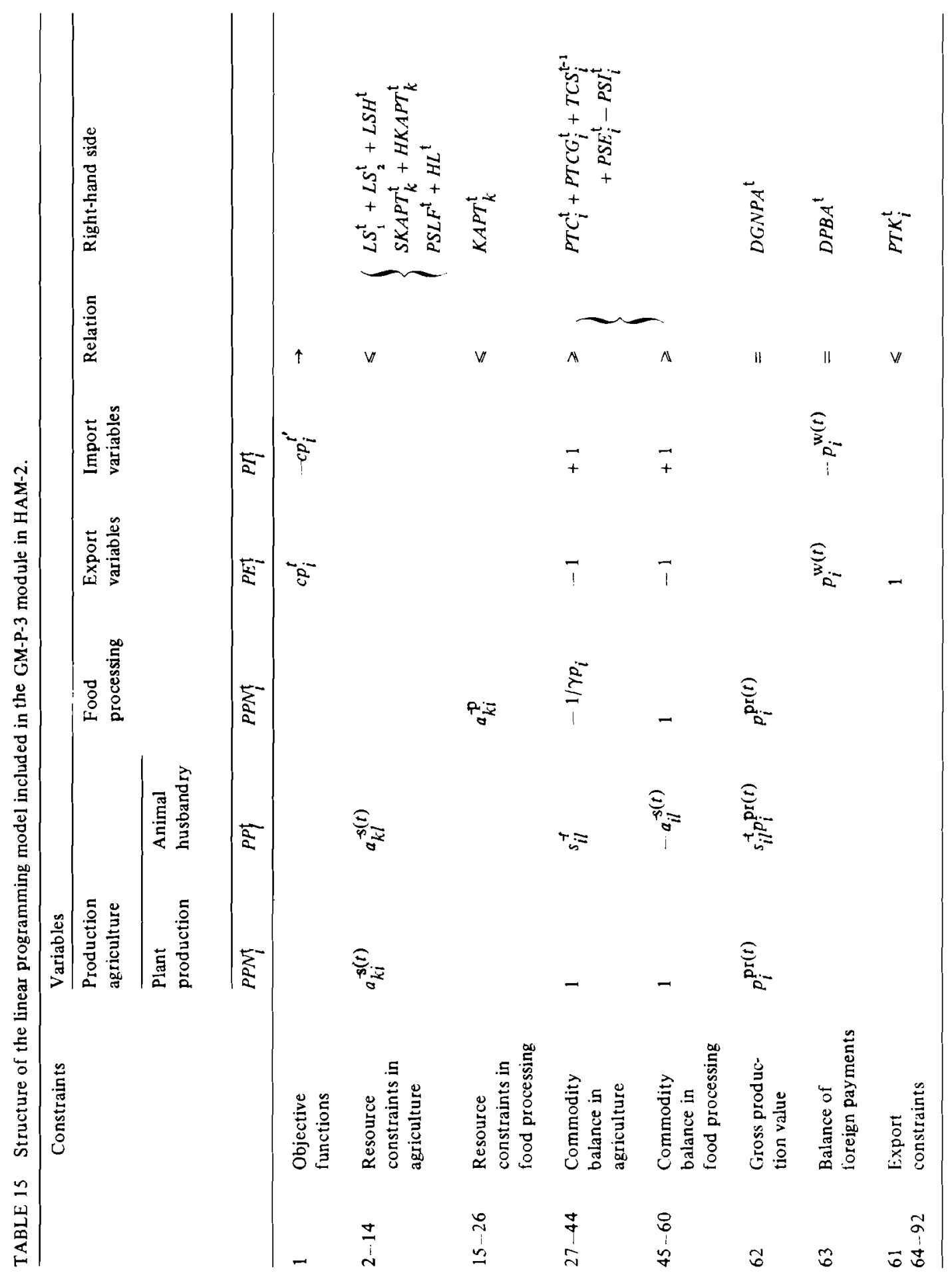


TABLE 16 Variables related to production and their symbols in the production block of HAM-2.

\begin{tabular}{|c|c|c|c|c|c|}
\hline \multirow[t]{2}{*}{ Branch product } & $\begin{array}{l}\text { Technological } \\
\text { alternative } \\
\text { considered }\end{array}$ & $\begin{array}{l}\text { Scale of } \\
\text { the crop }\end{array}$ & $\begin{array}{l}\text { Total } \\
\text { production }\end{array}$ & $\begin{array}{l}\text { Output } \\
\text { from } \\
\text { sector }\end{array}$ & $\begin{array}{l}\text { Household } \\
\text { production }\end{array}$ \\
\hline & \multicolumn{2}{|c|}{ Value or physical unit } & \multicolumn{2}{|c|}{ Tonnes, head, or value } & \\
\hline \multicolumn{6}{|l|}{ Agriculture } \\
\hline $\begin{array}{l}\text { Feed grain } \\
\text { production }\end{array}$ & $\begin{array}{l}S P T 011 \\
S P T 012\end{array}$ & $S P 01$ & & & \\
\hline 1 Feed grain & & & $S P N 01$ & $S P A 01$ & $H P 01$ \\
\hline $\begin{array}{l}\text { Coarse grain } \\
\text { production }\end{array}$ & $\begin{array}{l}S P T 021 \\
S P T 022\end{array}$ & $S P 02$ & & & \\
\hline 2 Coarse grain & & & $S P N 02$ & $S P A 02$ & \\
\hline Corn production & $\begin{array}{l}\text { SPT031 } \\
\text { SPT032 }\end{array}$ & $S P 03$ & & & \\
\hline 3 Corn & & & $S P N 03$ & $S P A 03$ & HP03 \\
\hline $\begin{array}{l}\text { Oil crop } \\
\text { production }\end{array}$ & $\begin{array}{l}S P T 041 \\
S P T 042\end{array}$ & $S P 04$ & & & \\
\hline 4 Oil seeds & & & SPN04 & $S P A 04$ & \\
\hline $\begin{array}{l}\text { Sugarbeet } \\
\text { production }\end{array}$ & $\begin{array}{l}\text { SPT051 } \\
S P T 052 \\
S P T 053\end{array}$ & $S P 05$ & & & \\
\hline 5 Sugarbeet & & & SPN05 & $S P A 05$ & \\
\hline $\begin{array}{l}\text { Green feed } \\
\text { production }\end{array}$ & $\begin{array}{l}S P T 061 \\
S P T 062 \\
S P T 063 \\
S P T 064 \\
S P T 065 \\
S P T 066\end{array}$ & SP06 & & & \\
\hline 6 Green fodder & & & SPN06 & $S P A 06$ & HP06 \\
\hline Potato production & $\begin{array}{l}S P T 071 \\
S P T 072 \\
S P T 073\end{array}$ & $S P 07$ & & & \\
\hline 7 Potatoes & & & SPN07 & $S P A 07$ & HP07 \\
\hline $\begin{array}{l}\text { Vegetable } \\
\text { production }\end{array}$ & $\begin{array}{l}S P T 081 \\
S P T 082\end{array}$ & $S P 08$ & & & \\
\hline 8 Vegetables & & & $S P N 08$ & $S P A 08$ & HP08 \\
\hline $\begin{array}{l}\text { Other field crop } \\
\text { production }\end{array}$ & $\begin{array}{l}S P T 091 \\
S P T 092\end{array}$ & $S P 09$ & & & \\
\hline 9 Other field crops & & & SPN09 & $S P A 09$ & HP09 \\
\hline Fruit production & $\begin{array}{l}S P T 101 \\
S P T 102\end{array}$ & $S P 10$ & & & \\
\hline 10 Fruits & & & $S P N 10$ & $S P A 11$ & $H P 11$ \\
\hline Grape production & $\begin{array}{l}S P T 111 \\
S P T 112\end{array}$ & $S P 11$ & & & \\
\hline
\end{tabular}


TABLE 16 (continued)

\begin{tabular}{|c|c|c|c|c|c|}
\hline \multirow[t]{2}{*}{ Branch product } & $\begin{array}{l}\text { Technological } \\
\text { alternative } \\
\text { considered }\end{array}$ & $\begin{array}{l}\text { Scale of } \\
\text { the crop }\end{array}$ & $\begin{array}{l}\text { Total } \\
\text { production }\end{array}$ & $\begin{array}{l}\text { Output } \\
\text { from } \\
\text { sector }\end{array}$ & \multirow[t]{2}{*}{$\begin{array}{l}\text { Household } \\
\text { production }\end{array}$} \\
\hline & \multicolumn{2}{|c|}{ Value or physical unit } & \multicolumn{2}{|c|}{ Tonnes, head, or value } & \\
\hline 11 Grapes & & & $S P N 11$ & $S P A 11$ & $H P 11$ \\
\hline Cattle production & $\begin{array}{l}S P T 121 \\
S P T 122 \\
S P T 123 \\
S P T 124\end{array}$ & $S P 12$ & & & \\
\hline 12 Beef & & & $S P N 12$ & $S P A 12$ & $H P 12$ \\
\hline 13 Milk & & & SPN13 & $S P A 13$ & $H P 13$ \\
\hline Pig production & $\begin{array}{l}S P T 141 \\
S P T 142\end{array}$ & $S P 14$ & & & \\
\hline 14 Pork & & & SPN14 & $S P A 14$ & $H P 14$ \\
\hline Sheep production & $\begin{array}{l}S P T 151 \\
S P T 152 \\
S P T 153\end{array}$ & $S P 15$ & & & \\
\hline 15 Lamb & & & $S P N 15$ & $S P A 15$ & $H P 15$ \\
\hline 16 Wool & & & $S P N 16$ & $S P A 16$ & $H P 16$ \\
\hline Poultry production & $\begin{array}{l}S P T 171 \\
S P T 172 \\
S P T 173 \\
S P T 174\end{array}$ & $S P 17$ & & & \\
\hline 17 Poultry meat & & & $S P N 17$ & $S P A 17$ & HP17 \\
\hline 18 Eggs & & & SPN18 & $S P A 18$ & $H P 18$ \\
\hline $\begin{array}{l}\text { Other animal } \\
\text { husbandry }\end{array}$ & $\begin{array}{l}S P T 191 \\
S P T 192\end{array}$ & $S P 19$ & & & \\
\hline 19 Other animal products & & & SPN19 & $S P A 19$ & HP19 \\
\hline Feed dehydrating & $S P T 201$ & $S P 20$ & & & \\
\hline 20 Alfalfa pellets & & & SPN20 & $S P A 20$ & \\
\hline Additional activities & $S P T 211$ & $S P 21$ & & & \\
\hline $\begin{array}{l}21 \text { Service of additional } \\
\text { activities }\end{array}$ & & & $S P N 21$ & $S P A 21$ & \\
\hline Food processing. & & & & & \\
\hline Milling industry & & $F P 22$ & & & \\
\hline 22 Flour & & & $F P N 22$ & FPA22 & \\
\hline 23 Bran & & & FPN23 & FPA23 & \\
\hline Oil seed processing & & $F P 24$ & & & \\
\hline 24 Vegetable oil & & & $F P N 24$ & $F P A 24$ & \\
\hline 25 Oil cake & & & FPN25 & FPA 25 & \\
\hline Meat industry & & $F P 26$ & & & \\
\hline
\end{tabular}


TABLE 16 (continued)

\begin{tabular}{|c|c|c|c|c|c|}
\hline \multirow[t]{2}{*}{ Branch product } & $\begin{array}{l}\text { Technological } \\
\text { alternative } \\
\text { considered }\end{array}$ & $\begin{array}{l}\text { Scale of } \\
\text { the crop }\end{array}$ & $\begin{array}{l}\text { Total } \\
\text { production }\end{array}$ & $\begin{array}{l}\text { Output } \\
\text { from } \\
\text { sector }\end{array}$ & $\begin{array}{l}\text { Household } \\
\text { production }\end{array}$ \\
\hline & \multicolumn{2}{|c|}{ Value or physical unit } & \multicolumn{2}{|c|}{ Tonnes, head, or value } & \\
\hline 26 Beef & & & FPN26 & FPA 26 & \\
\hline 27 Pork & & & FPN27 & FPA27 & \\
\hline 28 Lamb & & & FPN28 & $F P A 28$ & \\
\hline $\begin{array}{l}29 \text { Slaughtering } \\
\text { wastes, offal }\end{array}$ & & & FPN29 & $F P A 29$ & \\
\hline $\begin{array}{l}30 \text { Processed meat, high } \\
\text { moisture content }\end{array}$ & & & $F P N 30$ & $F P A 30$ & \\
\hline $\begin{array}{l}31 \text { Processed meat, } \\
\text { smoked }\end{array}$ & & & FPN31 & FPA31 & \\
\hline Poultry industry & & $F P 32$ & & & \\
\hline $\begin{array}{l}32 \text { Processed } \\
\text { poultry meat }\end{array}$ & & & FPN32 & $F P A 32$ & \\
\hline 33 Processed eggs & & & FPN33 & $F P A 33$ & \\
\hline $\begin{array}{l}34 \text { Slaughtering } \\
\text { wastes (poultry) }\end{array}$ & & & FPN34 & $F P A 34$ & \\
\hline Dairy industry & & FP35 & & & \\
\hline 35 Dairy products & & & FPN35 & $F P A 35$ & \\
\hline 36 Milk powder & & & FPN36 & $F P A 36$ & \\
\hline Protein feed production & & FP37 & & & \\
\hline 37 Protein feeds & & & FPN37 & FPA37 & \\
\hline 38 Feed mix & & & FPN38 & $F P A 38$ & \\
\hline Sugar industry & & FP39 & & & \\
\hline 39 Sugar & & & FPN39 & $F P A 39$ & \\
\hline Canning industry & & $F P 40$ & & & \\
\hline 40 Canned fruits & & & FPN40 & $F P A 40$ & \\
\hline 41 Canned vegetables & & & FPN41 & $F P A 41$ & \\
\hline Wine ind ustry & & $F P 42$ & & & \\
\hline 42 Wine & & & $F P N 42$ & $F P A 42$ & \\
\hline Other Food Processing & & $F P 43$ & & & \\
\hline $\begin{array}{l}43 \text { Other processed } \\
\text { food }\end{array}$ & & & $F P N 43$ & $F P A 43$ & \\
\hline
\end{tabular}

In HAM-2 the production activities of state and cooperative farms are represented by a relatively wide range of variables, as shown in Table 16 . The available resources and resource utilization are considered using 19 constraints. Product utilization is described by 21 equations. In the P- 2 module the linear programming model includes at least two 


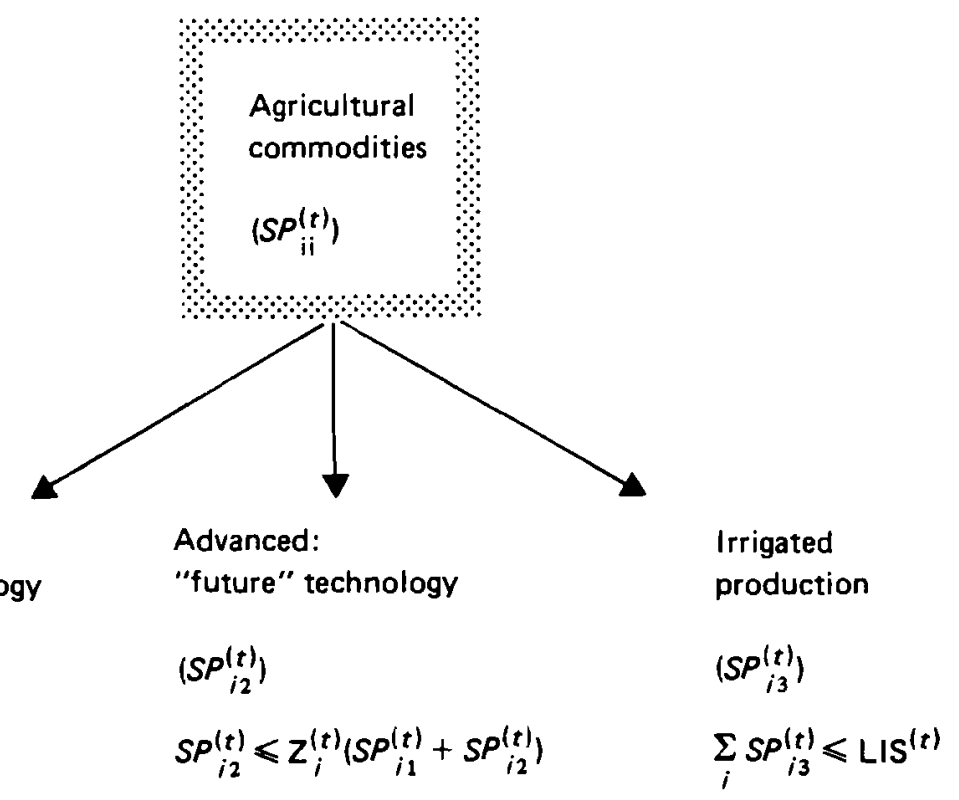

FIGURE 32 Technological change in HAM.

production technologies for each commodity (see Fig. 32). Relatively wide ranges of resources and input factors are considered, as shown in Table 17, and changes in production structure are constrained by upper and lower bounds that are partly updated annually and partly given exogenously.

As has been mentioned, HAM-2 does not include module P-3. Methods for considering weather conditions have not yet been developed within the Food and Agriculture Program. The routines applied, if necessary, to distribute products between processing and consumption are included in module P-4.

In module P-4 of HAM-2 the production program of the food processing industry is calculated according to the major branches of the industry. This procedure is based on the following equations.

(a) Milling industry*:

$$
\begin{aligned}
& F E L H_{1}^{(t)}=\left(1 / \gamma_{1}\right)\left(P T C_{22}^{(t)}+P T C G_{22}^{(t)}+\gamma_{28} F P N_{43}^{(t-1)}\right) \\
& F P N_{22}^{(t)}=P T C_{22}^{(t)}+P T C G_{22}^{(t)}+\gamma_{28} F P N_{43}^{(t-1)} \\
& F P N_{23}^{(t)}=\gamma_{2} F E L H_{1}^{(t)} \\
& K A P I G^{(t)}=F E L H_{1}^{(t)}
\end{aligned}
$$

The symbols are explained in the Appendix. 
TABLE 17 Production resources and inputs in HAM.

\begin{tabular}{lll}
\hline Crop production & Animal husbandry & Food processing \\
\hline $\begin{array}{l}\text { Land } \\
\text { - Plowland }\end{array}$ & $\begin{array}{l}\text { Buildings } \\
\text { - Pastures and meadows }\end{array}$ & Processing facilities \\
- Irrigated land & - Other buildings and & Labor \\
- Plantations & equipment & Materials \\
Machinery & Labor & - Agricultural raw \\
- Tractors & materials \\
- Other equipment & Materials & - Industrial materials \\
Buildings & - Feeds & and services \\
& - Other agricultural & \\
Labor & materials & \\
Materials and services & - Industrial materials & \\
- Fertilizer & and services & \\
- Pesticides & & \\
- Other industrial materials & & \\
and non-agricultural services & & \\
- Materials of agricultural origin & &
\end{tabular}

(b) Vegetable oil processing:

$$
\begin{aligned}
& F E L H_{4}^{(t)}=S P N_{4}^{(t)}-P E_{4}^{(t)} \\
& F P N_{24}^{(t)}=\gamma_{3} F E L H_{4}^{(t)} \\
& F P N_{25}^{(t)}=\gamma_{4} F E L H_{4}^{(t)} \\
& K A P I G_{2}^{(t)}=F E L H_{4}^{(t)}
\end{aligned}
$$

(c) The meat industry is modeled according to two levels of processing. Firstly slaughtering and primary meat processing is described:

$$
\begin{aligned}
& F E L H_{12}^{(t)}=S P N_{12}^{(t)}+H P_{12}^{(t)}-P E_{12}^{(t)} \\
& F P N_{26}^{(t)}=\gamma_{5} F E L H_{12}^{(t)} \\
& F E L H_{14}^{(t)}=S P N_{14}^{(t)}+H P_{14}^{(t)}-T C S_{14}^{(t)}-P E_{14}^{(t)} \\
& F P N_{27}^{(t)}=\gamma_{6} F E L H_{14}^{(t)} \\
& F E L H_{15}^{(t)}=S P N_{15}^{(t)}+H P_{15}^{(t)}-P E_{15}^{(t)} \\
& F P N_{28}^{(t)}=\gamma_{7} F E L H_{15}^{(t)}
\end{aligned}
$$




$$
\begin{aligned}
& K A P I G_{3}^{(t)}=F E L H_{12}^{(t)}+F E L H_{14}^{(t)}+F E L H_{15}^{(t)} \\
& F P N_{29}^{(t)}=\gamma_{8} F E L H_{12}^{(t)}+\gamma_{9} F E L H_{14}^{(t)}+\gamma_{10} F E L H_{15}^{(t)}
\end{aligned}
$$

Then further processing of meat (production of sausages, salami etc.) is threated:

$$
\begin{aligned}
& F E I H_{26}^{(t)}=\alpha_{2} F P N_{26}^{(t)} \\
& F E L H_{27}^{(t)}=F P N_{27}^{(t)}-P T C_{27}^{(t)}-P E_{27}^{(t)}-P T C G_{27}^{(t)} \\
& F P N_{30}^{(t)}=\gamma_{11} F E L H_{26}^{(t)}+\gamma_{12} \alpha_{3} F E L H_{27}^{(t)} \\
& F P N_{31}^{(t)}=\gamma_{13}\left(1-\alpha_{3}\right) F E L H_{27}^{(t)} \\
& F E L H_{17}^{(t)}=S P N_{17}^{(t)}+H P_{17}^{(t)}-T C S_{17}^{(t)}-P E_{17}^{(t)} \\
& F P N_{32}^{(t)}=\gamma_{14} F E L H_{17}^{(t)} \\
& F E L H_{18}^{(t)}=S P A_{18}^{(t)}+H P_{18}^{(t)}-T C S_{18}^{(t)} \\
& F P N_{33}^{(t)}=\gamma_{15} F E L H_{18}^{(t)} \\
& F P N_{29}^{(t)}=\gamma_{16} F E L H_{17}^{(t)}+F P N_{29}^{(t)} \\
& \operatorname{KAPIG}_{4}^{(t)}=F P N_{30}^{(t)}+F P N_{31}^{(t)}
\end{aligned}
$$

The wastes in meat processing are determined as follows:

$$
\begin{aligned}
K A P I G_{5}^{(t)} & =F P N_{29}^{(t)} \\
K A P I G_{16}^{(t)} & =F E L H_{17}^{(t)}
\end{aligned}
$$

If

$$
K A P T_{5}^{(t)}<K A P I G_{5}^{(t)}
$$

then

$$
\begin{aligned}
& F P N_{34}^{(t)}=\gamma_{16} K A P T_{5}^{(t)} \\
& F E L H_{29}^{(t)}=K A P T_{5}^{(t)}
\end{aligned}
$$

If

$$
K A P T_{5}^{(t)} \geqslant K A P I G_{5}^{(t)}
$$

then 


$$
\begin{aligned}
& F P N_{34}^{(t)}=\gamma_{16} F P N_{29}^{(t)} \\
& F E L H_{29}^{(t)}=F P N_{29}^{(t)}
\end{aligned}
$$

(d) Dairy industry:

$$
\begin{aligned}
& F E L H_{13}^{(t)}=S P A_{13}^{(t)}+H P_{13}^{(t)}-T C S_{13}^{(t)} \\
& F P N_{35}^{(t)}=\gamma_{17} F E L H_{13}^{(t)} \\
& F P N_{36}^{(t)}=\gamma_{18} F E L H_{13}^{(t)} \\
& K A P I G_{7}^{(t)}=F P N_{35}^{(t)} \\
& K A P I G_{8}^{(t)}=F P N_{36}^{(t)}
\end{aligned}
$$

(e) Feed industry: the modeling of this branch required a more complicated procedure. First the production of protein feeds is calculated:

$$
\begin{aligned}
& Y_{1}^{(t)}=K E V T I^{(t)}+H D_{7}^{(t)}-S T A K G^{(t)}-S K U K^{(t)}-H D_{14}^{(t)}-H D_{15}^{(t)} \\
& F P N_{37}^{(t)}=F P N_{34}^{(t)}+F P N_{25}^{(t)}+F P N_{36}^{(t)}
\end{aligned}
$$

If

$$
\left(F P N_{37}^{(t)}+S_{37}^{(t-1)}-Y_{1}^{(t)}\right)>0
$$

then

$$
F E L H_{20}^{(t)}=0
$$

Otherwise if

$$
\left(F P N_{37}^{(t)}+S_{37}^{(t-1)}+F P N_{20}^{(t)}+S_{20}^{(t-1)}-Y_{1}^{(t)}\right)>0
$$

then

$$
F E L H_{20}^{(t)}=Y_{1}^{(t)}-F P N_{37}^{(t)}-S_{37}^{(t-1)}
$$

If

$$
\left(F P N_{37}^{(t)}+S_{37}^{(t-1)}+F P N_{20}^{(t)}+S_{20}^{(t-1)}-Y_{1}\right) \leqslant 0
$$

then

$$
F E L H_{20}^{(t)}=F P N_{20}^{(t)}+S_{20}^{(t-1)}
$$




$$
\begin{aligned}
& F E L H_{34}^{(t)}=F P N_{34}^{(t)} \\
& F E L H_{25}^{(t)}=F P N_{25}^{(t)} \\
& F E L H_{36}^{(t)}=F P N_{36}^{(t)} \\
& F P N_{37}^{(t)}=F P N_{37}^{(t)}+F E L H_{20}^{(t)}
\end{aligned}
$$

The production of feed mix is described as follows:

If

$$
H D_{14}^{(t)}+S T A K G^{(t)}>F P N_{23}^{(t)}
$$

then

$$
F E L H_{2}^{(t)}=H D_{14}^{(t)}+S T A K G^{(t)}-F P N_{23}^{(t)}
$$

and

$$
F E L H_{23}^{(t)}=F P N_{23}^{(t)}
$$

If

$$
H D_{14}^{(t)}+S T A K G^{(t)} \leqslant F P N_{23}^{(t)}
$$

then

$$
\begin{aligned}
& F E L H_{2}^{(t)}=0 \\
& F E L H_{23}^{(t)}=H D_{14}^{(t)}+S T A K G^{(t)} \\
& F E L H_{3}^{(t)}=S K U K^{(t)}+H D_{15}^{(t)} \\
& F P N_{38}^{(t)}=Y_{1}^{(t)}+F E L H_{2}^{(t)}+F E L H_{3}^{(t)}+F E L H_{23}^{(t)} \\
& F E L H_{37}^{(t)}=Y_{1}^{(t)}
\end{aligned}
$$

If

$$
Y_{1}^{(t)}-F P N_{37}^{(t)}-S_{37}^{(t-1)}>0
$$

then

$$
X_{1}^{(t)}=Y_{1}^{(t)}-F P N_{37}^{(t)}-S_{37}^{(t-1)}
$$

otherwise 


$$
\begin{aligned}
& X_{1}^{(t)}=0 \\
& K E V T E^{(t)}=X_{1}^{(t)} \gamma_{20}+F E L H_{34}^{(t)} \gamma_{19}+F E L H_{25}^{(t)} \gamma_{20}+F E L H_{36}^{(t)} \gamma_{21} \\
& K A P I G_{9}^{(t)}=F P N_{38}^{(t)}
\end{aligned}
$$

(e) Sugar industry:

$$
\begin{aligned}
& F E L H_{5}^{(t)}=\gamma_{23} S P N_{5}^{(t)}+K A P I G_{10}^{(t)} \\
& K A P I G_{10}^{(t)}=(n i p-0.01) K A P T_{10}^{(t)} \\
& F P N_{39}^{(t)}=\gamma_{23} S P N_{5}^{(t)}+K A P I G_{10}^{(t)} \\
& F E L H_{3}^{(t)}=F E L H_{3}^{(t)}+\left(1 / \gamma_{24}\right) K A P \\
& K A P I G_{11}^{(t)}=\gamma_{23} S P N_{5}^{(t)}
\end{aligned}
$$

(f) Canning industry:

$$
\begin{aligned}
& F E L H_{10}^{(t)}=S P N_{10}^{(t)}+H P_{10}^{(t)}-P T C_{10}^{(t)}-P T C G_{10}^{(t)}-T C S_{10}^{(t)}-P E_{10}^{(t)} \\
& F P N_{40}^{(t)}=\gamma_{25} F E L H_{10}^{(t)} \\
& F E L H_{8}^{(t)}=S P N_{8}^{(t)}+H P_{8}^{(t)}-P T C_{8}^{(t)}-P T C G_{8}^{(t)}-T C S_{8}^{(t)}-P E_{8}^{(t)} \\
& F P N_{41}^{(t)}=\gamma_{26} F E L H_{8}^{(t)} \\
& K A P I G_{12}^{(t)}=F P N_{40}^{(t)}+F P N_{41}^{(t)}
\end{aligned}
$$

(g) Wine industry:

$$
\begin{aligned}
& F E L H_{11}^{(t)}=S P N_{11}^{(t)}+\left(1-\alpha_{4}\right) H P_{11}^{(t)}-P T C_{11}^{(t)}-P E_{11}^{(t)}-P T C G_{11}^{(t)} \\
& F P N_{42}^{(t)}=\gamma_{27} F E L H_{11}^{(t)} \\
& K A P I G_{13}^{(t)}=F P N_{42}^{(t)}
\end{aligned}
$$

(h) Other food processing:

$$
\begin{aligned}
& F P N_{43}^{(t)}=\left(1+\alpha_{5}\right) F P N_{43}^{(t-1)} \\
& F E L H_{22}^{(t)}=\gamma_{28} F P N_{43}^{(t)} \\
& F E L H_{33}^{(t)}=\gamma_{29} F P N_{43}^{(t)} \\
& F E L H_{39}^{(t)}=\gamma_{30} F P N_{43}^{(t)}
\end{aligned}
$$




$$
\begin{gathered}
F E L H_{42}^{(t)}=\gamma_{31} F P N_{43}^{(t)} \\
F E L H_{9}^{(t)}=\gamma_{32} F P N_{43}^{(t)} \\
K A P I G_{14}^{(t)}=F P N_{43}^{(t)}
\end{gathered}
$$

After the program of production, the unit production costs are calculated using commodity-specific rules as follows:

$$
\begin{aligned}
& w f^{(t)}=\left(1+t^{\mathrm{wa}}\right) w^{\mathrm{p}(t)} \\
& O K T_{22}^{(t)}=\left(p_{1}^{\mathrm{pr}(t)} F E L H_{1}^{(t)}+w f^{(t)} m_{1} F E L H_{1}^{(t)}+d r p_{1} R F_{1}^{(t)}+A K T_{1}^{(t)}\right. \\
& \left.-p_{23}^{\mathrm{pr}(t)} F P N_{23}^{(t)}\right) / F P N_{22}^{(t)} \\
& O K T_{23}^{(t)}=p_{23}^{\mathrm{pr}(t)} \\
& O K T_{24}^{(t)}=\left(p_{24}^{\mathrm{pr}(t)} F E L H_{4}^{(t)}+d r p_{2} R F_{2}^{(t)}+w f^{(t)} m_{2} F E L H_{4}^{(t)}+A K T_{2}^{(t)}\right. \\
& \left.-p_{25}^{\operatorname{pr}^{(t)}} F P N_{25}^{(t)}\right) / F P N_{24}^{(t)} \\
& O K T_{25}^{(t)}=p_{25}^{\mathrm{pr}(t)} \\
& O K T_{26}^{(t)}=\left\{\left(p_{12}^{\mathrm{pr}(t)} F E L H_{12}^{(t)}+w f^{(t)} m_{3} F E L H_{12}^{(t)}\right.\right. \\
& \left.+\left(F E L H_{12}^{(t)} / K A P I G_{3}^{(t)}\right)\left(d r p_{3} R F_{3}^{(t)}+A K T_{3}^{(t)}\right)\right\} / F P N_{26}^{(t)} \\
& O K T_{27}^{(t)}=\left\{\left(p_{14}^{\mathrm{pr}(t)}+w f^{(t)} m_{3}\right) F E L H_{14}^{(t)}+\left(F E L H_{14}^{(t)} / K A P I G_{3}^{(t)}\right)\left(d r p_{3} R F_{3}^{(t)}\right.\right. \\
& \left.\left.+A K T_{3}^{(t)}\right)\right\} / F P N_{27}^{(t)} \\
& O K T_{28}^{(t)}=\left\{\left(p_{15}^{\mathrm{pr}(t)}+w f^{(t)} m_{3}\right) F E L H_{15}^{(t)}+\left(F E L H_{15}^{(t)} / K A P I G_{3}^{(t)}\right)\left(d r p_{3} R F_{3}^{(t)}\right.\right. \\
& \left.\left.+A K T_{3}^{(t)}\right)\right\} / F P N_{28}^{(t)} \\
& O K T_{29}^{(t)}=0 \\
& O K T_{30}^{(t)}=\left\{p_{26}^{\mathrm{pr}(t)} F E L H_{26}^{(t)}+p_{27}^{\mathrm{pr}(t)} \alpha_{3} F E L H_{27}^{(t)}+w f^{(t)} m_{4} F P N_{30}^{(t)}\right. \\
& \left.+\left(F P N_{30}^{(t)} / K A P I G_{4}^{(t)}\right)\left(d r p_{4} R F_{4}^{(t)}+A K T_{4}^{(t)}\right)\right\} / F P N_{30}^{(t)} \\
& O K T_{31}^{(t)}=\left\{p_{27}^{\mathrm{pr}(t)}\left(1-\alpha_{3}\right) F E L H_{27}^{(t)}+w f^{(t)} m_{4} F P N_{31}^{(t)}\right. \\
& \left.+\left(F P N_{31}^{(t)} / K A P I G_{4}^{(t)}\right)\left(d r p_{4} R F_{4}^{(t)}+A K T_{4}^{(t)}\right)\right\} / F P N_{31}^{(t)}
\end{aligned}
$$




$$
\begin{aligned}
& O K T_{32}^{(t)}=\left[p_{17}^{\mathrm{pr}(t)} F E L H_{17}^{(t)}+w f^{(t)} m_{6} F E L H_{17}^{(t)}+d r p_{6} R F_{6}^{(t)}\right. \\
& \left.+\left\{p_{32}^{\mathrm{pr}(t)} F P N_{32}^{(t)} /\left(p_{32}^{\mathrm{pr}(t)} F P N_{\mathbf{3 2}}^{(t)}+p_{33}^{\mathrm{pr}(t)} F P N_{33}^{(t)}\right)\right\} A K T_{6}^{(t)}\right] / F P N_{32}^{(t)} \\
& O K T_{33}^{(t)}=\left[p_{18}^{\mathrm{pr}(t)} F E L H_{18}^{(t)}+\left\{p_{33}^{\mathrm{pr}(t)} F P N_{33}^{(t)} /\left(p_{32}^{\mathrm{pr}(t)} F P N_{32}^{(t)}\right.\right.\right. \\
& \left.\left.\left.+p_{33}^{\mathrm{pr}(t)} F P N_{33}^{(t)}\right)\right\} A K T_{6}^{(t)}\right] / F P N_{33}^{(t)} \\
& O K T_{34}^{(t)}=\left(w f^{(t)} m_{5} F E L H_{29}^{(t)}+d r p_{5} R F_{5}^{(t)}+A K T_{5}^{(t)}\right) / F P N_{34}^{(t)} \\
& X_{1}^{(t)}=p_{35}^{\mathrm{pr}(t)} F P N_{35}^{(t)} /\left(p_{35}^{\mathrm{pr}(t)} F P N_{35}^{(t)}+p_{36}^{\mathrm{pr}(t)} F P N_{36}^{(t)}\right) \\
& O K T_{35}^{(t)}=\left(p_{13}^{\mathrm{pr}(t)} F E L H_{13}^{(t)} X_{1}+w f^{(t)} m_{7} F P N_{35}^{(t)}+d r p_{7} R F_{7}^{(t)}+A K T_{7}^{(t)}\right) / F P N_{35}^{(t)} \\
& O K T_{36}^{(t)}=\left\{p_{13}^{\mathrm{pr}(t)} F E L H_{13}^{(t)}\left(1-X_{1}^{(t)}\right)+w f^{(t)} m_{8} F P N_{36}^{(t)}+d r p_{8} R F_{8}^{(t)}\right. \\
& \left.+A K T_{8}^{(t)}\right\} / F P N_{36}^{(t)} \\
& O K T_{37}^{(t)}=\left(p_{34}^{\mathrm{pr}(t)} F P N_{34}^{(t)}+p_{25}^{\mathrm{pr}(t)} F P N_{25}^{(t)}+p_{36}^{\mathrm{pr}(t)} F P N_{36}^{(t)}\right. \\
& \left.+p_{20}^{\mathrm{pr}(t)} F E L H_{20}^{(t)}\right) / F P N_{37}^{(t)} \\
& O K T_{38}^{(t)}=\left\{F E L H_{37}^{(t)} p_{32}^{\mathrm{pr}(t)}+p_{23}^{\mathrm{pr}(t)} F E L H_{23}^{(t)}+p_{2}^{\mathrm{pr}(t)} F E L H_{2}^{(t)}+p_{3}^{\mathrm{pr}(t)}\left(F E L H_{3}^{(t)}\right.\right. \\
& \left.-K A P T_{10}^{(t)} / \gamma_{24}+w f^{(t)} m_{9} F P N_{38}^{(t)}+d r p_{9} R F_{9}^{(t)}+A K T_{9}^{(t)}\right\} / F P N_{38}^{(t)} \\
& O K T_{39}^{(t)}=\left\{p_{5}^{\mathrm{pr}(t)} S P N_{5}^{(t)}+p_{3}^{\mathrm{pr}(t)} K A P T_{10}^{(t)} / \gamma_{24}+w f^{(t)}\left(m_{10} K A P T_{10}^{(t)}\right.\right. \\
& \left.+m_{11} K A P I G_{11}^{(t)}\right)+d r p_{10} R F_{10}^{(t)}+d r p_{11} R F_{11}^{(t)}+A K T_{10}^{(t)} \\
& \left.+A K T_{11}^{(t)}\right\} / F P N_{39}^{(t)} \\
& O K T_{40}^{(t)}=\left\{p_{10}^{\mathrm{pr}(t)} F E L H_{10}^{(t)}+w f^{(t)} m_{12} F P N_{40}^{(t)}+\left(F P N_{40}^{(t)} / K A P G_{12}^{(t)}\right)\left(d r p_{12} R F_{12}^{(t)}\right.\right. \\
& \left.\left.+A K T_{12}^{(t)}\right)\right\} / F P N_{40}^{(t)} \\
& O K T_{41}^{(t)}=\left\{p_{\mathbf{8}}^{\operatorname{pr}(t)} F E L H_{\mathbf{8}}^{(t)}+w f^{(t)} m_{12} F P N_{41}^{(t)}\right. \\
& \left.+\left(F P N_{41}^{(t)} / K A P K G_{12}^{(t)}\right)\left(d r p_{12} R F_{12}^{(t)}+A K T_{12}^{(t)}\right)\right\} / F P N_{41}^{(t)} \\
& O K T_{42}^{(t)}=\left(p_{11}^{\mathrm{pr}(t)} F E L H_{11}^{(t)}+w f^{(t)} m_{13} F P N_{42}^{(t)}+d r p_{13} R F_{13}^{(t)}+A K T_{13}^{(t)}\right) / F P N_{42}^{(t)} \\
& O K T_{43}^{(t)}=\left(p_{22}^{\mathrm{pr}(t)} F E L H_{22}^{(t)}+p_{33}^{\mathrm{pr}(t)} F E L H_{33}^{(t)}+p_{39}^{\mathrm{pr}(t)} F E L H_{39}^{(t)}+p_{42}^{\mathrm{pr}(t)} F E L H_{42}^{(t)}\right. \\
& \left.+p_{9}^{\mathrm{pr}(t)} F E L H_{9}^{(t)}+d r p_{14} R F_{14}^{(t)}+A K T_{14}^{(t)}\right) / F P N_{43}^{(t)}
\end{aligned}
$$



lated.

Finally, the financial consequences of the given food processing activities are calcu-

(a) Labor requirements and expenses:

$$
\begin{aligned}
P L F^{(t)}= & m_{2} F E L H_{1}^{(t)}+m_{2} F E L H_{4}^{(t)}+m_{3}\left(F E L H_{12}^{(t)}+F E L H_{14}^{(t)}+F E L H_{15}^{(t)}\right) \\
& +m_{4}\left(F P N_{30}^{(t)}+F P N_{31}^{(t)}\right)+m_{5} F E L H_{29}^{(t)}+m_{6} F E L H_{17}^{(t)}+m_{7} F P N_{35}^{(t)} \\
& +m_{8} F P N_{36}^{(t)}+m_{9} F P N_{38}^{(t)}+m_{10} K A P T_{10}^{(t)}+m_{11} K A P I G_{11}^{(t)} \\
& +m_{12}\left(F P N_{40}^{(t)}+F P N_{41}^{(t)}\right)+m_{13} F P N_{42}^{(t)}+m_{14} F P N_{43}^{(t)} \\
w^{\mathrm{p}(t)}=w^{\mathrm{p}(t-1)}\left(1+o^{(t)}\right) & \\
W E P^{(t)}= & w^{\mathrm{p}(t)} P L F^{(t)} \\
L E P^{(t)}= & \left(1+t^{\mathrm{wa}}\right) W E P^{(t)}
\end{aligned}
$$

(b) Other expenses:

$$
\begin{aligned}
& D E P^{(t)}=\sum_{i=1}^{14} d r p_{i} R F_{i}^{(t)} \\
& \operatorname{MEPS}^{(t)}=\sum_{i=1}^{21} p_{i}^{\mathrm{pr}(t)} F E L H_{i}^{(t)} \\
& \operatorname{MEPP}^{(t)}=\sum_{i=22}^{43} p_{i}^{\mathrm{pr}(t)} F E L H_{i}^{(t)} \\
& \operatorname{MEPI}^{(t)}=\sum_{k=1}^{14} A K T_{i}^{(t)} \\
& \operatorname{MEP}^{(t)}=\operatorname{MEPS}^{(t)}+\operatorname{MEPP}^{(t)}+\operatorname{MEPI}^{(t)}
\end{aligned}
$$

(c) Gross production value:

$$
P A P^{(t)}=\sum_{i=22}^{43} p_{i}^{\mathrm{pr}(t)} F P N_{i}^{(t)}
$$

(d) Net income from food processing:

$$
I N C P^{(t)}=P A P^{(t)}-\sum_{i=22}^{43} F P N_{i}^{(t)} O K T_{i}^{(t)}
$$

\subsection{Consumption and Trade Block}

The Consumption and Trade Block of HAM-2 follows the general model outline completely. Parameters of the demand system were estimated on the basis of 25 years' data. The supply vector $(Y)$ in HAM-2 is structured according to Table 18 . The elements of the Q matrix in HAM-2 are shown in Table 19. 
TABLE 18 Supply vector $Y$ in HAM $-2^{a}$.

\begin{tabular}{|c|c|c|c|c|c|c|}
\hline Stocks & Production & $\begin{array}{l}\text { Household } \\
\text { production }\end{array}$ & $\begin{array}{l}\text { Used in } \\
\text { processing }\end{array}$ & $\begin{array}{l}\text { Inputs in } \\
\text { household sector }\end{array}$ & $\begin{array}{l}\text { Self } \\
\text { consumption }\end{array}$ & $\begin{array}{l}\text { Supply } \\
\text { vector } Y\end{array}$ \\
\hline \multirow{6}{*}{$\begin{array}{l}+S_{1}^{(t-1)} \\
+S_{2}^{(t-1)} \\
+S_{3}^{(t-1)} \\
+S_{4}^{(t-1)}\end{array}$} & $+S P A_{01}$ & $+H P_{01}$ & $-F E L H_{01}$ & $-H D_{8}$ & & $=1$ \\
\hline & $+S P A_{02}$ & & $-F E L H_{02}$ & $\cdots D_{4}$ & & $=2$ \\
\hline & $+S P A_{03}$ & $+H P_{03}$ & $-F E L H_{03}$ & $-H D_{5}-H B F_{3}$ & & $=3$ \\
\hline & $+S P A_{04}$ & & $-F E L H_{04}$ & & & $=4$ \\
\hline & $+S P A_{\text {os }}$ & & $-F E I . H_{05}$ & & & $=5$ \\
\hline & $+S P A_{\propto 6}$ & $+H P_{06}$ & & $-H D_{6}-H B F_{6}$ & & $=6$ \\
\hline \multirow{13}{*}{$\begin{array}{l}+S_{7}^{(t-1)} \\
+S_{8}^{(t-1)} \\
+S_{9}^{(t-1)} \\
+S_{10}^{(t-1)}\end{array}$} & $+S P A_{07}$ & $+H P_{07}$ & & $-H D_{9}$ & $-T C S_{7}$ & $=7$ \\
\hline & $+S P A_{08}$ & $+H P_{\mathrm{OB}}$ & $-F E L H_{\mathrm{OB}}$ & & $-T C S_{\mathrm{g}}$ & $=8$ \\
\hline & $+S P A_{09}$ & $+H P_{0 S}$ & $-F E L H_{09}$ & & $-I N F E L$ & $=9$ \\
\hline & $+S P A_{10}$ & $+H P_{10}$ & $-F E L H_{10}$ & & $-T C S_{10}$ & $=10$ \\
\hline & $+S P A_{11}$ & $+H P_{11}$ & $-F E L H_{11}$ & $-H B F_{11}$ & $-T C S_{11}$ & $=11$ \\
\hline & $+S P A_{12}$ & $+H P_{12}$ & $-F E L H_{12}$ & & & $=12$ \\
\hline & $+S P A_{13}$ & $+H P_{13}$ & $-F E L H_{13}$ & & $-T C S_{13}$ & $=13$ \\
\hline & $+S P A_{14}$ & $+H P_{14}$ & $-F E L H_{14}$ & & $-T C S_{14}$ & $=14$ \\
\hline & $+S P A_{15}$ & $+H P_{15}$ & $-F E L H_{15}$ & & & $=15$ \\
\hline & $+S P A_{16}$ & $+H P_{16}$ & & & $-G Y F E L$ & $=16$ \\
\hline & $+S P A_{17}$ & $+H P_{17}$ & $-F E L I_{17}$ & & $-T C S_{17}$ & $=17$ \\
\hline & $+S P A_{18}$ & $+H P_{18}$ & $-F E L H_{18}$ & & $-T C S_{\mathrm{t} 8}$ & $=18$ \\
\hline & $+S P A_{19}$ & $+H P_{19}$ & & & $-T C S_{19}$ & $=19$ \\
\hline \multirow[t]{2}{*}{$+S_{20}^{(t-1)}$} & $+S P A_{20}$ & & $-F E L H_{20}$ & & & $=20$ \\
\hline & $+S P A_{21}$ & & & & $-M T F E L$ & $=21$ \\
\hline$+S_{22}^{(t-1)}$ & $+F P A_{22}$ & & & & & $=22$ \\
\hline$+S_{23}^{(t-1)}$ & $+F P A_{23}$ & & & & & $=23$ \\
\hline \multirow[t]{2}{*}{$+S_{24}^{(t-1)}$} & $+F P A_{24}$ & & & & & $=24$ \\
\hline & $+F P A_{25}$ & & & & & $=25$ \\
\hline$+S_{26}^{(t-1)}$ & $+F P A_{26}$ & & & & & $=26$ \\
\hline$+S_{27}^{(t-1)}$ & $+F P A_{27}$ & & & & & $=27$ \\
\hline \multirow[t]{2}{*}{$+S_{28}^{(t-1)}$} & $+F P A_{28}$ & & & & & $=28$ \\
\hline & $+F P A_{29}$ & & & & & $=29$ \\
\hline$+S_{30}^{(t-1)}$ & $+F P A_{30}$ & & & & & $=30$ \\
\hline$+S_{31}^{(t-1)}$ & $+F P A_{31}$ & & & & & $=31$ \\
\hline$+S_{32}^{(t-1)}$ & $+F P A_{32}$ & & & & & $=32$ \\
\hline \multirow[t]{2}{*}{$+S_{33}^{(t-1)}$} & $+F P A_{33}$ & & & & & $=33$ \\
\hline & $+F P A_{34}$ & & & & & $=34$ \\
\hline$+S_{35}^{(t-1)}$ & $+F P A_{35}$ & & & & & $=35$ \\
\hline$+S_{36}^{(t-1)}$ & $+F P A_{36}$ & & & & & $=36$ \\
\hline
\end{tabular}


TABLE 18 (continucd)

\begin{tabular}{|c|c|c|c|c|c|c|c|c|}
\hline Stocks & Production & $\begin{array}{l}\text { Household } \\
\text { production }\end{array}$ & $\begin{array}{l}\text { Used in } \\
\text { processing }\end{array}$ & $\begin{array}{l}\text { Inputs in } \\
\text { household }\end{array}$ & sector & \multicolumn{2}{|l|}{$\begin{array}{l}\text { Self } \\
\text { consumption }\end{array}$} & $\begin{array}{l}\text { Supply } \\
\text { vector } Y\end{array}$ \\
\hline$+S_{37}^{(t-1)}$ & $+F P A_{37}$ & & & & & & & $=37$ \\
\hline$+S_{38}^{(t-1)}$ & $+F P A_{38}$ & & KEVTI & $H D_{7}$ & & & & $=38$ \\
\hline$+S_{39}^{(t-1)}$ & $+F P A_{39}$ & & & & & & & $=39$ \\
\hline$+S_{40}^{(t-1)}$ & $+F P A_{40}$ & & & & & & & $=40$ \\
\hline$+S_{41}^{(f-1)}$ & $+F P A_{41}$ & & & & & & & $=41$ \\
\hline$+S_{42}^{(t-1)}$ & $+F P A_{42}$ & $+H P_{42}$ & & & & $T C S_{42}$ & & $=42$ \\
\hline$+S_{43}^{(t-1)}$ & $+F P A_{43}$ & & & & & & & $=43$ \\
\hline$+S_{44}^{(t-1)}$ & & & & & & & & $=44$ \\
\hline$+S_{43}^{(t-1)}$ & & & & & & & & $=45$ \\
\hline$+S_{46}^{(t-1)}$ & & $\alpha^{\mathrm{n}} p^{(l)}-M E S I$ & $-M E P I$ & $-M E H I$ & $-I N S$ & $-I N P$ & $I N N$ & $=46$ \\
\hline & & $p_{n}^{\mathrm{pr}}$ & $p_{n}^{\mathrm{pr}}$ & $p_{n}^{\mathrm{pr}}$ & $p_{n}^{\text {pr }}$ & $p n^{p r}$ & $p_{n}^{\mathrm{pr}}$ & \\
\hline
\end{tabular}

${ }^{a}$ Symbols can be identified from Table 4 and the Appendix. All variables in Table 17 except stocks are related to period $(t)$.

\subsection{Economic Analysis of the Government and Updating of Parameters}

The revision of government policy instruments in HAM-2 is modeled as explained in Part 1 and block updating also follows the general model outline.

\section{VERIFICATION AND VALIDATION OF HAM-2}

Through simulation models various real-life situations can be studied. The model must suit the purpose of the specific study and must also truly represent the aspect of reality in which we are interested. Accordingly, in developing HAM-2 great attention was paid both to the model's relation to reality and to the problem of the reliability of the results generated by the model.

The problems of agriculture, replete with random effects and biological correlations, can generally be represented only by complicated mathematical models and handled only by elaborate computer programs. It is not a simple task, therefore, to estimate how accurately a large-scale agricultural model such as HAM-2 reflects reality and how well the simulation system can be used with regard to the targets. Unfortunately there is almost no method that can be of definite help in this field.

The methodology of controlling and pretesting simulation models is still at a rudimentary stage. The philosophical interdependences and aspects of evaluating models cannot be regarded as fully or clearly defined and no widely accepted method of model evalua. tion has yet been established in international technical literature on simulation practice. 
TABLE 19 Non-committed demands Q in HAM-2.

\begin{tabular}{|c|c|c|c|c|c|c|c|c|c|c|c|c|}
\hline & \multicolumn{3}{|c|}{ Stocks } & \multicolumn{4}{|c|}{ Investments } & \multicolumn{3}{|c|}{ Community consumption } & \multicolumn{2}{|c|}{ Private consumption } \\
\hline & $\lambda_{1}$ & $\lambda_{2}$ & $\bar{\lambda}_{3}$ & $\lambda_{4}$ & $\lambda_{s}$ & $\lambda_{0}$ & $\lambda_{1}$ & $\overline{\lambda_{8}}$ & $\lambda_{0}$ & $\overline{\lambda_{10}}$ & $\begin{array}{ll}\lambda_{11} & \lambda_{12} \\
\end{array}$ & $\lambda_{13}$ \\
\hline 1 & & $S 1$ & & & & & & & & & & \\
\hline 2 & & $S 2$ & & & & & & & & & & \\
\hline 3 & & 53 & & & & & & & & & & \\
\hline 4 & & & $S 4$ & & & & & & & & & \\
\hline 5 & & & & & & & & & & & & \\
\hline 6 & & & & & & & & & & & & \\
\hline 7 & & & $S 7$ & & & & & & & PTCG7 & & $T C 7$ \\
\hline 8 & & & 58 & & & & & & & PTCG8 & & $T C 8$ \\
\hline 9 & & & $S 9$ & & & & & & & & & \\
\hline 10 & & & $S 10$ & & & & & & & PTCG 10 & & $T C 10$ \\
\hline 11 & & & & & & & & & & PTCG11 & & $T C 11$ \\
\hline \multicolumn{13}{|l|}{12} \\
\hline \multicolumn{13}{|l|}{13} \\
\hline \multicolumn{13}{|l|}{14} \\
\hline \multicolumn{13}{|l|}{15} \\
\hline \multirow{2}{*}{\multicolumn{13}{|c|}{16}} \\
\hline & & & & & & & & & & & & \\
\hline \multicolumn{13}{|l|}{18} \\
\hline 19 & & & & & & & & & & PTCG19 & & $T C 19$ \\
\hline 20 & & & $S 20$ & & & & & & & & & \\
\hline \multicolumn{13}{|l|}{21} \\
\hline 22 & & & $S 22$ & & & & & & & PTCG 22 & & $T C 22$ \\
\hline 23 & & & $S 23$ & & & & & & & & & \\
\hline 24 & & & $S 24$ & & & & & & & PTCG 24 & & $T C 24$ \\
\hline \multicolumn{13}{|l|}{25} \\
\hline 26 & & & $S 26$ & & & & & & & PTCG26 & & $T C 26$ \\
\hline 27 & & & $S 27$ & & & & & & & PTCG 27 & & $T C 27$ \\
\hline 28 & & & $S 28$ & & & & & & & & & \\
\hline \multicolumn{13}{|l|}{29} \\
\hline 30 & & & $S 30$ & & & & & & & PTCG 30 & & $T C 30$ \\
\hline 31 & & & $S 31$ & & & & & & & PTCG 31 & & TC31 \\
\hline
\end{tabular}




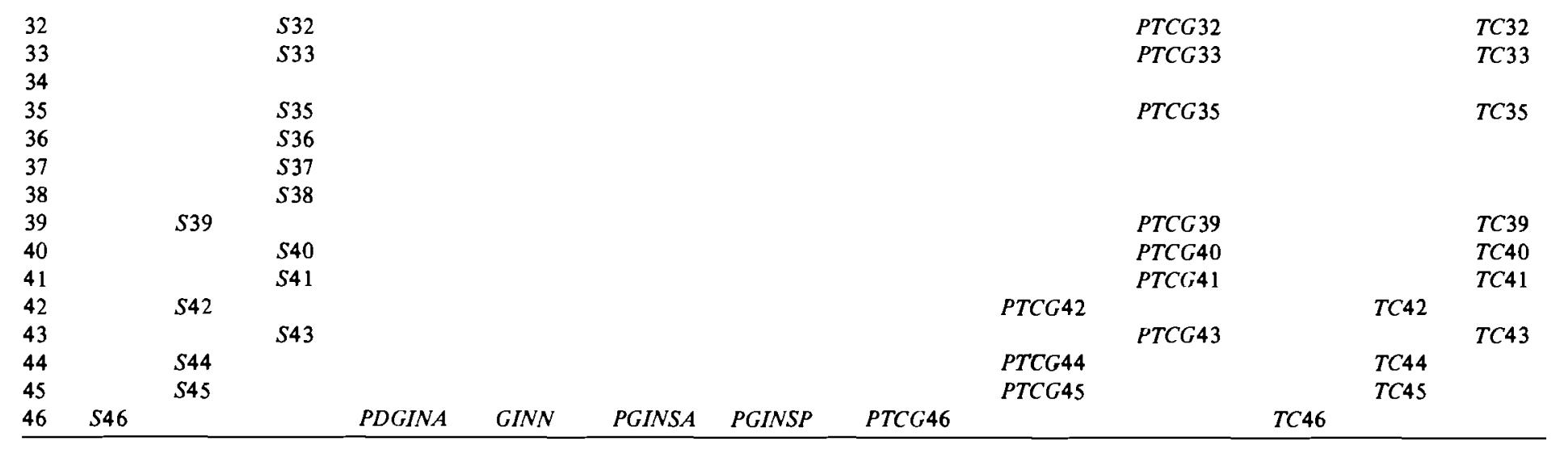


However, most works dealing more thoroughly with simulation emphasize the advantages of performing a two-way analysis before operating the model. The first stage is the verification of the model, that is, the confrontation of the model with reality to determine whether the model truly represents reality. The second stage is the validation of the model, that is, the necessary evaluation of the model in respect of a specific analysis, rather than with regard to reality, to study to what extent the model satisfies certain objectives of research or investigation.

The model's relation to reality can be expressed by the relation of the characteristics of the system studied determined by the computer on the basis of the model and the characteristics of the real system. Thus the proof of reliability is the total or partial conformity of certain values of the dependent variables with the results of the empirical studies concerning the phenomena symbolized by the former. On this basis one can decide whether the model properly represents the situation to be described. In principle, therefore, the model's relation to reality can be easily defined, but to prove this in specific cases is more difficult. This is due not only to the lack of suitable methods for this purpose but frequently also to the missing bases of comparison. There are almost no empirical data about how a certain part of the modeled systems operate. There are also cases where the system studied (some plan interrelations, for instance) does not even exist in reality and therefore no factual data concerning its functioning are available either.

Verification is relatively simpler if the model describes an existing system and the results of the model can be compared with factual data from real-life situations. The various methods of statistical analysis may play an important part in evaluating simulation methods. If model results are given in the form of time series, the following tests are suggested:

-... statistical tests, indifferent to distribution, to check whether actual and simulated time series tend in the same direction;

- regression of simulated time series with the actual time series;

- factor analysis of the two time series to check whether the levels of factors differ considerably.

When results are given in the form of averages, ratios or probability distributions, the usual statistical methods of verifying the hypotheses are applied. None of these tests can generally be done during the course of the simulation study. The executors of the simulation therefore have to choose those indicators through which they intend to verify the relation of the simulation model to reality.

T.H. Naylor's so-called multiple-stage model verification process is perhaps the bestknown procedure in the technical literature on simulation. The essentials of this three-phase method are as follows:

- selection of assumptions and hypotheses of basic importance from the point of view of describing the system studied;

- the logical testing of the basic assumptions;

- the empirical study of the model's behavior.

Naylor's method comprises an evaluation of a logical type. Such an evaluation is necessary because normally the basic hypotheses of the models cannot be checked in any other way. 
In the further phases of the checking process, Naylor starts from the assumption that the behavior of the simulation model as a whole may be forecast on the basis of only some of the variables. If values are attributed to some of the variables, the results expected on the basis of the model, i.e. the features of the operation of the simulated system, can be obtained. These features can then be compared with the data for the operation of the real system. For comparison the aforementioned statistical methods may be applied.

If empirical data for the operation of the modeled system is lacking, an evaluation can be performed only on a subjective basis. Subjective judgment cannot be excluded even if we can carry our exact tests. The level and the exactness of the approach considered as the proof of the correspondence to reality undoubtedly also have a bearing on the problem, but primarily results depend on the objectives of the study and to a large extent on the subjective judgment of the person in charge of checking. No absolute standards or levels can be set to estimate the model's relation to reality. Lacking such objective standards, we must accept the results of various confidence limits in the simulation practice. It is important to stress, therefore, that the realization of the simulation process overwhelmingly depends on the sense of scientific responsibility and the conscience of the executors.

Depending on the nature of the problem, model verification and testing may be covered in either a simpler or a more complicated way. In the case where the system exists in real life and can be described by a linear-deterministic model, verification can generally rely on objective bases and statistical methods. However, for the simulation of more complicated biological and economic systems, logical testing of the main postulates of the model should not be neglected either. The applicability of such models can be considered as confirmed only if both logical and exact tests show positive results.

Because HAM-2 describes a rather complex and complicated system, several controls were made in the process of developing the model.

As part of the model construction, the correspondence to reality of the mathematical model was studied first. Having constructed the model, the positive results of control evaluations permitted procedure to the next stages and ensured that possible errors in the early stage were avoided. If the model is regarded problematically at some point or points, it is necessary to return to the model construction, or eventually to the analysis of the system itself, and to repeat and to check on the stages of model construction mentioned previously.

It should be borne in mind when evaluating the model's mathematical structure that the use of mathematical models always implies certain abstractions from the particulars of reality and that objective conditions of ten make the precise, exact modeling of certain interdependences impossible from the outset. We considered the following to be characteristic features of a satisfactory model:

- each component of the system studied is represented by a corresponding variable or variables;

- the parameters are reliable;

- concerning logic and mathematics, the interdependences are formulated exactly and correctly;

-- the model is easily explicable and applicable;

- the structure of the model is determined by the objectives of the study;

- the model can be easily adapted to new postulates and relatively easily developed. 
In the case of HAM-2, the satisfaction of these requirements has been confirmed logically, empirically and by subjective judgment. Verification on a logical basis included comparison with the field studied, the examination of the model's structure and the thorough, logical analysis of the interdependences of the model. Empirical investigations included simpler, manual calculations to show what values the dependent variables may take and how these values relate to empirical results for the phenomena represented by them. The evaluation of certain model parts was performed on a subjective basis. While it is generally not good for subjective judgment to play too great a part, in some situations this is the only method available and there is no other choice but to rely on general experience and knowledge.

In relation to the structure of HAM-2, a so-called sensitivity analysis was also performed. The sensitivity analysis was connected with parameters, coefficients and other factors of the model whose values had been fixed in advance and thus do not change during the operation of the model. Of the components of the model mentioned. those primarily selected were those which were in some respect uncertain or less exact, or whose reliability was doubtful.

In the course of the sensitivity analysis of HAM-2 we changed the values of the selected parameters that were considered unreliable, leaving the rest of the model unaltered. In this way we were able to estimate how and to what degree this change influenced the operation of the model, and in what way the characteristics of the simulated system changed. The main purpose of the sensitivity analysis was to show whether al teration of the uncertain parameters influenced the model's correspondence to reality and, if it did, to what extent. In general a model is in sensitive relation to one or more of its parameters if their values considerably influence the picture drawn of the system studied by the model. Sensitivity means therefore that if we modify the values of unreliable parameters the model loses its suitability for simulating the system studied. To gain positive results from the sensitivity analysis, it is necessary to return to an earlier phase of the model building and to reconsider the interrelations of the studied system as described by the model. At the same time, additional data has to be collected to carry on the survey further in order to define the parameters in question more exactly and thoroughly. A simulation will be really reliable only if the results of a sensitivity analysis are satisfactory. In the case of HAM-2, the sensitivity analysis was mainly related to parameters of the production block and parameters in the government economic analysis submodel.

In addition to analyzing the relationship between the model and reality, we tested whether HAM-2 was correct from the point of view of computer programming. Several computer runs of the model were made to answer these questions. These test runs were aimed at revealing any errors and shortcomings in the computer program. In this work we applied the following methods:

- the model was run simulating a shorter time period (only one year) and the results were compared with those of manual calculations;

- the more complicated independent routines were separately run and tested;

- simple control situations were constructed to test the most frequently occurring circumstances.

The checking of the model, especially the sensitivity analysis and the program testing, involved a great deal of calculation and time. We have learnt from HAM-2 that the verification 
and validation of the model play a very important part in the simulation process. We also learnt through experience that repeated checking during the course of simulation is very necessary since the probability of making errors multiplies itself. Errors can occur during the construction of the mathematical model, during computer programming, in data collection, in operating the model and in evaluating the information yielded by the model.

The first control point comes after building the mathematical model. Having settled all questions related to computer processing, a complex testing of the whole simulation system should be made. Either these tests confirm the answers to the problems of the model, or it is necessary to return to the model and eliminate the errors by carrying out certain alterations and repeating certain phases of the model construction. On the whole, the utility of the information can be the final standard of the success of the simulation. There may be cases when certain problems with the model appear only after the simulation is completed. Nothing else can then be done but to recommence model construction by the repeated study of the system and to try to find a solution that might produce really valuable information satisfying the objectives of the study. Figure 33 shows the role of testing in the development of HAM-2.

\section{EXPERIMENTS IN THE USE OF HAM-2}

The computer program of HAM-2 was developed in Hungary at the computer center of the Hungarian National Planning Bureau under the leadership of Laszlo Zeold. In the programming work the computer program of HAM-1 was used as a starting point. At present one program version exists, allowing us to do runs on the Hungarian Planning Bureau's ICL-System 4/70 computer.

At the end of the computation various types of output can be printed out. At present the output system of HAM-2 consists of the following two major elements.

(1) Annual Results, which provide the analysis of time periods, containing very detailed results on each simulated year and on each module of the model, including the updated model coefficients.

(2) A Summary of Results which covers time series of the most important indicators, naking possible the global analysis of the various runs.

The Summary of Results is the most useful type of output, and in most cases the information needs on the individual runs can be satisfied on the basis of it. Of course, the more detailed analysis or debugging can only be done using the Annual Results. The Summary of Results is structured according to eight tables as described in the following.

(1) Dynamics of production, trade, and prices: planned and actual production, export and import of individual commodities in physical units and unit production costs, and domestic producer, consumer and world market prices also according to commodities and simulated years.

(2) General indicators of development: general indicators of production, foreign trade, investment, income development on current and fixed prices for the entire simulated period and indexes of the development in comparison with major plan targets.

(3) Cropping structure and yields: share of individual crops in total plowland and their projected unit outputs in physical terms. 


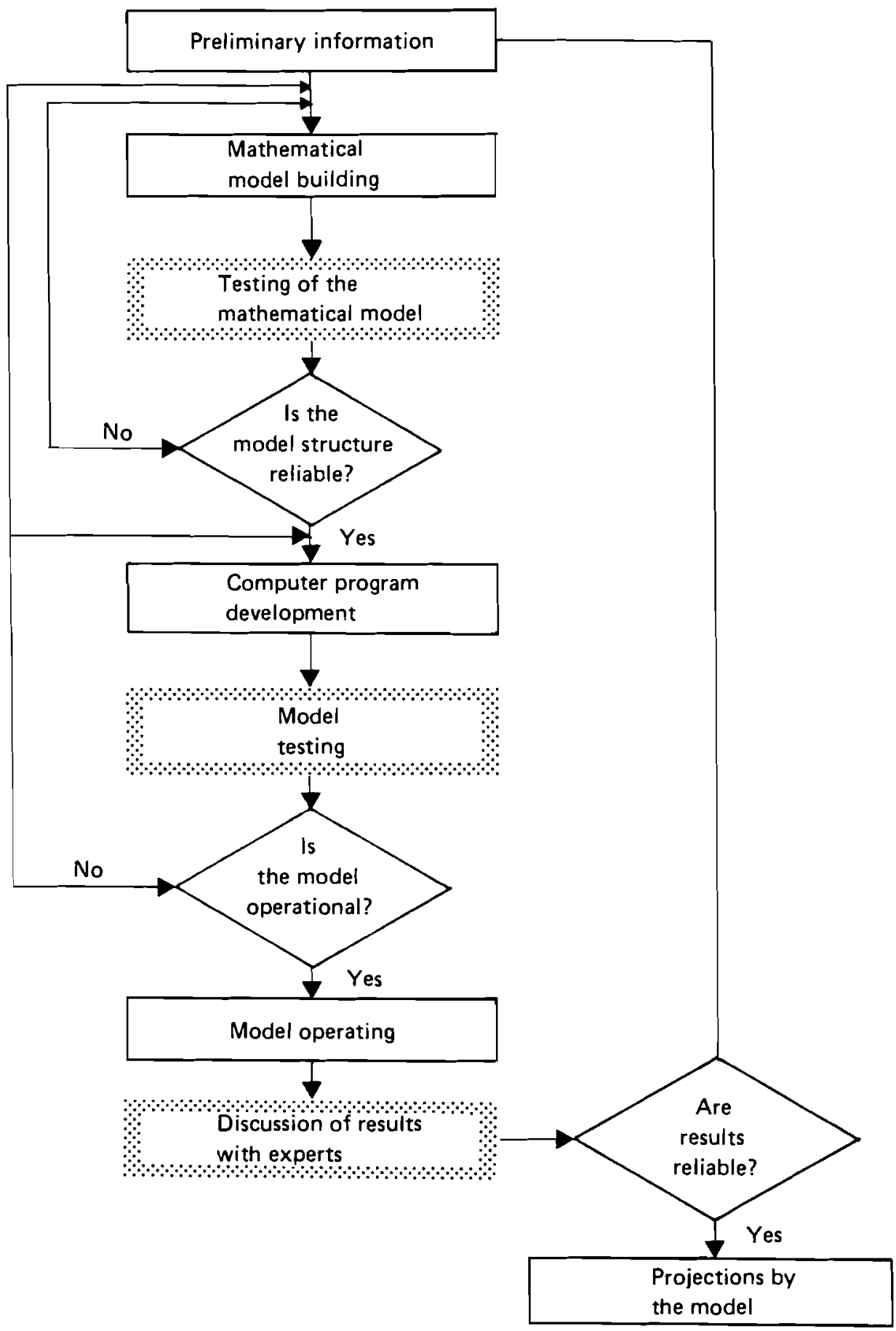

FIGURE 33 Structure of verification and validation in developing HAM-2. 
(4) Fixed Assets: the development of fixed assets of agriculture and food processing by major types, in physical units.

(5) Financing of investments: financial accounts for investment, for the producing sector and for the whole economy, according to simulated years.

(6) Resources: summary of major production resources including labor and land.

(7) Foreign trade: balance of payments for food and agriculture and the whole economy, total exports and imports according to dollar and ruble market values.

(8) Dynamics of consumption: the desired and actual per capita consumption by commodities in physical units.

(9) Policy instruments: tax rate and centralized part of amortization, annual growth of unit wages.

Numerous runs of HAM-2 have been done so far, representing two types of investigations, namely:

testing the operation of the whole system, and investigating the model's relation to reality;

-- investigation related to the elaboration of the five-year plan of Hungarian food and agriculture for the period $1981-85$.

A large number of runs belonged to the first of these two types, some of them simply serving debugging purposes. In other cases the sensitivities of the crucial parameters were investigated. Finally, several runs were required to test our assumptions on various decisionmaking procedures. These runs led us to the so-called basic variant of HAM-2, which can be considered as the appropriate description of the present Hungarian food and agriculture system, obviously on the aggregation level and accepting the assumptions of the model.

The use of HAM-2 for actual planning purposes began in mid-1979 and the work is far from finished. After first testing the model, HAM-2 was used to aid decision making on further development of domestic agricultural price systems as well as pricing mechanisms. Runs of HAM-2 have been made:

- with various assumptions about the relative prices of major agricultural commodities;

with modifications to the pricing mechanism built into the model according to the major alternatives considered as future possibilities by the National Planning Bureau.

As further stages in the use of HAM-2, the following were investigated:

-- strategies for the further development of the food export structure;

- the efficiency of increasing food exports in return for oil;

- the major alternatives for investment in food and agriculture (agriculture versus food processing);

-. the feasibility of major growth targets in food and agriculture;

- the alternatives for technological development.

HAM-2 will also be used to project the overall indicators of agricultural development and export-import possibilities within the framework of a research project of the 
Hungarian Academy of Sciences on the biological potential and ecological limits of Hungarian agriculture. On the basis of the results of this project, the Production block of HAM-2 might also be further refined.

\section{SOME PERSPECTIVES ON HUNGARIAN AGRICULTURE AS PROJECTED BY HAM-2}

During 197940 or so runs of HAM-2 were executed to answer questions related to the mid-range development of Hungarian agriculture. The detailed discussion of the results exceeds the scope of this study; only the major conclusions of the investigation will be summarized here.

One of the most important tasks during the calculations was to project the growth of the Hungarian national economy and agriculture. The basic trends of development in Hungarian agriculture are shown in Fig. 34. The results show that in comparison with the

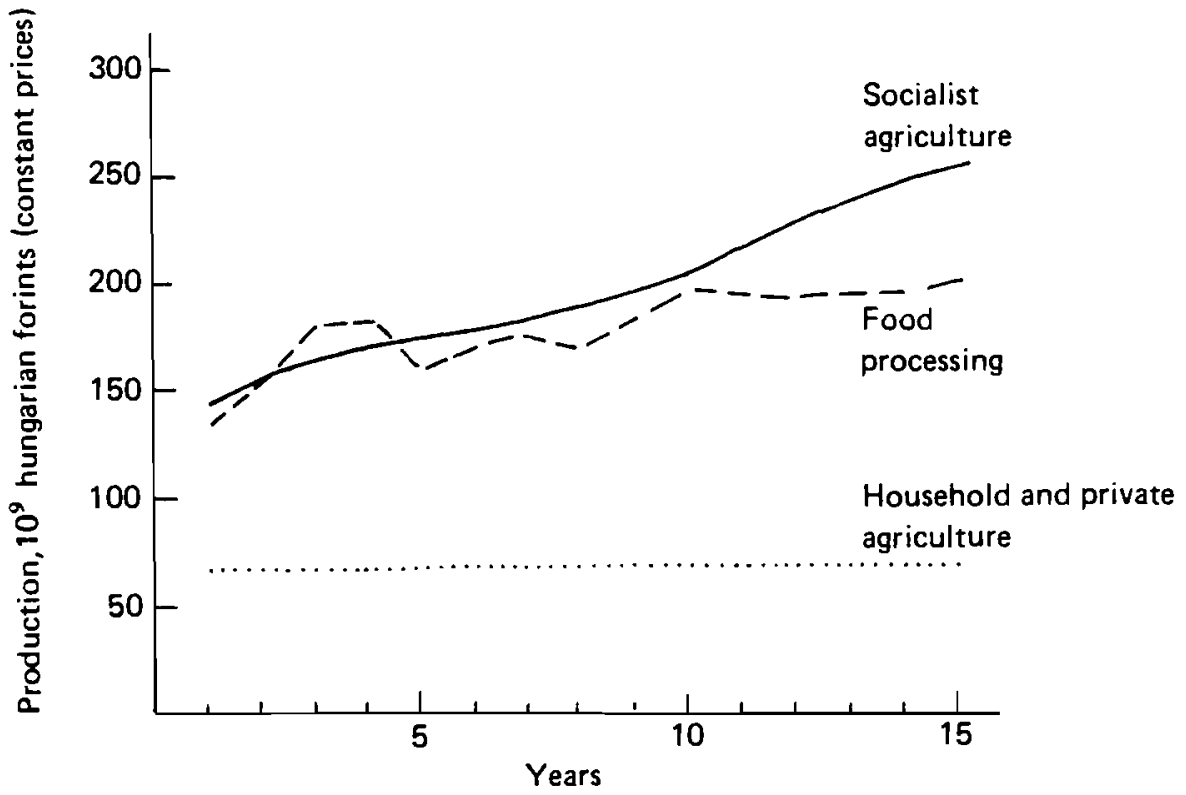

FIGURE 34 Basic trends in the development of Hungarian food and agriculture as projected by HAM-2. 
1960s the annual rate of growth will increase slightly, both on the national level and in food and agriculture. Within the conditions expressed by the model, it is most likely that the average annual rate of growth of the gross national product will be about $3 \%$. The annual growth will probably decrease toward the second five-year period within the time horizon modeled. Later it will increase again but it will probably not reach the level of the first five-year period. Food and agriculture grows in parallel with the growth of the rest of the economy in most of the runs. As far as growth rates are considered in various scenarios, substantial differences can be observed in the second half of the period modeled.

The various conditions impact to various extents upon growth. As far as external conditions are concerned, exogenously given scenarios have been investigated to aid decision making. Several assumptions on international prices and world market conditions were tested. The results indicate the following:

- that stable international market conditions help the achievement of growth targets;

- that the reactions of the Hungarian economy, including food and agriculture, to world market changes is slow;

- that changes in food export quotas do not significantly influence the overall growth figures.

Relations between government policy instruments, the economic management systen and growth were also studied. Some of the most important conclusions in this respect are as follows.

- The transfer of international market changes to producers is not efficient enough. Producers have no direct contact with the world market and their actions might therefore lead to undesired results.

- As had been expected, exchange rates proved to be inefficient instruments for controlling overall growth.

- Government policy objectives for the growth of private consumption impacts heavily on the overall economic growth. The overall economic growth is most favorable assuming only a $2 \%$ annual growth in consumption. An annual growth in consumption of more than $3.5 \%$ leads to a very substantial slowdown in overall economic development. However, too slow an increase in consumption also has negative effects on production. The most realistic target for the annual growth of private consumption for the forthcoming 15 years therefore seems to be $2.5-3.0 \%$.

- The impacts of various government pricing policies were also investigated. Results have confirmed our expectations: prices and price policy are the most efficient tool in the hands of the government to control producers' behavior within the framework of conditions expressed by HAM.

The desired relation of consumption to investment was also studied. As has already been mentioned from the point of view of the economic growth of the country, an annual growth in private consumption of 2.5-3.0\% seems the most desirable. According to the results of various runs, the given stage of the economy very seriously limits the possibilities for increased consumption. Obviously an increased share of consumption in total national income leads to less investment. An annual growth in consumption of more than $2.7-2.8 \%$ 
seems to be realistic only in those scenarios where very favorable international market conditions are assumed. Otherwise the higher growth in consumption decreases investment and overall economic growth falls below the desired level. An almost general conclusion of our calculations is that a slowly increasing rate of investment of national income would be the most desirable for the future; the growth of investment should therefore be higher than the growth of consumption.

Food and agriculture meet the consumers' demands in almost all situations considered, and there is also a substantial supply for export. The $100 \%$ self-sufficiency in commodities which can be produced in Hungary seems to be a realistic objective.

The share of food and agriculture in total accumulation varies to a great extent in the various scenarios. In general, agriculture is able to accumulate the funds necessary for its owll development, and government subsidies are used only in specific cases. However, in food processing, government subsidies are the major financial source for development. It is not surprising that most of our runs reflect a relatively acceptable level of incomes in agriculture. In food processing, partly owing to the age of the present production facilities, firms are unable to accumulate enough money to finance the desired investments at the domestic price level projected by HAM-2.

One of the major objectives of the investigation was connected with the export potential of Hungarian food and agriculture. The results indicate two rather important conclusions:

-. the export potential of Hungarian agriculture has so far not been fully utilized -the positive balance of food and agricultural foreign trade can be significantly increased;

- the quantity of exports might be increased, but the efficiency of exporting food above a certain limit is questionable.

The various scenarios led to different production structures in food and agriculture. On the whole, however, they do not indicate the need for any substantial change in the present production structure. However, they do indicate that the following changes should be considered:

- increasing the role of grain (wheat and corn) production and oil seeds within crop production;

- increasing the number of orchards and especially vineyards and the production of quality wine;

- increasing the share of processed and especially highly processed commodities in exports.

\section{BIBLIOGRAPHY}

Csáki, C. (1978) First Version of the Hungarian Agricultural Model (HAM-1). RM-78-38. Laxenburg, Austria: International Institu te for Applied Systems Analysis.

Csáki, C. (1979) Second Version of the Hungarian Agricultural Model (HAM-2) WP-79-71. Laxenburg, Austria: International Institute for Applied Systems Analysis. 
Csáki, C., A. Jonas, and S. Meszaros (1978) Modeling of Centrally Planned Food and Agricultural Systems: Framework for a National Policy Model for the Hungarian Food and Agricultural Sector. RM-78-11. Laxenburg, Austria: International Institute for Applied Systems Analysis.

de Haen, H., J.V. Schrader, and S. Tangermann (1978) Modeling the EC Agricultural Sector: Problem Assessment, Policy Scenarios and Model Outline. RM-78-23. Laxenburg, Austria: International Institute for Applied Systems Analysis.

Heady, E.O., and U.K. Srivestava (eds.) (1975) Spatial Sector Programming Models in Agriculture. Ames, Iowa: lowa State University Press.

Keyzer, M.A. (1977a) Analysis of a National Model with Domestic Price Policies and Quotas on International Trade. RM-77-19. Laxenburg Austria: International Insitute for Applied Systems Analysis.

Keyzer, M.A. (1977b) International Trade Policies in Models of Barter Exchange. RM-77-51. Laxenburg, Austria: International Institute for Applied Systems Analysis.

Keyzer, M.A. (1977c) Linking National Models of Food and Agriculture - An Introduction. RM-77-2. Laxenburg, Austria: International Institute for Applied Systems Analysis.

Leser, C.E.V. (1979) Econometric Techniques and Problems. London: Griffin.

Naylor, T.H. (1971) Computer Simulation Experiments with Models of Economic Systems. New York: Wiley.

Parikh, K.S. (1977) A Framework for an Agricultural Policy Model for India. RM-77-59. Laxenburg, Austria: International Institute for Applied Systems Analysis.

Rabar, F. (1977) Food and Agriculture Program Annual Report of IIASA. Laxenburg, Austria: International Institute for Applied Systems Analysis.

Rosmiller, G.E. (ed.) (1978) Agricultural Sector Planning - A General System Simulation Approach. East Lansing, Michigan: Michigan State University Press.

\section{APPENDIX List of Symbols in General Model Outline and in HAM-2}

\begin{tabular}{|c|c|c|}
\hline Symbol & Quantity & $\begin{array}{l}\text { Where } \\
\text { determined }\end{array}$ \\
\hline \multicolumn{3}{|l|}{$\mathbf{A}$} \\
\hline$a$ & Desired growth rate of GNP at constant prices & Exogenous \\
\hline$a_{k i j}^{s(t)}$ & Unit input coefficient in socialist agriculture & UD-4 \\
\hline$A D M S^{(t)}$ & Number of administrative staff in agriculture & P-2 \\
\hline$a f^{(t)}$ & Actual growth rate of GNP at constant prices & GM-A-1 \\
\hline$A G F^{(t)}$ & Total material expenses in million forints & CT-1 \\
\hline$a k^{\prime}, a k^{\prime \prime}$ & Lower and upper bounds of desired growth of GNP & Exogenous \\
\hline$a k_{1}$ & Minimum value of $a k^{\prime}$ & Exogenous \\
\hline$a k_{2}$ & Maximum value of $a k^{\prime \prime}$ & Exogenous \\
\hline$A K T_{k}$ & $\begin{array}{l}\text { Overhead expenses related to } k \text { th production's facility } \\
\text { of food processing in million forints }\end{array}$ & UD-4 \\
\hline$A P H_{i}$ & $\begin{array}{l}\text { Unit output of the } i \text { th commodity in household and } \\
\text { private sector }\end{array}$ & Exogenous \\
\hline$A S P^{\mathrm{t}}$ & New saving of populations in million forints & CT-1 \\
\hline$a t i_{k}$ & $\begin{array}{l}\text { Time requirement of } k \text { th investment }(k=1,2, \ldots \text {, } \\
\text { 26) }\end{array}$ & Exogenous \\
\hline
\end{tabular}




\section{B}

b

$B A R M I(t) \quad$ Total direct expenses in production of commodity $i$

$b_{i j}^{\mathrm{s}}(t)$

$b f_{1}^{t}$

$b f_{2}^{t}$

$b k^{\prime}, b k^{\prime \prime}$

$B N^{\mathrm{t}}$

$B P^{\mathrm{t}}$

$B S^{\mathrm{t}}$

C

$c^{\mathrm{t}}$

$c 1,-46\}$

$\left.c 3_{1 \ldots 19}\right\}$

$\left.c 4_{1-19}^{1-19}\right\}$

CON ${ }^{\mathrm{t}}$

$\operatorname{CONP}{ }^{\mathrm{t}}$

CONS

$C P E^{\mathrm{t}}$

D

$d c^{\mathrm{n}(t)}$

$d c^{\mathrm{p}(t)}$

$d c^{\mathrm{s}(t)}$

$d d n$

$d d p_{1-14}$

$d d s_{1-12}$

$D E F^{\mathbf{t}}$

$D E N^{\mathrm{t}}$
Desired growth rate of GNP in food and agriculture

Exogenous

P.2

Labor input coefficient in socialist agriculture

UD-4

Actual growth rate of GNP in food and agriculture

Growth rate of gross production in the rest of the economy at constant prices

Lower and upper bound of desired growth rate of

GNP in food and agriculture

Bonus paid by the rest of the economy in million forints

Bonus paid by food processing in million forints

CT-1

Bonus paid by socialist agriculture in million forints

CT-1

Planned decrease of allowed deficit of price balance of payments

Parameters of demand system

Exogenous

Parameters in supply function of household and private sector

Total value of goods bought by the population at constant price

Total value of goods bought by the population at producer price

Self-consumption of products of household and private farms at producer price

Per capita endowment of consumers

CT-1

Centralized part of amortization in the rest of the economy

GM-A-1

Centralized part of amortization in food processing

GM-A-1

Centralized part of amortization in socialist agriculture

Rate of renewal of facilities in the rest of the economy

Exogenous

Rate of renewal of facilities in food processing

Exogenous

Rate of renewal of facilities in socialist agriculture

Exogenous

Total loss in producing sectors

CT-1

Total amortization in rest of the economy 
$D E P$

Total amortization in food processing

CT-1

$D E S^{\mathbf{t}}$

Total amortization in socialist agriculture

CT-1

$D_{E S P N}{ }^{\mathrm{t}}$

Total amortization in the rest of the economy

CT-1

$\operatorname{dev} c p_{i}$

Allowed deviation of consumer price from scale of

Exogenous producer price as percentage of producer price

devla

Steps in changing $\lambda$ parameters

Exogenous

$\operatorname{devpp}_{i}$

Scale of allowed deviation of actual production from

Exogenous target as a percentage of target

$\operatorname{devpp}_{i}$

Scale of allowed deviation of producer price from

Exogenous production expenses as a percentage of expenses

devtc $_{i}$

Scale of allowed deviation from desired per capita

Exogenous consumption of commodity $i$ in percentage of actual figure

$D G N P^{\mathrm{t}} \quad$ Planned value of GNP

GM-P-12

$D G N P A^{t} \quad$ Planned value of GNP from food and agriculture

GM-P-12

$D P B A^{\mathrm{t}}$

Planned balance of payments from food and agricul-

GM-P-12

$d r n$ ture in million forints

$d r p_{1-14}$

Rate of amortization in the rest of the economy

Exogenous

Rate of amortization of production facilities in food processing

$d r s_{1-12}$

Rate of amortization of production facilities in socialist agriculture

$d s$

US dollar/Hungarian forint exchange rate

Exogenous

Exogenous

Exogenous

E

$e \quad$ Desired growth rate of net national product

Exogenous

$e f^{(t)}$

Actual growth rate of net national product at current

CT-1

$e p^{g(t)}$ prices

es ${ }^{\mathrm{g}} \quad$ Growth rate of government social expenditures

Exogenous

Planned growth rate of community consumption

Exogenous

$e_{\mathrm{a}}, e_{\mathrm{m}}, e_{\mathrm{n}}$

Coefficients used to forecast general management and

Exogenous

$E_{i}^{\mathrm{t}}$ overhead expenses

$E I_{i}^{\mathrm{t}}$

Export of commodity $i$

CT-3

Balance of export--import of commodity $i$

CT-3

F

$f^{t}$

Desired share of consumption in national income

GM-A-1

FELH ${ }_{i}^{t}$

Quantity of commodity $i$ used for processing

P4 
Actual share of consumption in national income

CT 4

$F P_{i}^{\mathrm{t}}$

Scale of branch $i$ in food processing

P4

$F P A_{i}^{\mathrm{t}}$

Net production of commodity $i$ in food processing

P4

$F P N_{i}^{\mathrm{t}}$

Production of $i$ th commodity in food processing

P4

G

$g^{\mathrm{t}}$

Planned share of food and agriculture in total invest-

GM-A-1

$G C S^{\mathrm{t}}$

ment

$G D^{\mathrm{t}}$

Government subsidy to consumer prices

CT 4

$G E^{\mathfrak{t}}$

Centralized amortization

CT-1

$G E S^{\mathrm{t}}$

Total government expenditure

CT 4

$g^{\mathrm{t}}$

Total export subsidy

CT 4

$G I^{\mathrm{t}}$

Actual share of food and agriculture in total investment

CT 4

$G I N A^{\mathrm{t}}$

Total income of government

CT 4

$G I N N^{\mathrm{t}}$

Direct government investment in food and agriculture

CT-3

Direct government investment in the rest of the econ-

CT-3

GINS $^{\mathrm{t}}$ omy

\section{$G I S^{\mathrm{t}}$}

Government subsidy to investment in food and agri-

CT-3

culture

$G I S X^{\mathrm{t}}$

Government import subsidy

CT-3

$G N P^{\mathbf{t}}$

Balance of government budget

CT 4

$G N P A^{\mathrm{t}}$

Gross national product

CT 4

$G P^{\mathrm{t}}$

$G P E^{\mathrm{t}}$

Gross national product in food and agriculture

CT 4

Government price subsidies

CT 4

$G S P^{\mathrm{t}}$

Community consumption at producer prices

CT-1

$G T^{\mathrm{t}}$

Government social expenditures

CT-I

$G T R P^{\mathrm{t}}$

Total tax returns of government

CT-1

GYFEL ${ }^{\mathrm{t}}$

Tariff receipts of government

CT 4

P-3

\section{H}

h

Desired share of investment in socialist agriculture in

$H A P^{\mathrm{t}}$ investment in the whole food and agricultural sector

$H B F_{3} \quad$ Intermediate consumption of corn in household and Gross production value of household and private

P-1 agriculture private agriculture

P-1 


\begin{tabular}{|c|c|c|}
\hline$H B F_{6}$ & $\begin{array}{l}\text { Intermediate consumption of green feeds in household } \\
\text { and private agriculture }\end{array}$ & P-1 \\
\hline$H B F_{11}$ & $\begin{array}{l}\text { Intermediate consumption of grapes in household and } \\
\text { private agriculture }\end{array}$ & P-1 \\
\hline$h c i$ & $\begin{array}{l}\text { Growth rate of self-consumption of commodities } \\
\text { produced by household and private agriculture }\end{array}$ & Exogenous \\
\hline$H D_{k}^{\mathrm{t}}$ & $\begin{array}{l}\text { Demand of household and private agriculture for } k \text { th } \\
\text { production facility of socialist agriculture }\end{array}$ & P-1 \\
\hline$H D E S^{\mathrm{t}}$ & $\begin{array}{l}\text { Amortization of resources of socialist agriculture used } \\
\text { in the household and private sector }\end{array}$ & $\mathrm{P}-1$ \\
\hline$H M I^{\mathrm{t}}$ & $\begin{array}{l}\text { Industrial in puts related to production facilities of the } \\
\text { rest of the economy used in household and private } \\
\text { sector }\end{array}$ & $P-1$ \\
\hline$H P_{i}^{\mathrm{t}}$ & $\begin{array}{l}\text { Production of commodity } i \text { in household and private } \\
\text { sector }\end{array}$ & P-1 \\
\hline hpri & $\begin{array}{l}\text { Projected growth of production in the household and } \\
\text { private sector }\end{array}$ & Exogenous \\
\hline$H W E S^{\mathbf{t}}$ & $\begin{array}{l}\text { Labor expenses related to production facilities of } \\
\text { socialist agriculture used in the household and private } \\
\text { sector }\end{array}$ & P-1 \\
\hline \multicolumn{3}{|l|}{ I } \\
\hline$i^{\mathrm{t}}$ & Desired growth rate of total consumption & GM-A-1 \\
\hline$I_{i}^{\mathrm{t}}$ & Import of the commodity $i$ & CT-3 \\
\hline$I F E A N^{\mathrm{t}}$ & $\begin{array}{l}\text { Investment fund of enterprises in the rest of the } \\
\text { economy }\end{array}$ & CT-1 \\
\hline$I F E P^{\mathrm{t}}$ & Investment fund of firms in food processing & CT-1 \\
\hline$I F E S^{\mathrm{t}}$ & Investment fund of farms in socialist agriculture & CT-1 \\
\hline$I K T_{1}$ & Unit costs of tractor type I usage & Exogenous \\
\hline$I K T_{2}$ & Unit costs of tractor type II usage & Exogenous \\
\hline$I K T_{3}$ & Unit cost of additional equipment use & Exogenous \\
\hline$I K T O^{\mathrm{t}}$ & $\begin{array}{l}\text { Total expenses of resources of socialist agriculture } \\
\text { used in household and private agriculture }\end{array}$ & P-1 \\
\hline$I R A_{1}^{\mathrm{t}}$ & Expenses of ferrtilizer usage in socialist agriculture & $\mathrm{P}-2$ \\
\hline$I R A_{2}^{\mathrm{t}}$ & Total expenses on pesticides in socialist agriculture & P-2 \\
\hline$I R A_{3}^{\mathrm{t}}$ & $\begin{array}{l}\text { Value of products and services of the rest of the } \\
\text { economy used in socialist agriculture }\end{array}$ & P-2 \\
\hline$I N C N^{\mathrm{t}}$ & Net income realized in the rest of the economy & CT-1 \\
\hline
\end{tabular}




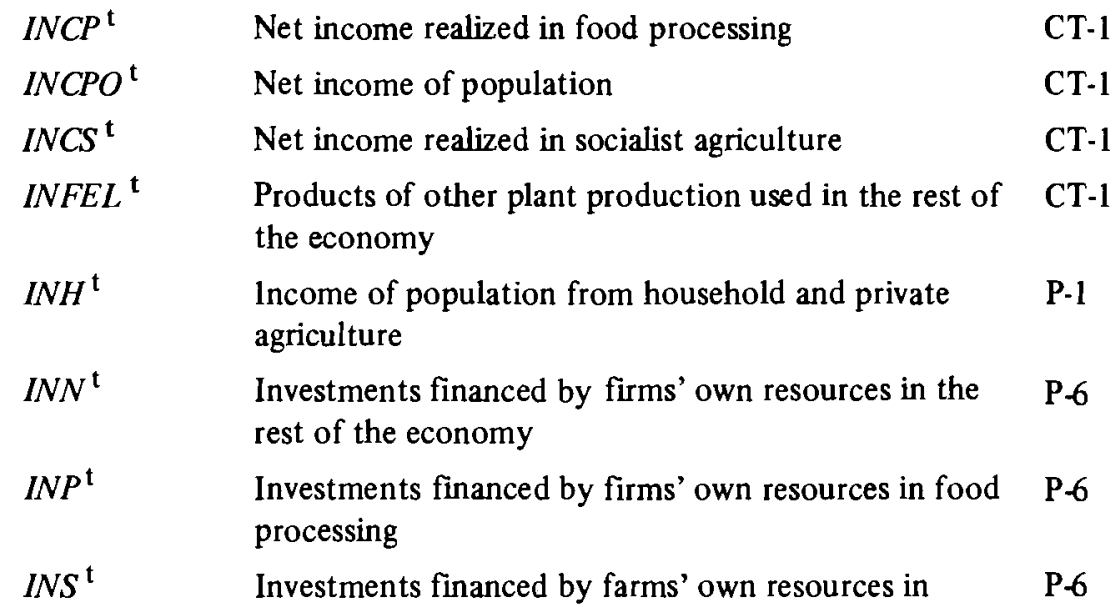
socialist agriculture

$I N V_{k}^{\mathrm{t}}$

$I N V I_{k}$

$I N V U_{k}$

$I T C_{i}^{\mathrm{t}}$

itci $_{i}$

$\mathbf{K}$

$K A^{\mathrm{t}} \quad$ Permitted balance of payments deficit

$K A P_{k}^{(t)} \quad$ Availability of production facility $k$ in socialist agriculture

$K A P I G_{k}^{\mathrm{t}} \quad$ Need for production facility $k$ in food processing

$K A P T_{k}$

$K E V A B^{\mathrm{t}}$

$K E V F E^{\mathbf{t}}$

$K E V T I^{\mathrm{t}}$

$\mathbf{L}$

$l_{i}$

$L A F^{\mathrm{t}}$

$L E N^{\mathrm{t}}$

$L E P^{\mathrm{t}}$

Amount of enterprise level investments in $k$ th production facility for a given year

Scale of investment in production facility $k$

Desired per capita consumption of commodity $i$

Rate of change of desired per capita consumption of commodity $i$

P-2

P4

Availability of $k$ th production facility in food proces- $\quad \mathrm{P} 4$ sing

Protein requirement of socialist agriculture

P-2

Protein feed requirement of socialist agriculture

P-2

Feed mix requirement of socialist agriculture

P.2

Change of $i$ th element of vector $\lambda I$

P. 24

Labor force in agriculture and food processing

P-5

Wages and related tax in the rest of the economy

$\mathrm{P} 4$

GM-P 4

GM-P 4

Exogenous

GM-A-2

Exogenous

GM-P-1-2

Exogenous 
LES ${ }^{\mathrm{t}} \quad$ Wages and related tax in socialist agriculture P-2

lh $\quad$ Annual rate of change of land resource in household and private agriculture

$L S_{1}^{(t)}$

Plowland of socialist agriculture

Exogenous

$L S_{2}^{(t)}$

Pastures and meadows in socialist agriculture

P-2

$L S H^{\mathrm{t}}$

Land availability for household and private agriculture

P-2

$l s i_{1}$ Annual rate of change of plowland belonging to socialist agriculture

$l s i_{2}$

Rate of change of available pastures and meadows

Exogenous

$L T S^{\mathrm{t}}$

Land tax paid by socialist agriculture

P-2

$\mathbf{M}$

Unit labor input coefficient related to $k$ th production facility

$M E H^{\mathrm{t}}$

Expenses of household and private agriculture related

P-1 to usage of production facility

$M E H I^{\mathrm{t}}$

Fertilizer and pesticides expenses in household and

P-1 private agriculture

$M E N^{\mathbf{t}}$

Intermediate inputs of $n$th commodity in the rest of

P-5 the economy

$M E P^{\mathrm{t}}$

Total material expenses in food processing

P4

$M E P I^{\mathrm{t}}$

Value of the $n$th commodity used in food processing

Exogenous

$M E P P^{\mathrm{t}}$

Intermediate inputs of food processing

P4

$M E P S^{\mathrm{t}}$

Value of raw materials used in agriculture and in food

P4 processing

$M E S^{\mathfrak{t}}$

Total material expenses in socialist agriculture

P.2

$M E S I^{\mathrm{t}}$

Value of $n$th commodity used in socialist agriculture

P.2

$M E S P^{\mathrm{t}}$

Value of feed mix used in socialist agriaculture

P-2

$M E S S^{\mathrm{t}}$

Value of agricultural materials used in socialist agri-

P-2 culture

N

$N L F^{\mathrm{t}} \quad$ Labor force of the rest of the economy P-5

$N N P^{\mathrm{t}}$

Net national product

CT 4

0

$o^{t} \quad$ Rate of change in wages

GM-P-1-2

$O K T_{i}^{\mathrm{t}}$

Production expenses of one unit $i$ th commodity

P-3, P-5 
P

$p_{i}^{\mathrm{c}(t)}$

$p_{i}^{\mathrm{pr}(t)}$

Consumer price of $i$ th commodity

GM-A-3

$p_{i}^{w}(t)$

Producer price of $i$ th commodity

GM-A-2

International price of $i$ th commodity

Exogenous

$P_{n}^{\mathrm{t}}$

Gross production in the rest of the economy

P-5

$P A F^{\mathrm{t}}$

Planned investment fund for the whole national

GM-P-1-2 economy

$P A F A^{\mathrm{t}}$

Planned investment fund in agriculture and food

GM-P-1-2 processing

$P A F N^{\mathrm{t}} \quad$ Planned investment fund in the rest of the economy

GM-P-1-2, CT-3

$P A P^{\mathrm{t}}$

$P B A^{t}$

Gross production value of food processing

P4

pci

Balance of foreign trade related to food and agriculture

CT 4

$P C F^{\mathrm{t}}$

Consumer price index

GM-A-1-2

$P C P E^{\mathrm{t}}$

Planned consumption fund

GM-P-1 2

PCTOT $^{\mathrm{t}}$

Planned value of per capita consumption

GM-P-1-2

$P D G I N A^{\mathrm{t}}$

Planned consumption at producers' price

GM-P-1-2

Planned direct government investment in socialist

GM-P-1-2

$P E_{i}^{\dagger}$ agriculture

PGINS ${ }^{\mathrm{t}} \quad$ Planned investments of firms in food and agriculture

GM-P-3

$P G I N S A^{\mathrm{t}} \quad$ Planned government subsidy to agricultural investments

GM-P-1 -2

PGINSP ${ }^{\mathrm{t}}$

Planned government subsidy to investments in food

GM-P 4, CT-3 processing

GM-P 4, CT-3

$P G P E^{\mathrm{t}} \quad$ Planned value of community consumption

GM-P-1-2

$P I_{i}^{\mathrm{t}}$

Planned imports of commodity $i$

GM-P-3

PJOV $^{\mathrm{t}}$

Planned value of income of population used for buying

GM-P-1-2 goods

$p k p_{k} \quad \quad$ Unit price of $k$ th production facility of food processing

UD4

$p k s_{k}$

Unit price of $k$ th production facility in socialist agri-

UD-4 culture

$P L F^{\mathfrak{t}}$

Labor force in food processing

P4

PMUTR ${ }^{\mathrm{t}}$

Unit price of fertilizer

UD-4

$P N N P^{\mathrm{t}}$

Planned net national product

GM-P-1-2

POT $_{k}^{\mathrm{t}}$

Value of replacement from production facility $k$

P-6

$P P_{i}^{\mathrm{t}}$

Planned scale of production

GM-P-3

$P P N_{i}^{\mathrm{t}}$

Planned production of commodity $i$

GM-P-3 


\begin{tabular}{|c|c|c|}
\hline$P S L F^{(t)}$ & Planned labor force of socialist agriculture & $P \cdot 2$ \\
\hline$P T C_{i}^{\mathrm{t}}$ & Planned quantity of commodity $i$ bought by population & GM-P-3 \\
\hline$P T C G_{i}^{1}$ & Planned community consumption of commodity $i$ & GM-P-1-2, CT-3 \\
\hline$P T P E^{\mathrm{i}}$ & Planned endowment of population & GM-P-1-2 \\
\hline$P Y O^{\mathrm{t}}$ & Planned balance of export and import & GM-P-1-2 \\
\hline \multicolumn{3}{|l|}{$Q$} \\
\hline Q & Matrix on noncommitted demands & CT -3 \\
\hline \multicolumn{3}{|l|}{$\mathbf{R}$} \\
\hline$r_{1}^{t}$ & $\begin{array}{l}\text { Share of food and agriculture in the gross national } \\
\text { product }\end{array}$ & GM-A-1 \\
\hline$r_{2}^{t}$ & $\begin{array}{l}\text { Share of the rest of the economy in the gross national } \\
\text { product }\end{array}$ & GM-A-1 \\
\hline$R F_{k}^{\mathrm{t}}$ & Value of capital stock in food processing & UD-2 \\
\hline$R N^{\mathrm{t}}$ & Capital stock in the rest of the economy & UD-2 \\
\hline$R S_{k}^{\mathrm{t}}$ & Capital stock in agriculture & UD-2 \\
\hline \multicolumn{3}{|l|}{$s$} \\
\hline$S_{i}^{\mathrm{t}}$ & Stock of commodity $i$ & $\mathrm{CT} 4$ \\
\hline$S A G^{\mathrm{t}}$ & Accumulated savings of population & $\mathrm{CT}-4$ \\
\hline$S A P^{\mathrm{t}}$ & Gross production value of socialist agriculture & $\mathbf{P}-2$ \\
\hline$S D N^{\mathrm{t}}$ & $\begin{array}{l}\text { Value of the increase in stocks in the rest of the } \\
\text { economy }\end{array}$ & CT 4 \\
\hline$S D P^{\mathrm{t}}$ & Value of the increase in stocks in food processing & $\mathrm{CT}-4$ \\
\hline$S D S^{\mathrm{t}}$ & Value of increase of stocks in socialist agriculture & $\mathrm{CT}-4$ \\
\hline$S E X P^{\mathrm{t}}$ & Exports at producers' prices & $\mathrm{CT} 4$ \\
\hline$S G M^{\mathrm{t}}$ & Overhead expenses in socialist agriculture & $\mathrm{P}-2$ \\
\hline$S G M A^{\mathrm{t}}$ & $\begin{array}{l}\text { Other fixed asset requirements of management activi- } \\
\text { ties in socialist agriculture }\end{array}$ & P-2 \\
\hline$S G M M^{\mathrm{t}}$ & Labor expenses within overhead expenses & P-2 \\
\hline$S G M N^{\mathrm{t}}$ & $\begin{array}{l}\text { Use of } n \text {th commodity as a fraction of overhead } \\
\text { expenses }\end{array}$ & P.2 \\
\hline $\operatorname{SIM} P^{\mathrm{t}}$ & Import at producer price & $\mathrm{CT} 4$ \\
\hline$S K A P I G_{k}^{\mathrm{t}}$ & Needs for $k$ th production facility in socialist agriculture & $\mathbf{P}-2$ \\
\hline$S K A P T_{k}^{\mathrm{t}}$ & $\begin{array}{l}\text { Capacity of } k \text { th production facility in socialist agri- } \\
\text { culture }\end{array}$ & UD-2 \\
\hline$S L F^{\mathrm{t}}$ & Labor force of socialist agriculture & $\mathrm{P}-2$ \\
\hline$S P_{i}^{\mathrm{t}}$ & Scale of production branch $i$ in socialist agriculture & P.2 \\
\hline
\end{tabular}


$S P A_{i}$
$S P N$

$S P R I_{k}^{\mathrm{t}}$

$S P T_{i, j}^{\mathrm{t}}$

T

$t^{\text {in, }} \mathrm{h}(t) \quad$ Income tax rate in household farms

$t^{\text {in }, \mathrm{n}(t)}$

$t^{\mathrm{in}, \mathrm{p}(t)}$

$t^{\text {in }, \mathrm{po}(t)}$

$t^{\mathrm{in}, \mathrm{s}(t)}$

$t^{1(t)}$

$t^{\mathrm{wa}(t)}$

$T C_{i}^{\mathrm{t}}$

$T C S_{i}^{\mathrm{t}}$

$T E S^{\mathrm{t}}$

$T I N^{\mathrm{t}}$

TINP ${ }^{\mathrm{t}}$

$T I N S^{\mathrm{t}}$

$t p^{\mathrm{t}}$

$T P E^{\mathrm{t}}$

tpi

$T R C P^{t}$

TREP ${ }^{\mathrm{t}}$

$T R I P^{\mathrm{t}}$

$T X H^{\mathrm{t}}$

$T X N^{\mathrm{t}}$

$T X P^{\mathrm{t}}$

$T X P O^{\mathrm{t}}$

$T X S^{\mathrm{t}}$

$T W H^{\mathrm{t}}$

$T W H A^{\mathrm{t}}$

$T W H V^{\mathfrak{t}}$

Income tax rate in food processing

Income tax rate of the population

Land tax rate in period $t$

Wage tax rate income of population

Total accumulation

Investment in food processing

Investment in agriculture

Total population

Government receipts from exports

Government receipts from imports

Tax paid by food processing

Tax paid by population

Tax paid by socialist agriculture
Output of commodity $i$ from socialist agriculture

P-2

Total production of commodity $i$ in socialist agriculture

Shadow price of production facility $k$

GM-P-3, P-2

Scale of production of commodity $i$ using technology $j$
GM-A-1

Income tax rate in the rest of the economy

GM-A-1

GM-A-1

GM-A-1

Income tax rate of socialist agriculture

GM-A-1

GM-A-1

GM-A-1

Total consumption of commodity $i$ from personal

Consumption of commodity $i$ in household farms

P-1

Total production expenses of socialist agriculture

P.2

CT-4

CT-4

CT-4

UD-1

Income of population used for consumption

CT-1

Annual growth rate of total population

Exogenous

Government receipts from consumer prices

CT-5

CT-5

CT-5

Income tax paid by household farms

P-1

Tax paid by the rest of the economy

P-5

CT-1

CT-1

CT-1

Total hours of work used in farming households

UD-1

Hours of work used in household animal husbandry

P.1

Hours of work used in household plant production

\section{P-1}


U

uip Level of utilization of production facilities in food

Exogenous processing above which new investment is desirable

upp

Level of utilization of resources in food processing

Exogenous above which replacement of obsolescent facilities is desirable

ups

Level of utilization of production facilities in socialist

Exogenous agriculture above which replacement of obsolescent facilities is desirable

V

$v^{n}$

Share of rewards in the net income of the rest of

Exogenous the economy

$v^{\mathrm{p}}$

Share of rewards in the net income of food processing

Exogenous

$v^{\mathrm{s}}$

Share of rewards in the net income of socialist agricul-

Exogenous ture

w

$w^{\mathrm{n}(t)}$

$w^{\mathrm{p}(t)}$

Per capita wages in the rest of the economy

P-5

$w^{\mathrm{s}(t)}$

Per capita wages in food processing

$\mathrm{P} 4$

WEN ${ }^{\mathrm{t}}$

Per capita wages in socialist agriculture

P-2

$W E P^{t}$

Total wages in the rest of the economy

P.5

$W_{E S}{ }^{\mathrm{t}}$

Total wages in food processing

P-4

$W H_{i}$

Total wages in socialist agriculture

P-3

Labor input coefficient of the $i$ th commodity in

Exogenous household and private agriculture

$w i$

Annual growth rate of labor inputs in the household

Exogenous sector

$w p^{t} \quad$ Total working population

Exogenous

wpi

Annual rate of employment of working population

Exogenous

$\mathbf{X}$

$X_{l}^{(t)}$

$X T_{e}^{(t)}$

Investment in new food processing facilities in period $t$

P-6

Total production expenses of commodity $e$

P.2

$\mathbf{Y}$

Y Vector of supply after deducting intermediate inputs

CT-3

and committed demands

$Y O^{t} \quad$ Balance of foreign trade

CT 4 


\begin{tabular}{|c|c|c|}
\hline$\alpha_{1}$ & $\begin{array}{l}\text { Rate of slaughtering of pigs produced by household } \\
\text { and private sector }\end{array}$ & Exogenous \\
\hline$\alpha_{2}$ & Rate of conversion of beef to processed beef & Exogenous \\
\hline$\alpha_{3}$ & Rate of conversion of pork to processed pork & Exogenous \\
\hline$\alpha_{4}$ & $\begin{array}{l}\text { Rate of own processing of grapes produced by the } \\
\text { household and private sector }\end{array}$ & Exogenous \\
\hline$\alpha_{s}$ & $\begin{array}{l}\text { Annual growth rate of production of other processed } \\
\text { food }\end{array}$ & Exogenous \\
\hline $\left.\begin{array}{l}\alpha_{6} \\
\alpha_{7} \\
\alpha_{8}\end{array}\right\}$ & $\begin{array}{l}\text { Parameters of the production function of the rest } \\
\text { of the economy }\end{array}$ & Exogenous \\
\hline$\alpha_{9}$ & Share of amortization in expenses of tractor type I use & Exogenous \\
\hline$\alpha_{10}$ & Share of wages in expenses of tractor type I use & Exogenous \\
\hline$\alpha_{11}$ & $\begin{array}{l}\text { Share of industrial inputs in expense of tractor type I } \\
\text { use }\end{array}$ & Exogenous \\
\hline$\alpha_{12}$ & Share of amortization in expenses of tractor type IJ use & Exogenous \\
\hline$\alpha_{13}$ & Share of wages in expenses of tractor type II use & Exogenous \\
\hline$\alpha_{14}$ & $\begin{array}{l}\text { Share of industrial inputs in expenses of tractor type } \\
\text { Il use }\end{array}$ & Exogenous \\
\hline$\alpha_{15}$ & $\begin{array}{l}\text { Share of amortization in expenses of additional } \\
\text { equipment use }\end{array}$ & Exogenous \\
\hline$\alpha_{16}$ & Share of wages in expenses of additional equipment use & Exogenous \\
\hline$\alpha_{17}$ & $\begin{array}{l}\text { Share of industrial inputs in expenses of additional } \\
\text { equipment use }\end{array}$ & Exogenous \\
\hline$\alpha_{18}$ & $\begin{array}{l}\text { Share of the rest of the economy in the utilization of } \\
\text { other crops }\end{array}$ & Exogenous \\
\hline$\alpha_{n, n}^{\mathrm{n}(t)}$ & $\begin{array}{l}\text { Rate of intermediate inputs in total output of the } \\
\text { rest of the economy }\end{array}$ & Exogenous \\
\hline$\beta_{1}$ & Rate of change of consumption trend & Exogenous \\
\hline$\beta_{2}$ & $\begin{array}{l}\text { Rate of change of share of food and agriculture in } \\
\text { total investments }\end{array}$ & Exogenous \\
\hline$\beta_{3}$ & Rate of change of growth rate of unit wages & Exogenous \\
\hline$\beta_{4}$ & $\begin{array}{l}\text { Rate of change of growth rate of community con- } \\
\text { sumption }\end{array}$ & Exogenous \\
\hline$\beta_{5}$ & Rate of change of growth rate of consumption & Exogenous \\
\hline$\beta_{6}$ & Change of income tax rate of rest of the economy & Exogenous \\
\hline$\beta_{7}$ & Change of income tax rate of socialist agriculture & Exogenous \\
\hline$\beta_{8}$ & Change of income tax rate of food processing & Exogenous \\
\hline
\end{tabular}




\begin{tabular}{|c|c|c|}
\hline$\beta_{9}$ & $\begin{array}{l}\text { Change of rate of centralized part of depreciation } \\
\text { from rest of economy }\end{array}$ & Exogenous \\
\hline$\beta_{10}$ & $\begin{array}{l}\text { Change rate of centralized part of depreciation from } \\
\text { socialist agriculture }\end{array}$ & Exogenous \\
\hline$\beta_{11}$ & $\begin{array}{l}\text { Change of rate of centralized part of depreciation } \\
\text { from food processing }\end{array}$ & Exogenous \\
\hline$\beta_{12}$ & $\begin{array}{l}\text { Change of desired upper and lower bound of planned } \\
\text { growth rate of GNP }\end{array}$ & Exogenous \\
\hline$\gamma_{i}^{\mathrm{h}(t)}$ & Yield of commodity $i$ & P-2, P-3 \\
\hline$\delta 1_{i}$ & Change of producer price in percent of previous price & Exogenous \\
\hline$\delta 2_{i}$ & Change of consumer price in percent of previous price & Exogenous \\
\hline$\epsilon 1$ & $\begin{array}{l}\text { Allowed deviation between planned and actual buying } \\
\text { power }\end{array}$ & Exogenous \\
\hline$\epsilon 2$ & $\begin{array}{l}\text { Allowed deviation from planned growth rate of con- } \\
\text { sumption }\end{array}$ & Exogenous \\
\hline$\lambda_{1 \ldots 32}$ & Conversion rates in food processing & Exogenous \\
\hline$\mu_{j, i}$ & $\begin{array}{l}\text { Resource requirement coefficient in household and } \\
\text { private agriculture }\end{array}$ & Exogenous \\
\hline$\rho_{i}^{(t)}$ & Share of commodity $i$ in planned consumer expenditure & GM-P-2, CT-2 \\
\hline $\mathrm{h} \rho_{i}^{(t)}$ & $\begin{array}{l}\text { Share of commodity } i \text { in production capacities of } \\
\text { household and private sector }\end{array}$ & P-1 \\
\hline
\end{tabular}


